Prepared for the U.S. Department of Energy

under Contract DE-AC05-76RL01830

\title{
Annual Report: 2010-2011 Storm Season Sampling for None-Dry Dock Stormwater Monitoring for Puget Sound Naval Shipyard, Bremerton WA
}
JM Brandenberger
C Gebhardt
D Metallo
L Hsu
RK Johnston

September 2012

\section{Pacific Northwest}

NATIONAL LABORATORY

Proudly Operated by Battelle Since 1965 



\title{
DISCLAIMER
}

This report was prepared as an account of work sponsored by an agency of the United States Government. Neither the United States Government nor any agency thereof, nor Battelle Memorial Institute, nor any of their employees, makes any warranty, express or implied, or assumes any legal liability or responsibility for the accuracy, completeness, or usefulness of any information, apparatus, product, or process disclosed, or represents that its use would not infringe privately owned rights. Reference herein to any specific commercial product, process, or service by trade name, trademark, manufacturer, or otherwise does not necessarily constitute or imply its endorsement, recommendation, or favoring by the United States Government or any agency thereof, or Battelle Memorial Institute. The views and opinions of authors expressed herein do not necessarily state or reflect those of the United States Government or any agency thereof.

\author{
PACIFIC NORTHWEST NATIONAL LABORATORY \\ operated by \\ BATTELLE \\ for the \\ UNITED STATES DEPARTMENT OF ENERGY \\ under Contract DE-AC05-76RL01830
}

Printed in the United States of America
Available to DOE and DOE contractors from the Office of Scientific and Technical Information,
P.O. Box 62, Oak Ridge, TN 37831-0062;
ph: (865) 576-8401
fax: $(865)$ 576-5728
email: reports@adonis.osti.gov

\begin{abstract}
Available to the public from the National Technical Information Service, U.S. Department of Commerce, 5285 Port Royal Rd., Springfield, VA 22161 ph: (800) 553-6847 fax: $(703) 605-6900$ email: orders@ntis.fedworld.gov online ordering: http://www.ntis.gov/ordering.htm
\end{abstract}

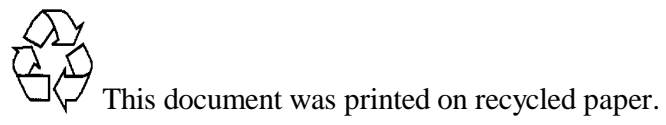




\section{FINAL}

Annual Report: 2010-2011 Storm Season Sampling

For

\section{NON-DRY DOCK STORMWATER MONITORING FOR PUGET SOUND NAVAL SHIPYARD, BREMERTON, WA}

PSNS Project ENVVEST Study Area

September 2012

Prepared By:

Pacific Northwest National Laboratory

Marine Science Laboratory, Sequim, WA

And

Taylor Associates Division of TEC

Contract No.: N4523A10MP00034 Amendment 1
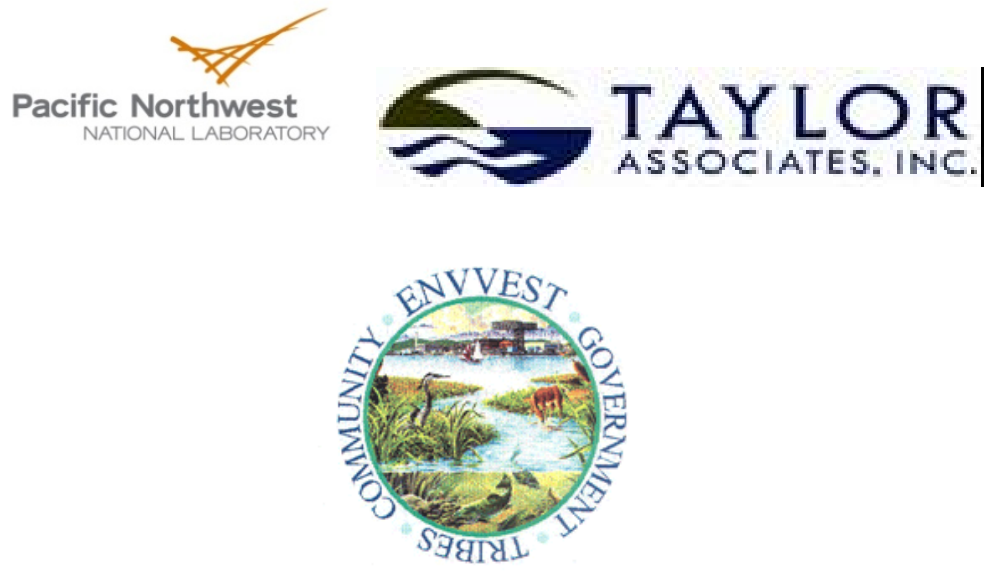


\section{Contents}

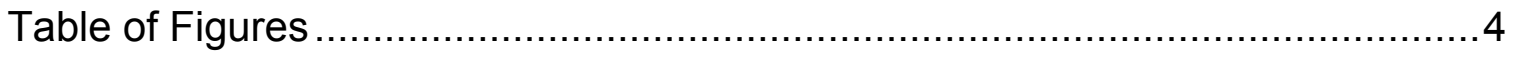

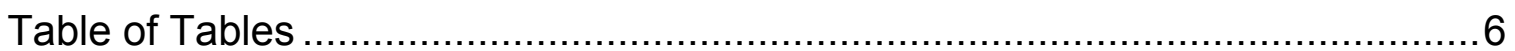

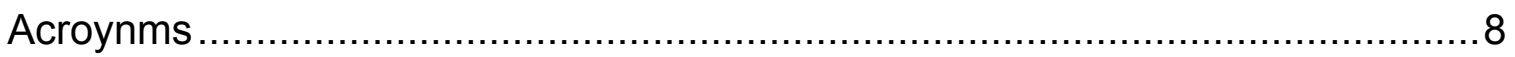

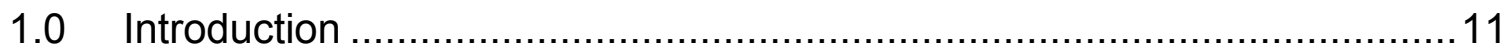

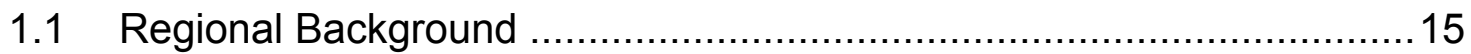

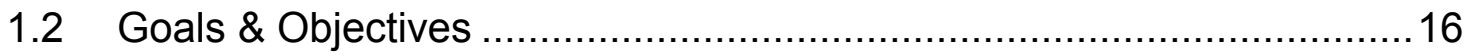

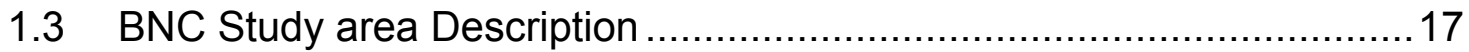

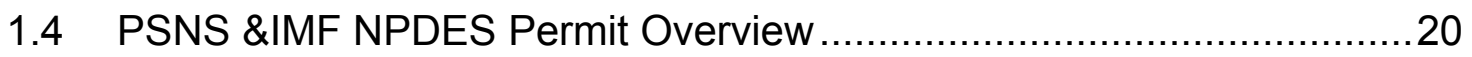

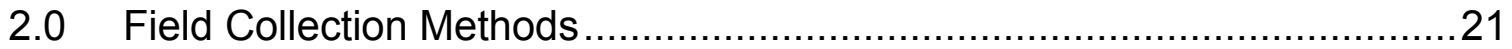

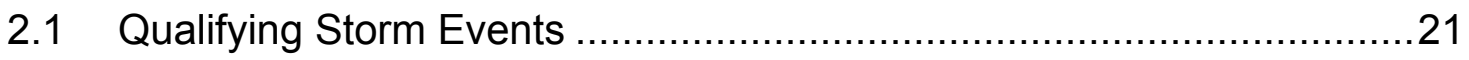

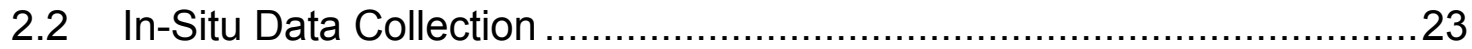

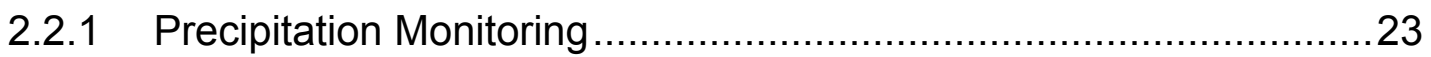

2.2.2 Water Level, Temperature, Conductivity, and Salinity Monitoring ...25

2.2.3 Autosampler Collection Information..........................................27

2.2.4 Data Collection, Storage and Management.................................27

2.3 Stormwater Monitoring System / equipment ..................................28

2.4 Stormwater Sample Collection........................................................ 30

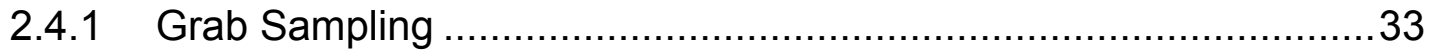

2.4.2 Automated Time-Proportionate Composite Sampling …................33

2.4.3 Field Sample Validation, Preservation, and Handling......................34

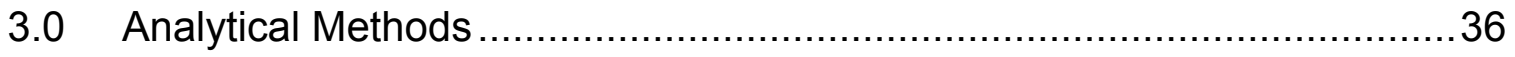

4.0 Quality Assurance and Quality Control .............................................38

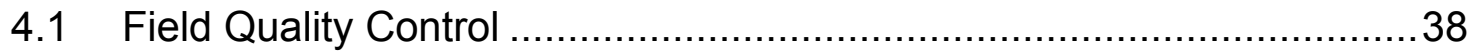

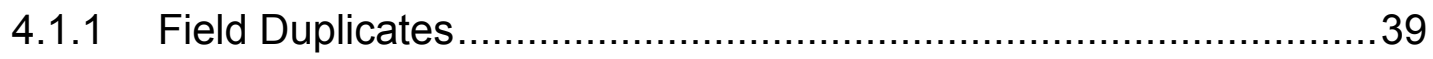

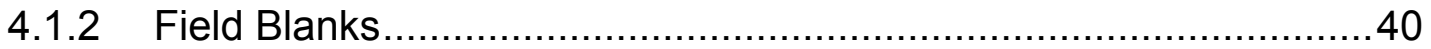

4.1.3 Field Data Review and Verification ......................................... 41

4.2 Laboratory Quality Control ..........................................................

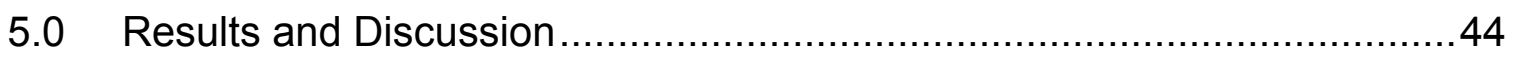

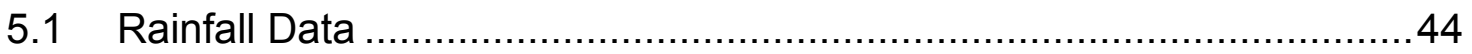




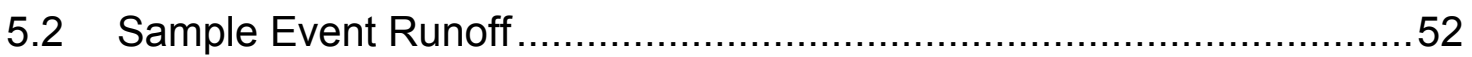

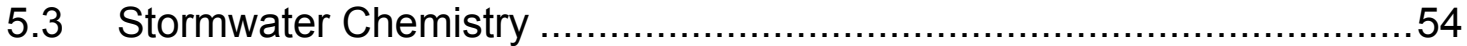

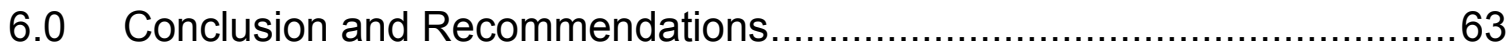

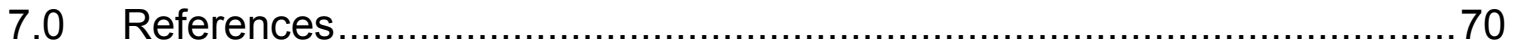

Appendix A

Appendix B

Appendix C 


\section{TABLE OF FIGURES}

Figure 1. Location of the Puget Sound Naval Shipyard \& Intermediate Maintenance Facility (Naval Shipyard) on Sinclair Inlet. The study region for the Navy ENVVEST project is the watershed boundary supporting the receiving waters of Sinclair Inlet, Dyes Inlet, and the passage ways to the main basin of Puget Sound.

Figure 2. Bremerton Naval Complex with the industrial area $(\mathrm{CIA})$ in red and

Naval Base Kitsap (NBK) in green. 14

Figure 3. Phase I stormwater sampling locations at PSNS\&IMF 17

Figure 4. Generalized schematic of monitoring station components

Figure 5. Total metal event mean concentrations (EMCs) in stormwater collected from the seven Phase I outfalls during seven storm events. The top, middle black line, and bottom of the box represent the 75th percentile, 50th, and 25th percentile, respectively. The whiskers are the 5th and 95th percentile and the asterisks are outliers in this sampling set $(n=24)$. The blue dashed line is the average.

Figure 6. The concentrations of dissolved (DME) and particulate (PME) $\mathrm{Cu}$ measured in event mean concentration samples from CIA and NBK outfalls. The storm event number (SW01, etc.) is on the x-axis below the station name. The tops of each column represent the total recoverable (TR) Cu. The reference lines are the NPDES outfall permit concentration ( $\mathrm{red}=33 \mu \mathrm{g} / \mathrm{L}$ ), Navy General Permit (blue $=14 \mu \mathrm{g} / \mathrm{L}$ ) and draft permit for (orange $=5.8$ $\mu \mathrm{g} / \mathrm{L})$ for TR Cu.

Figure 7. The concentrations of dissolved (DME) and particulate (PME) Zn measured in event mean concentration samples from CIA and NBK outfalls. The storm event number (SW01, etc.) is on the x-axis below the station name. The tops of each column represent the total recoverable (TR) Zn. The reference lines are the Navy General Permit (blue $=117.0 \mu \mathrm{g} / \mathrm{L}$ ) and draft permit for (orange $=95.0 \mu \mathrm{g} / \mathrm{L}$ ) for TR $\mathrm{Zn}$

Figure 8. The concentrations of dissolved (DME) and particulate (PME) Hg measured in event mean concentration samples from CIA and NBK outfalls. The storm event number (SW01, etc.) is on the x-axis below the station name. The tops of each column represent the total recoverable (TR) Hg. ..62

Figure 9. The particulate versus dissolved concentration ranges for each outfall during Phase I. 
Figure 10. The total recoverable (TR) and dissolved (d) Cu from the Phase I 2010-11, Kitsap County streams, and Urban outfalls from Kitsap County as a function of storm size.

Figure 11. The ENVVEST relational model (Cullinan et al. 2007) predicted concentrations and Phase I 2010-11 measured total recoverable $\mathrm{Cu}$ concentrations in industrial outfalls. The existing relational model does not have sufficient data to predict concentrations for larger storm sizes. 69 


\section{TABLE OF TABLES}

Table 1. Drainage basins selected for monitoring and the associated primary work activity

Table 2. Drainage basin attributes for the Phase I outfall sampling events 20102011

Table 3. Proposed stormwater monitoring requirements and final effluent limitations.

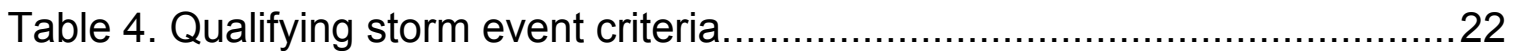

Table 5. Stormwater outfall basin attributes and total discharge volume. ..........26

Table 6. The outfalls, sample types, and storm event dates sampled during 20102011 season.

Table 7. Sample container types, preservatives, recommended handling, and

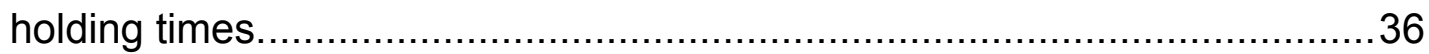

Table 8. Preparation and analytical methods for the non-dry dock stormwater samples.

Table 9. The summary of equipment blank concentrations for the metals. .........41

Table 10. Laboratory quality control sample summary ...................................43

Table 11. Total rainfall for each storm event and the ENVVEST storm size classification.

Table 12. Storm event rainfall descriptive summary for each $2010-11$ storm and station.

Table 13. Historical monthly rainfall summary (inches) for Bremerton, WA (450872) from 1899 to 2010 (http://www.wrcc.dri.edu/).

Table 14. PSNS Building 427 monthly rain gauge summary for 2010-11 sampling

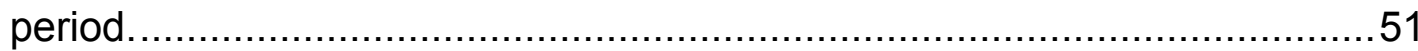

Table 15. Station runoff (RO) summary for each storm event. 53

Table 16. Descriptive statistics for Phase I Event Mean Composite (EMC) stormwater samples. The draft permit concentrations are included for reference and all concentrations greater than the draft permit concentration are highlighted orange.

Table 17. Descriptive statistics for composite stormwater samples collected during the Phase I 2010-11 storm season. The metals are not included in the draft permit, but provided for project ENVVEST mass balance calculations.

Table 18. Descriptive statistics for total petroleum (TPH) diesel range (DRO) and residual range $(\mathrm{RRO})$ along with the ancillary parameters for all stations. ..63 
Table 19. Comparison of 2010-11 stormwater concentrations with regional urban stormwater outfall and commercial/industrial (C\&I) land use/cover stormwater concentrations... 65

Table 20. The lines of evidence used to prioritize the Phase I stations including: 1) total number of event mean concentrations (EMC) greater than the draft NPDES permit; 2) Navy General Permit; 3) high relative load for permitted metals; and 4) high fraction of particulate versus dissolved metals. 66 


\section{ACROYNMS}

$\begin{array}{ll}\text { Ag } & \text { Silver } \\ \text { Al } & \text { Aluminum } \\ \text { As } & \text { Arsenic } \\ \text { BLM } & \text { Biotic Ligand Model } \\ \text { BMP } & \text { Best Management Practice } \\ \text { BNC } & \text { Bremerton Naval Complex } \\ \text { C\&I } & \text { Commercial and Industrial Land-use and Land-cover } \\ \text { CAS } & \text { Columbia Analytical Services } \\ \text { CIA } & \text { Controlled Industrial Area } \\ \text { CFR } & \text { Codes of Federal Registration } \\ \text { Cd } & \text { Cadmium }\end{array}$

CDMA Code Division Multiple Access

COC Chain-of-Custody

$\mathrm{Cu} \quad$ Copper

CWA Clean Water Act

DI Deionized Water

DME Dissolved Metals

DOC Dissolved Organic Carbon

DOD Department of Defense

DRO Diesel Range TPH

DUP Laboratory Duplicate

EB Equipment Blank

Ecology Washington State Department of Ecology

EMC Event Mean Composite 
ENVVEST Project Environmental Investment (U.S. Navy)

ES\&H Field Environmental Health and Safety Plan

FC Fecal Coliform

GFF Glass Fiber Filter

Hg Mercury

HRD Hardness

HSPF Hydrological Simulation Model Program Fortran

ICP-MS Inductively Coupled Plasma/ Mass Spectrometer

INW Instrumentations Northwest Inc.

LCS Laboratory Control Sample

LDPE Low Density Polyethylene

LULC Land-use and Land-cover

MDL Method Detection Limit

MS Matrix Spike

MSD Matrix Spike Duplicate

MLLW Mean Lower Low Water

NBK Naval Base Kitsap

NPDES National Pollutant Discharge Elimination System

NWTPH-Dx Northwest Total Petroleum Hydrocarbons - Diesel fraction

$\mathrm{Pb} \quad$ Lead

PME Particulate Metals

PNNL Pacific Northwest National Laboratories

PP Polypropylene

PPB Parts-per-billion

PPT Parts-per-thousand

PSNS\&IMF Puget Sound Naval Shipyard \& Intermediate Maintenance Facility 


\begin{tabular}{ll} 
PVDF & Polyvinylidene Fluoride \\
PWP & Project Work Plan \\
QAPP & Quality Assurance Project Plan (documented in the PWP) \\
QA/QC & Quality Assurance/Quality Control \\
RCM & Runoff Coefficient Method \\
RL & Reporting Limit \\
RO & Storm Runoff \\
RPD & Relative Percent Difference \\
RRO & Residual Range TPH \\
SRM & Standard Reference Material \\
TMDL & Total Maximum Daily Load \\
TME & Total Metals \\
TOC & Total Organic Carbon \\
TPH & Total Petroleum Hydrocarbon \\
TR or TRM & Total Recoverable Metals \\
TSS & Total Suspended Solids \\
USEPA & U.S. Environmental Protection Agency \\
USGS & United Stated Geological Survey \\
Zn & Zinc \\
\hline
\end{tabular}




\subsection{INTRODUCTION}

The Puget Sound Naval Shipyard \& Intermediate Maintenance Facility (PSNS\&IMF) and Naval Base Kitsap-Bremerton (NBK-Bremerton) located in Bremerton, WA are committed to a culture of continuous process improvement for all aspects of shipyard operations, including reducing the release of hazardous substances in stormwater discharges. The facilities are collectively known as the Bremerton Naval Complex (BNC) and referred to as the Shipyard, for brevity. The Shipyard is located about 15 miles west of Seattle, Washington along the northern shore of Sinclair Inlet on Puget Sound and is bounded by the City of Bremerton (Figure 1). The complex covers approximately 350 acres of land and an additional 340 acres of tidelands along 11,000 feet of shoreline and contains over 300 buildings and structures consisting of industrial, supply and base facilities, a steam plant, six dry docks, piers and numerous moorings. The predominant land cover within the Shipyard is rooftops, paved areas (roads, parking areas, sidewalks, and concrete working areas), and piers.

The Shipyard is divided into two areas: 1) Controlled Industrial Area (CIA) and 2) NBK (Figure 2). The CIA is one of Washington State's largest industrial installations and is responsible for overhaul, maintenance, docking, refueling, and decommissioning of naval vessels, as well as, dismantling of ships and submarines. The NBK provides base operating services, including support for home-ported surface ships and submarines. Support areas include housing, parking, shopping, entertainment, and recreation facilities. The stormwater system draining these two areas includes 156 distinct storm drainage systems, many of which serve small drainage areas. There are more than 1,000 catch basins and track drains on piers draining into Sinclair Inlet and an extensive rail system, which provides a pathway for stormwater to seep through the subsurface. Depending on the flow rate and whether the track drains become clogged, this runoff will ultimately discharge directly into the Sinclair Inlet (Jabloner 2009).

Industrial facility and municipal stormwater runoff has a number of unique attributes that make the identification of stormwater contaminant problems and their associated solutions difficult to determine. Stormwater contains a broad variety of pollutants whose concentrations can vary widely depending on storm event size, LULC, and a number of other local and regional factors. The quality of stormwater runoff can often be difficult to manage due to the seasonal, sporadic nature of surface water discharges and the character and unpredictability of storm events. Most industrial facilities and municipal areas have a large number of stormwater outfalls, with a wide diversity of locations and 
outfall types. Monitoring stormwater discharges within the Shipyard presents additional challenges unique to a facility located within an industrial waterfront:

- Stormwater runoff from all BNC non-dry dock properties drains directly into adjacent marine receiving water.

- Most of the drainage basins are tidally influenced.

- The non-dry dock stormwater drainage systems are relatively short in length (from head to bay outfall), and many systems have limited access, eliminating the opportunity to conduct monitoring in non-tidally influenced areas.

- Industrial processes occurring within the sampling area must be isolated from the water sampled from the conveyance. Contamination of the composite sample during or after collection with process specific contaminants would not represent their concentration in the conveyance during a storm event.

Therefore, the United States Environmental Protection Agency Region X (USEPA), Washington State Department of Ecology (Ecology), and the Shipyard are working to renew the National Pollution Discharge Elimination System (NPDES) permit for discharges into Sinclair Inlet, Puget Sound, WA (USEPA 2008a,b). The discharge of stormwater from Shipyard operations is permitted by the USEPA Region 10 under the Clean Water Act (CWA; NPDES permit WA-00206-2, 1994). Under the NPDES program, the Shipyard is required to implement Best Management Practices (BMPs) designed to reduce, treat, and control discharges of contaminants from Shipyard operations (Jabloner 2009). 


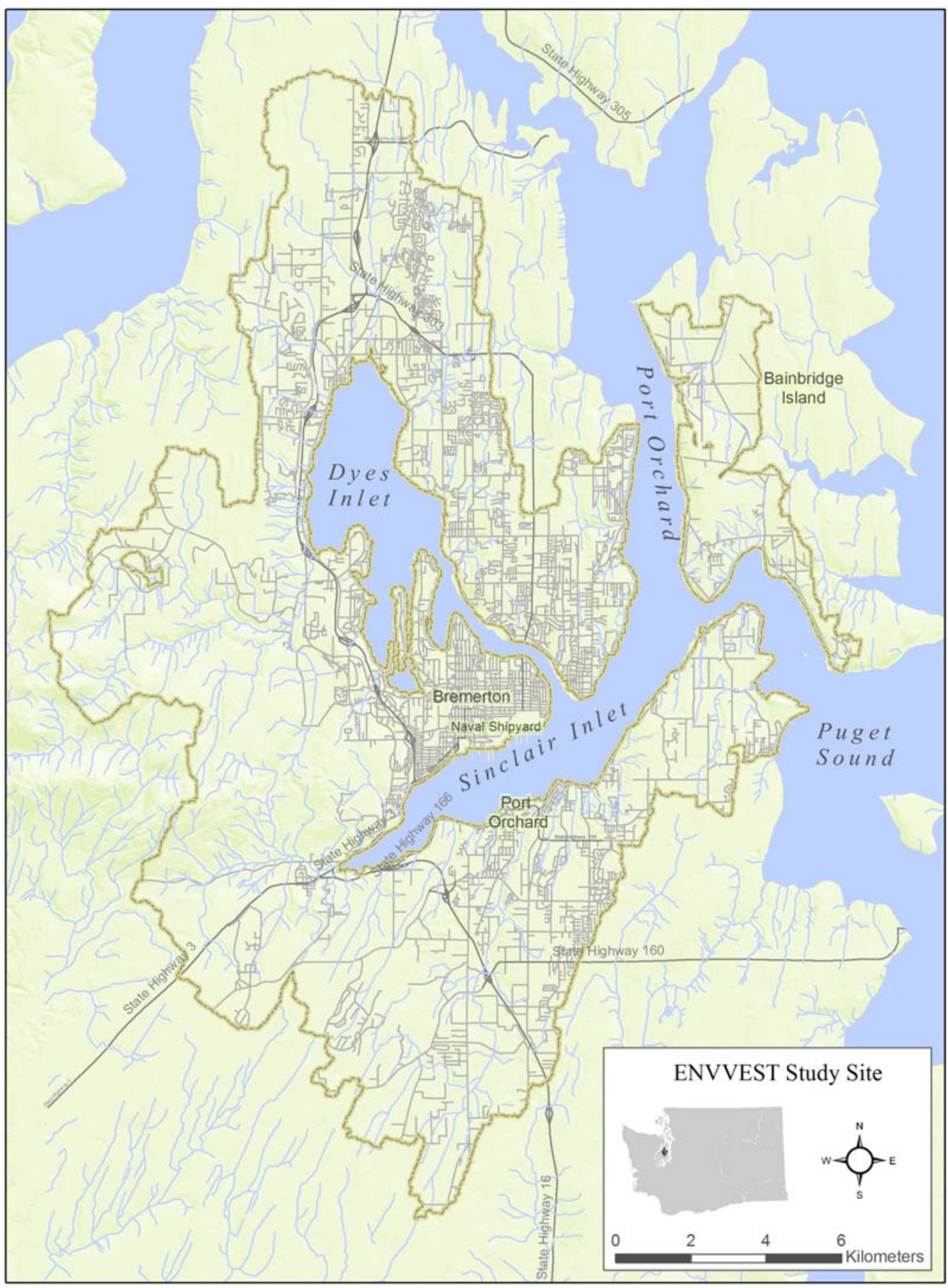

Figure 1. Location of the Puget Sound Naval Shipyard \& Intermediate Maintenance Facility (Naval Shipyard) on Sinclair Inlet. The study region for the Navy ENVVEST project is the watershed boundary supporting the receiving waters of Sinclair Inlet, Dyes Inlet, and the passage ways to the main basin of Puget Sound. 


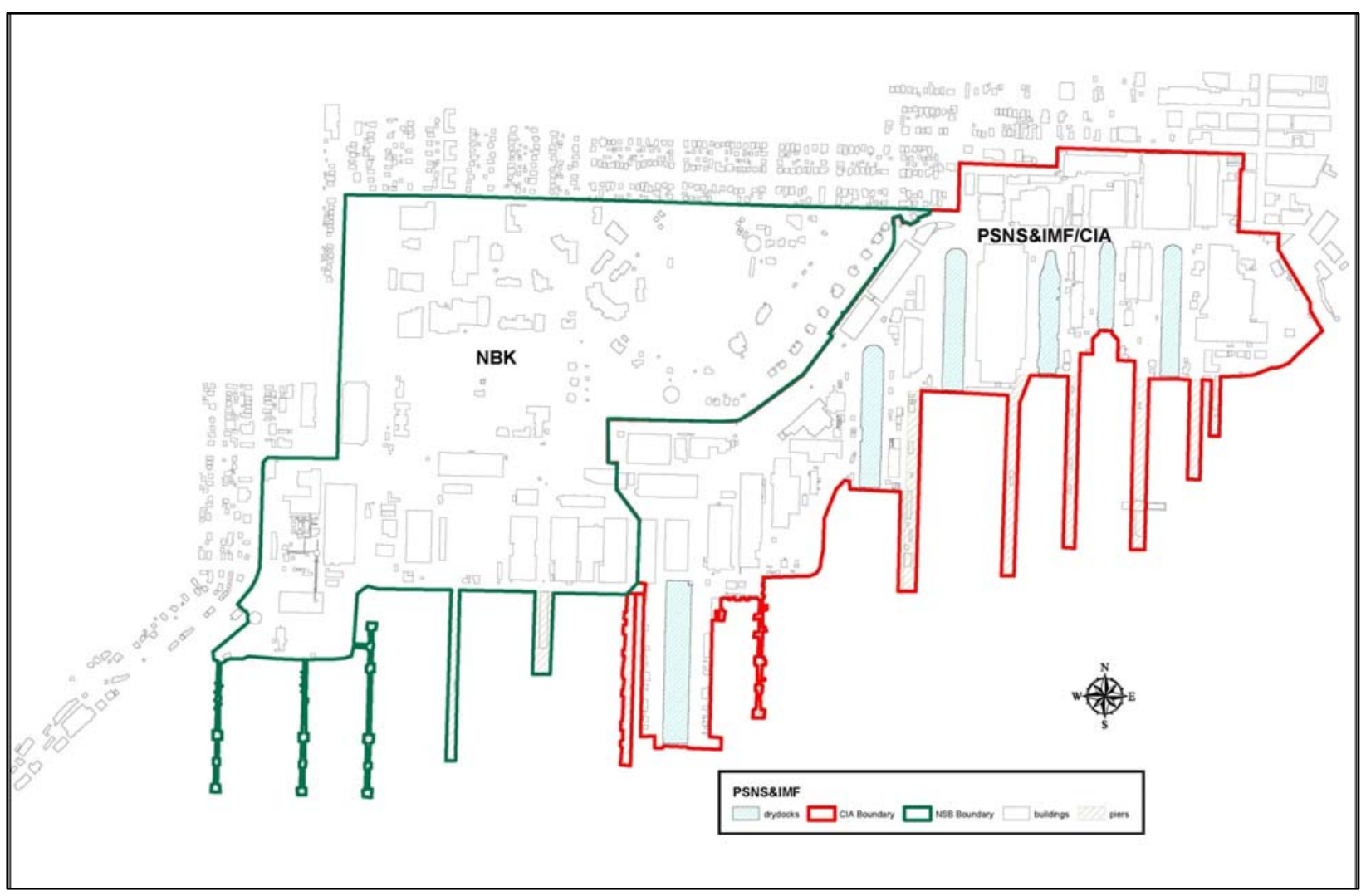

Figure 2. Bremerton Naval Complex with the industrial area ( $\mathrm{CIA})$ in red and Naval Base Kitsap (NBK) in green.

This interim report summarizes the stormwater monitoring conducted for non-dry dock outfalls in both the CIA and the NBK. This includes the collection, analyses, and descriptive statistics for stormwater sampling conducted from November 2010 through April 2011. Seven stormwater basins within the Shipyard were sampled during at least three storm events to characterize non-dry dock stormwater discharges at selected stormwater drains located within the facility (Figure 3). This serves as the Phase I component of the project and Phase II is planned for the 2011-2012 storm season. These data will assist the Navy, USEPA, Ecology and other stakeholders in understanding the nature and condition of stormwater discharges from the Shipyard and helps inform the permitting process (USEPA 2008a, b).

This report summarizes the current stormwater data available from the Shipyard, Sinclair/Dyes Inlet watershed, and Puget Sound in order to support technical investigations for the Draft NPDES permit. The permit would require storm event sampling at selected stormwater drains located within the Shipyard. However, the data must be considered on multiple scales to truly understand potential impairments to beneficial uses within Sinclair and Dyes Inlets. The results from the 2010-2011 
sampling, reported herein, are synthesized with the existing regional data and will eventually be combined with additional stormwater data collection currently in progress.

\subsection{Regional BACKGROUND}

In 2000, A cooperative ENVironmental inVESTment Project (ENVVEST) was created in partnership with the Shipyard, USEPA, Ecology, and local stakeholders to support the development of a Total Maximum Daily Load (TMDLs) for fecal coliform (FC) and other contaminants entering the Sinclair and Dyes Inlet watershed (Figure 1, ENVVEST 2002a, b, 2006). As part of Project ENVVEST, 13 stormwater drainage basins within the watershed, including three basins within the Shipyard, were monitored for flow and sampled during storm events (Brandenberger et al. 2007a, b). The stormwater outfalls selected for flow monitoring were determined by a technical evaluation of 35 stormwater outfalls (including streams and other urbanized natural drainage areas) located within the City of Bremerton, City of Port Orchard, City of Bainbridge Island, Kitsap County, and the Shipyard (TEC 2003a, b, c). This work resulted in a calibrated and verified Hydrological Simulation Program Fortan (HSPF) for drainage basins within the watershed including the Shipyard (Skahill and LaHatte 2007) and estimates of stream and storm event runoff quality as a function of upstream land use and cover (LULC) and storm intensity (Brandenberger et al. 2007a, b; Cullinan et al. 2007). This provided the ENVVEST data to develop a contaminant mass balance for heavy metals, PAHs, PCBs, and nutrients where all sources and sinks were considered to allow a relative evaluation of the dominant sources (Brandenberger et al. 2008).

The integrated watershed assessment approach of Project ENVVEST provided data on the current quality of the water, sediment, and biota present in both Sinclair and Dyes Inlets. Establishing a solid baseline and understanding the variability on a spatial and seasonal scale provides a means from which to assess process improvements within the Shipyard and bound the data in terms of regional sources of contaminants. This ENVVEST approach implements scientific methodologies to be employed in stormwater monitoring efforts, including analytical chemistry, marine geochemical analysis, watershed analysis, urban stream ecology, salmonid habitat assessment, watershed monitoring, and the documentation of scientific findings and results. The data from this interim report of non-dry dock stormwater sampling improves the estimate of ENVVEST stormwater loading, the mass balance of chemical contaminants from the Shipyard, and augments the ambient monitoring to demonstrate ongoing environmental performance in support of NPDES requirements (Johnston et al. 2010). 
An evaluation of existing stormwater monitoring data for the Shipyard and a review of technical and regulatory requirements was conducted and reported in the Quality Assurance Project Plan (QAPP) for non-dry dock stormwater monitoring conducted under the NPDES (Taylor Associates Inc. 2009). This report documents the technical strategy and procedures for monitoring non-dry dock stormwater basins within the Shipyard. The Phase I stormwater monitoring plan recommended sampling seven representative storm drains within the Shipyard followed by Phase II focused within the CIA. A Project Work Plan (PWP often referred to as a QAPP) was written to detail the field methodology, collection protocol, and laboratory methods necessary to conduct stormwater monitoring at the seven selected monitoring locations for Phase I during at least three qualifying storm events from November 2010 to April 2011 (Figure 3, TEC and PNNL, 2011). The annual PWP provided the supporting documentation, which includes the environmental health and safety plan (ES\&H) and details on sample collection and analyses methods.

\subsection{GoALS \& OBJECTIVES}

The goal of Phase I was to collect and characterize non-dry dock stormwater and associated data from the selected locations within the Shipyard to provide preliminary data in support of the (Working Draft) NPDES Permit Number WA-00206-2 (USEPA 2008a, b). In addition, these data support development of the ENVVEST LULC stormwater relational model (Brandenberger et al. 2007a, b; Cullinan et al. 2007) as part of the contaminant mass balance for Sinclair and Dyes Inlet (Brandenberger et al. 2008).

The Phase I objectives were

1. Document logistics and site information for all seven Phase I stations along with field and laboratory quality control procedures necessary to allow the non-dry dock stormwater data to be comparable to the ENVVEST stormwater data set;

2. Collect grab and composite stormwater samples during three qualifying storm events at each of the seven stormwater sampling locations consistent with methodology reported by ENVVEST;

3. Conduct chemical analyses utilizing appropriate analytical techniques to ensure data are representative of storm water quality;

4. Prepare field-sampling reports documenting the results of each storm event sampling including ancillary data (rainfall, temperature, salinity, etc.); and

5. Prepare an annual report summarizing the results of chemical analysis relative to other regional data and providing the status of non-dry dock stormwater 
monitoring at the Shipyard to inform the stormwater management program and future permit requirements (USEPA 2008a).

\subsection{BNC STUDY AREA DESCRIPTION}

Design features and conditions of the stormwater drainage infrastructure were assessed at selected basins for stormwater monitoring logistics. Sampling sites were selected that maximized the upstream drainage area, minimized tidal effects and accounted for operational constraints (see PWP; TEC and PNNL, 2011). Figure 3 illustrates the Phase I location in both the CIA and non-industrial NBK. They represent the main industrial operations and processes at PSNS\&IMF and support functions in the surrounding NBK. These basins were selected because of their relatively large size (in comparison to other basins with similar activity); heavy industrial use (for applicable primary work tasks); close proximity to legacy sites; and contained unique and/or representative land use. Table 1 list the drainage basins selected for monitoring and their associated stormwater outfall number, geographical area and primary work activity.

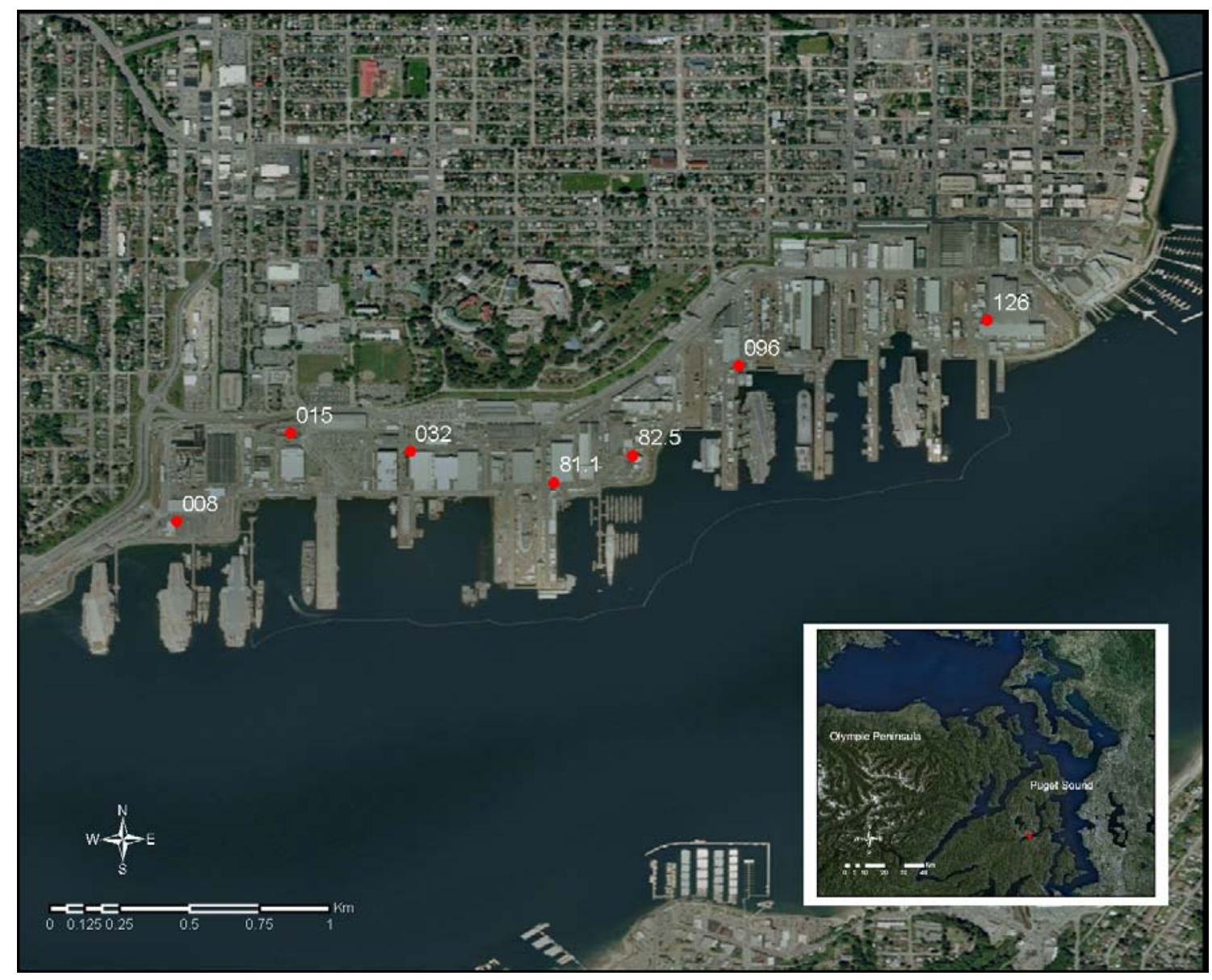

Figure 3. Phase I stormwater sampling locations at PSNS\&IMF. 
Table 1. Drainage basins selected for monitoring and the associated primary work activity.

\begin{tabular}{|c|l|l|}
\hline $\begin{array}{c}\text { PSNS\&IMF } \\
\text { Outfall \# }\end{array}$ & Geographical Area & Primary Work Activity \\
\hline 126 & $\begin{array}{l}\text { East CIA, Southwest B460 } \\
\text { along "C" Street, east of DD3 }\end{array}$ & Materials storage (outdoor) \\
\hline 096 & $\begin{array}{l}\text { Mid CIA, west of DD4, southeast } \\
\text { of Bldg 457 along "N" St }\end{array}$ & Vessel maintenance \\
\hline 082.5 & $\begin{array}{l}\text { West CIA, southeast of B851, } \\
\text { RMTS Area }\end{array}$ & $\begin{array}{l}\text { Vessel, equipment and materials } \\
\text { recycling }\end{array}$ \\
\hline 081.1 & $\begin{array}{l}\text { West CIA, NE of DD6 and NW } \\
\text { of Pier 9, south side of BIdg 462 }\end{array}$ & Non-aircraft carrier support services \\
\hline 032 & East NBK, NW corner of B514 & Aircraft carrier support services \\
\hline 015 & $\begin{array}{l}\text { Mid NBK, south side of } \\
\text { McDonalds, east side of drive- } \\
\text { through lane }\end{array}$ & $\begin{array}{l}\text { Municipal/commercial/residential } \\
\text { services }\end{array}$ \\
\hline 008 & $\begin{array}{l}\text { West NBK, east side of Inactive } \\
\text { Fleet B550 }\end{array}$ & Parking/steam plant/truck traffic \\
\hline
\end{tabular}

As described in the AKART study (Jabloner 2009), the BNC stormwater system is composed primarily of clay pipe with a mixture of concrete, PVC, steel, and cementasbestos pipe. Stormwater is collected from buildings and roofs by rain gutters and roof drains, which then discharge into storm drainage pipes or into catch basins located around the buildings. On the piers and other surfaces located directly over the water there are drain holes in the deck that deposit the rainwater directly into Sinclair Inlet. The ground surfaces around the buildings are generally impervious, made up of either asphalt, concrete, or concrete base with asphalt over it. There are various cracks, breaks and holes in some of the surface cover, as well as crane track pathways and a sloped vegetated hillside (the northern boundary of the CIA) that infiltrates a small portion of precipitation and surface runoff within the CIA. However, because the vast majority of the CIA contains no unpaved or pervious areas, stormwater infiltration is assumed to be minimal.

The depth of the stormwater system ranges 1-20 ft. below ground surface. Most of the stormwater outfalls discharge to Sinclair Inlet below mean lower low water (MLLW). The Shipyard is only a few feet above high tide; therefore most of the stormwater piping is tidally influenced. Table 2 provides the specific attributes of the drainage basins and details are provided in the PWP (TEC and PNNL 2011). 
Table 2. Drainage basin attributes for the Phase I outfall sampling events 2010-2011.

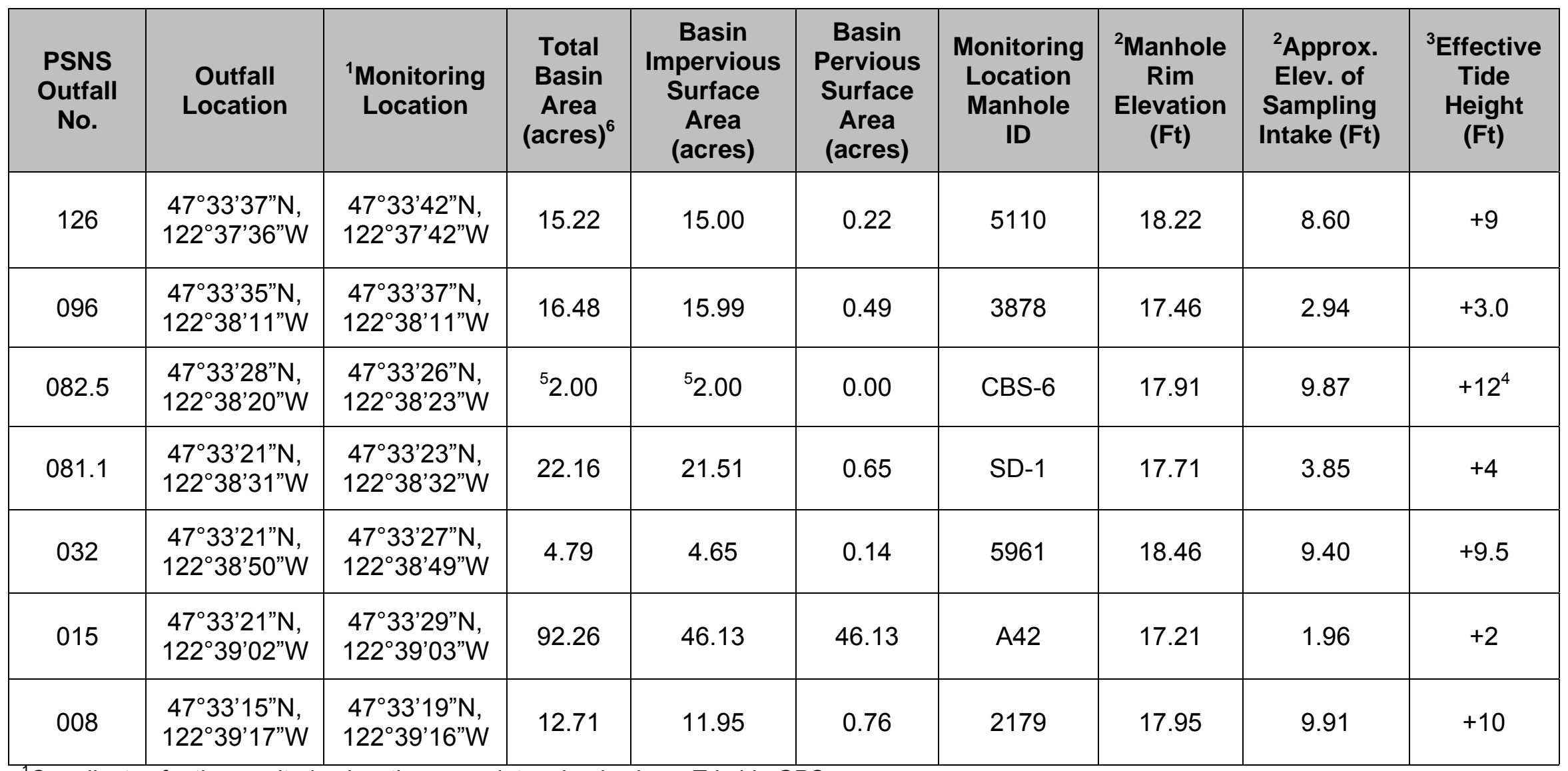

${ }^{1}$ Coordinates for the monitoring location were determined using a Trimble GPS.

${ }^{2}$ Referenced to Mean Lower Low Water (historical PSNS\&IMF documents 1994-2008).

${ }^{3}$ Expected tidal height based on NOAA tide predications that would cause tidewater, under non-storm conditions, to be detected at a certain monitoring location.

${ }^{4}$ The effective tide height at 082.5 is significantly higher than the approximate elevation of the sampling intake due to the design of the piping system at this location. A Tideflex valve is located in the manhole downstream from CBS-6, which only allows tide water to back up into CBS-6 at higher tidal ranges.

${ }^{5}$ This is an estimate of the area draining through CBS-6. CBS- 6 drains only a portion of the total PSNS\&IMF 082.5 basin area (14.56 acres).

${ }^{6}$ Total basin areas are included in the Basin Description Table and were determined on calculation supplied by the Navy. 


\subsection{PSNS \&IMF NPDES PERMIT OVERVIEW}

The Shipyard's first NPDES permit was issued in September 1986 and then reissued in April 1994. This 1994 permit is the current effectual stormwater discharge guidance for the Shipyard. The USEPA, Ecology, and the Shipyard are working together to renew the PSNS \&IMF's current NPDES permit for discharges into Sinclair Inlet, Puget Sound, WA (USEPA $2008 a, b)$. In accordance with the NPDES permit, PSNS\&IMF is required to monitor discharge from the following three operations:

- Dry dock discharges (covered separately; Johnston et al. 2009);

- Steam plant discharges (covered separately; Johnston et al. 2009); and

- Stormwater and miscellaneous runoff from non-dry dock areas.

In May 2008 the USEPA issued a Working Draft NPDES Permit for the Shipyards' consideration, review and preparation. In the 2008 Working Draft NPDES Permit, one stipulation addresses the characterization and assessment of non-dry dock stormwater runoff. Table 3 details the proposed permit requirements (per Permit §I.C.3 and §III.A) for non-dry dock stormwater monitoring assessment parameters, maximum daily effluent limits, sample frequency and sample type.

Table 3. Proposed stormwater monitoring requirements and final effluent limitations.

\begin{tabular}{|l|c|c|c|}
\hline Parameter & $\begin{array}{c}\text { Maximum Daily Effluent } \\
\text { Limit }\end{array}$ & $\begin{array}{c}\text { Sample } \\
\text { Frequency }\end{array}$ & Sample Type \\
\hline Copper, total recoverable & $5.8 \mu \mathrm{g} / \mathrm{L}$ & Quarterly & Composite. \\
\hline Lead, total recoverable & $221 \mu \mathrm{g} / \mathrm{L}$ & Quarterly & Composite \\
\hline Mercury, total recoverable & $2.1 \mu \mathrm{g} / \mathrm{L}$ & Quarterly & Composite \\
\hline Zinc, total recoverable & $95 \mu \mathrm{g} / \mathrm{L}$ & Quarterly & Composite \\
\hline Arsenic, total recoverable & $69 \mu \mathrm{L} / \mathrm{L}$ & Quarterly & Composite \\
\hline Total Suspended Solids & ---- & Quarterly & Composite \\
\hline Oil and Grease (NW-TPH-D) & ----- & Quarterly & Grab \\
\hline Oily Sheen & No oily sheen & Quarterly & Visual Observation \\
\hline Turbidity & 5 NTU above background & Quarterly & Composite \\
\hline
\end{tabular}

Taylor Associates Inc. (2009) evaluated existing stormwater monitoring data for the Shipyard and reviewed technical and regulatory requirements prior to recommending the technical strategy and procedures for monitoring non-dry dock stormwater basins within the Shipyard. Phase I, reported herein, provides the stormwater quality measured within seven distinct storm drainage systems that are representative of the seven main work activity types within the Shipyard (TEC and PNNL 2011). The primary activities include: 
(1) Materials storage

(2) Vessel, equipment and materials recycling

(3) Vessel maintenance

(4) Non-aircraft carrier vessel support services

(5) Aircraft carrier support services

(6) Parking/steam plant (stormwater discharges only)/truck traffic

(7) Municipal/commercial/residential services

This report provides the first year of monitoring for the non-dry dock stormwater from stormwater outfalls or conveyances that represent the primary work activities performed within the non-dry dock areas. In order to leverage the three years of existing stomrwater data conducted by ENVVEST within the Sinclair/Dyes Inlet watershed, the list of parameters was expanded from those in Table 3 to remain consistent with the ENVVEST program. The list of parameters are total recoverable and dissolved aluminum (Al), silver (Ag), arsenic (As), cadmium $(\mathrm{Cd})$, chromium $(\mathrm{Cr})$, copper $(\mathrm{Cu})$, lead $(\mathrm{Pb})$, mercury $(\mathrm{Hg})$ and zinc $(\mathrm{Zn})$; hardness; total organic carbon (TOC); dissolved organic carbon (DOC); total suspended solids (TSS); turbidity; conductivity and temperature.

Data from these monitoring efforts provide the first assessment of stormwater quality from non-dry dock outfalls considered in the draft NPDES permit. They may also be used to evaluate the effectiveness of BMPs, develop future effluent limitations, help identify sources of pollution potentially affecting the quality of stormwater discharges associated with industrial activity from the facility, and may lead to recommendations for implementation of measures to minimize pollutants in stormwater discharges.

\subsection{FIELD COLLECTION METHODS}

Consistent with the requirements specified in the draft NPDES permit, grab samples and automated, tidally-compensated, time-paced composite samples were collected at selected representative outfalls during Phase 1. Field collection methods for the 2010-11 stormwater sampling events followed guidance described in Taylor Associates (2009) and detailed in the PWP (TEC and PNNL 2011). A brief description of field collection methodologies is provided below. See Appendix A for detailed individual storm event reports.

\subsection{QUALIFYING STORM EVENTS}

Stormwater events were targeted from November 2010 through April 2011. Three qualifying storm events from each of the seven monitoring stations were successfully collected. Due to equipment limitations the outfalls were divided into two groups: four CIA stations and three 
NBK stations. The storm events at the CIA stations were collected from October through December then the equipment was demobilized and re-deployed at the NBK stations. Storms were sampled at the NBK sations from January through May. Qualitying storm events were targeted based on small modifications from the ENVVEST program criteria for wet season sampling. The criteria used for the 2010-11 qualifying storm events are listed in Table 4.

The ENVVEST storm event sampling from 2003-2005 provided a range of water quality concentrations for both streams and stormwater outfalls as a function of level of development within the subasin and storm event size. The critical gap in the sampling was larger storm events ( $\geq 1.0$ ") in urban and industrial basins. Therefore, the criteria were modified to add a conditional 24-hour antecedent qualification as necessary. The conditional qualification allows for the capture of discrete storm events during the more intensive wet season when the frequency of rain events is high. For example, this alteration is overwhelmed by the total storm volume, as long as, the antecedent rainfall is less than $10 \%$ of the associated total storm event volume. The larger storm volumes would have the potential to release and/or expose sources that otherwise may not occur during smaller events. This conditional antecedent qualification was applied on a station specific basis for each targeted event.

Table 4. Qualifying storm event criteria.

\begin{tabular}{|c|c|c|}
\hline Criteria & Wet Season & Dry Season \\
\hline Seasonal Period & October 1 - April 30 & May 1 - September 30 \\
\hline $\begin{array}{l}\text { Targeted Storm } \\
\text { Size and } \\
\text { Probability }\end{array}$ & $\begin{array}{l}\geq 0.20 " \text { in } 24 \text {-hours } \\
\geq 70 \% \text { forecasted probability of } \\
\text { occurrence } 24 \text {-hours prior }\end{array}$ & $\begin{array}{c}\geq 0.10 " \text { in } 24 \text {-hours } \\
\geq 50 \% \text { forecasted probability of } \\
\text { occurrence } 24 \text {-hours prior }\end{array}$ \\
\hline $\begin{array}{l}\text { Qualifying Storm } \\
\text { Size }\end{array}$ & $\begin{array}{l}\geq 0.10 \text { ", or a sufficient amount for } \\
\text { sampling to have occurred for at least } \\
2 \text { hours during stormwater runoff }\end{array}$ & $\begin{array}{l}\geq 0.10 \text {, or a sufficient amount } \\
\text { for sampling to have occurred } \\
\text { for at least } 2 \text { hours during } \\
\text { stormwater runoff }\end{array}$ \\
\hline $\begin{array}{l}\text { Antecedent } \\
\text { Precipitation } \\
\text { Conditions }\end{array}$ & $\begin{array}{l}\text { Less than or equal to } 0.1 \text { " rain in } \\
\text { previous } 24 \text {-hours } \\
\text { No rain in previous } 6 \text { hours }\end{array}$ & $\begin{array}{l}\text { Less than or equal to } 0.02 \text { " rain } \\
\text { previous } 72 \text {-hours } \\
\text { No rain in previous } 6 \text { hours }\end{array}$ \\
\hline $\begin{array}{l}\text { Conditional 24- } \\
\text { hr Antecedent } \\
\text { Qualification }\end{array}$ & $\begin{array}{l}\text { If there is greater than } 0.1 " \text { rain in a } \\
24 \text {-hr antecedent period, the overage } \\
\text { should not exceed } 10 \% \text { of the overall } \\
\text { storm event rainfall total. The } 6 \text {-hr } \\
\text { condition is unchanged }\end{array}$ & Does not apply for Dry Season \\
\hline $\begin{array}{l}\text { Inter-event Dry } \\
\text { Period }^{(1)}\end{array}$ & 6 hours minimum, 12 hours maximum & $\begin{array}{c}6 \text { hours minimum, } 12 \text { hours } \\
\text { maximum }\end{array}$ \\
\hline
\end{tabular}

(1) A storm event can be considered completed once there has been a 6-hour period with no precipitation. However water sampling could continue, as long as runoff is occurring or the station hydrograph is elevated above pre-storm conditions, for up to a 12-hour period with no precipitation, at which time the storm would be considered complete. 
Storm targeting procedures were detailed in the 2010-11 PWP and are briefly outlined here:

1. Weather forecasts for the Bremerton, WA area were checked weekly to determine if a qualifying storm event could occur during the next 7-day period.

2. If a forecast suggested a qualifying storm, the team conferred to decide if the storm should be considered for targeting and continued tracking. If yes, then forecasts were reviewed at least daily.

3. Precipitation forecasts were reviewed at $72-24$ hours prior to targeted storm and team made final "go/no-go" decision.

4. If a "go" then a sample event lead was designated.

5. The lead scheduled field team pre-storm site setup activities and was in control until all samples were delivered to the laboratory.

6. Internet-based forecasts were archived to document targeting decisions.

Prior to the start of the storm, the field team visited each sampling location to prepare the monitoring equipment for data and stormwater collection. Prior to deployment, autosampler bottles were pre-cleaned by the PNNL analytical laboratory, as described in the PWP (TEC and PNNL 2011). During the pre-storm site visit, the field team checked/modified the autosampler programs as detailed in each storm event report, conducted necessary maintenance and calibration activities, and placed sample bottles into the autosamplers. All setup, maintenance, and calibration activities were recorded on field data sheets, along with associated notes of other relevant site conditions (Appendix A).

\subsection{IN-Situ DATA COLLECTION}

At each of the monitoring stations a variety of in-situ data were collected. Data types included: precipitation (rain amount and intensity), water level in the associated piping systems (level responses due to both runoff/process inputs and tidal influences), temperature, conductivity, salinity and sample collection information. In-situ data were collected with sensors, gauges and autosamplers that were connected to, logged by, and/or controlled with a station-specific datalogger and telemetric control system. These in-situ data types and data collection, storage and management procedures are described in detail in the PWP and briefly summarized below.

\subsubsection{Precipitation Monitoring}

Precipitation was monitored via a network of rain gauges installed at each monitoring station and atop Building 427 (official PSNS gauge) within the CIA. Data from the monitoring station rain gauges were collected and stored on dataloggers and was accessible by either direct download or remotely through a telemetric network. Precipitation amounts (depth) and intensity were continuously monitored at each site. A continuous rainfall record allowed for 
the establishment of a rainfall/runoff relationship at each site. This relationship was used to estimate the total storm volume discharge, calculate the discharge volume for the sampling duration at each station using a variation of the Runoff Coefficient Method (RCM), and classify the storm event size consistent with the ENVVEST database. The RCM was previously used for volume estimation purposes during implementation of the 1994 PSNS NPDES compliance monitoring. The RCM method is an accepted industry standard and is an effective calculation method for providing an estimate of storm flow volumes in the absence of dedicated flow monitoring equipment. Section 7.4 of the PWP (TEC and PNNL 2011) detailed the application, selection of coefficients and calculation of the RCM.

Briefly, the RCM method uses the total storm rainfall, pervious and impervious drainage area size, and a runoff coefficient to calculate the total runoff volume in cubic feet. Runoff coefficients for the selected monitoring sites where chosen from published values for the following surface types: heavy (0.6-0.9) and light (0.5-0.8) industrial areas, railroad lines (0.2$0.4)$, continuous concrete or asphalt cover (0.7-0.95), heavy soil (0.18-0.22) and residential/suburban (0.25-0.4). The coefficient range gives latitude for consideration of particular basin characteristics. Typically the upper end of the coefficient range values are applied to the more impervious portions and the lower end of the coefficient range values are applied to the more pervious portions of a certain surface type when calculating runoff volumes. The formula below was slightly modified from the standard RCM so that it accounts for the effective runoff from both pervious and impervious areas from each monitored outfall drainage basin (Navy 1996):

Total Runoff Volume $(V)=R \times\left[\left(A_{i} \times C_{i}\right)+\left(A_{p} \times C_{p}\right)\right]$

Where $V$ is total runoff volume $\left(\mathrm{ft}^{3}\right), \mathrm{R}$ is total rainfall (ft.), $A_{i}$ is total impervious drainage area $\left(\mathrm{ft} .{ }^{2}\right), A_{p}$ is total pervious drainage area $\left(\mathrm{ft}^{2}{ }^{2}\right), C_{i}$ is runoff coefficient for impervious area of the drainage basin, and $C_{p}$ is the runoff coefficient for pervious area of drainage basin. Table 5 presents this information for the monitored drainage basins, their percent pervious and impervious areas, runoff coefficient value ranges for the basin surface types and the total discharge volume estimation equations. The upper range of coefficient values were used in all RCM calculations during the 2010-11 storm events.

In addition, the rain gauges were used for storm event tracking, identifying the event start (to schedule grab sampling) and end (to retrieve composite samples). Rain data were also used for enabling the autosamplers and in the validation of the storm events based on the criteria presented above. Rain gauges were maintained per established methods of data assessment and comparison, scheduled maintenance and appropriate calibration. The official PSNS rain gauge was maintained, serviced and downloaded by the Navy. 


\subsubsection{Water Level, Temperature, Conductivity, and Salinity Monitoring}

Water level data from within the drainage pipes or associated vaults were continuously recorded (except during maintenance or replacement periods) using pressure transducers installed at each monitoring station. These sensors measured both water level and temperature. Water level and temperature data were stored on dataloggers. This information was accessible by either direct download or remotely through a telemetric network. Water level data were used for several key functions including: autosampler enabling, stormwater hydrograph assessment and tidal inundation assessment. Pressure transducers were inspected and serviced as recommended by the manufacturer at least once each month and/or prior to targeted storm events, whichever was more frequent.

Conductivity was continuously measured at each of the monitoring stations during each targeted storm event. Conductivity data were used to enable the autosamplers at each station during sampling activities. Conductivity was also measured at the monitoring stations during non-storm periods to determine a relationship between conductivity and the tidal backwater conditions at that station. Salinity values were determined either by a postprocessed calculation (based on conductivity and temperature) completed by the datalogger or recorded directly from a multi-parameter sonde. The method of salinity value generation was determined by the particular monitoring gear utilized at each station. 
Table 5. Stormwater outfall basin attributes and total discharge volume.

\begin{tabular}{|c|c|c|c|c|c|c|c|}
\hline $\begin{array}{l}\text { PSNS } \\
\text { Drainage } \\
\text { Basin ID }\end{array}$ & $\begin{array}{l}\text { Total Basin } \\
\text { Area }\left(\mathrm{ft}^{2}\right)\end{array}$ & $\begin{array}{c}\text { Type } \\
\text { of Surface }\end{array}$ & $\begin{array}{c}\text { Percentage } \\
\text { of } \\
\text { Drainage } \\
\text { Basin } \\
\text { Surface Type }\end{array}$ & $\begin{array}{l}\text { Area of } \\
\text { Basin } \\
\text { Surface } \\
\text { Type }\left(\mathrm{ft}^{2}\right)\end{array}$ & $\begin{array}{l}{ }^{1} \text { Runoff } \\
\text { Coefficient } \\
\text { Range }\end{array}$ & $\begin{array}{l}\text { Area of Basin Surface } \\
\text { Type with Maximum } \\
\text { Coefficient Value } \\
\text { Applied }\left(\mathrm{ft}^{2}\right)\end{array}$ & $\begin{array}{l}{ }^{2} \text { Total Discharge } \\
\text { Volume }\left(\mathrm{ft}^{3}\right)\end{array}$ \\
\hline \multirow{2}{*}{126} & \multirow{2}{*}{662,986} & Impervious & 98.55 & 653,373 & $0.6-0.9$ & 588,036 & \multirow{2}{*}{$R(591,881)$} \\
\hline & & Pervious & 1.45 & 9,613 & $0.2-0.4$ & 3,845 & \\
\hline \multirow{2}{*}{096} & \multirow{2}{*}{717,872} & Impervious & 97 & 696,336 & $0.6-0.9$ & 626,702 & \multirow{2}{*}{$\mathrm{R}(635,317)$} \\
\hline & & Pervious & 3 & 21,536 & $0.2-0.4$ & 8,615 & \\
\hline 082.5 & 87,120 & Impervious & 100 & 87120 & $0.7-0.95$ & 82,764 & $\mathrm{R}(82,764)$ \\
\hline \multirow{2}{*}{081.1} & \multirow{2}{*}{965,294} & Impervious & 97 & 936,335 & $0.6-0.9$ & 842703 & \multirow{2}{*}{$\mathrm{R}(849,074)$} \\
\hline & & Pervious & 3 & 28,959 & $0.18-0.22$ & 6,371 & \\
\hline \multirow{2}{*}{032} & \multirow{2}{*}{208,653} & Impervious & 97 & 202,393 & $0.6-0.9$ & 182,154 & \multirow{2}{*}{$\mathrm{R}(184,658)$} \\
\hline & & Pervious & 3 & 6,260 & $0.2-0.4$ & 2,504 & \\
\hline \multirow{2}{*}{015} & \multirow{2}{*}{$4,018,862$} & Impervious & 50 & $2,009,431$ & $0.5-0.8$ & $1,607,549$ & \multirow{2}{*}{$\mathrm{R}(2,411,317)$} \\
\hline & & Pervious & 50 & $2,009,431$ & $0.25-0.4$ & 803,772 & \\
\hline \multirow{2}{*}{008} & \multirow{2}{*}{553,650} & Impervious & 94 & 520,431 & $0.5-0.8$ & 416349 & \multirow{2}{*}{$\mathrm{R}(429,637)$} \\
\hline & & Pervious & 6 & 33,219 & $0.2-0.4$ & 13,288 & \\
\hline
\end{tabular}

${ }^{1}$ These values are derived from various published sources regarding the RCM,

${ }^{2}$ Rainfall $(R)$ is in feet for calculation of total discharge volume 


\subsubsection{Autosampler Collection Information}

The autosampler units were also a source of system operations feedback. Each autosampler was connected to a Campbell Scientific datalogger and telemetry system, which allowed sample processing information to be immediately available to the storm lead. Necessary adjustments could be made from remotely. Feedback information from the autosamplers served as a record of setup and unit operation and was included in the storm reports (Appendix A). The autosampler downloads included programming data; enable date and time, sample marker designations, bottle information, pump cycle counts, aliquot success and associated source error codes, and sample completion date and time.

\subsubsection{Data Collection, Storage and Management}

There were primarily three types of data generated during this project: (1) field activity data, including non-sampling field task operations, sample collection tasks and monitoring equipment maintenance activities; (2) in-situ monitoring data, including precipitation, water level, temperature, conductivity, salinity and autosampler collection information; and (3) laboratory chemistry data. The procedures for hard copy and electronic data handling, quality review, and archival were detailed in the PWP (TEC and PNNL 2011). The field notes and ancillary data were provided in Appendix A. In-situ monitoring data were electronic stored. Data were typically transferred via telemetry to a data server on the TEC network, where it was archived. Rainfall data from the Navy's gauge atop Building 427 and autosampler report collection information were manually downloaded and also stored on the TEC network. Field data were split into raw and comma-delimited formats. The raw data were stored "as-is", remaining static and unedited, serving as an archive and backup to the field monitoring data. The comma-delimited data were maintained as .DAT files that were updated by deleting older data once uploaded to the database. This provided storage space for more recent data. Comma-delimited files were uploaded to a proprietary water quality data management and display database (e.g. Isco® Flowlink, v4.15). All electronic data were reviewed for errors, omissions and accuracy.

Laboratory generated data were also summarized for each storm event and provided in Appendix $B$. The data were also formatted for the electronic database submission into the ENVVEST database. Copies of analytical raw data are stored at the laboratory of generation and available upon request. All project data were maintained as part of the official project record and stored for a period as described in the PWP (TEC and PNNL 2011). 


\subsection{STORMWATER MONITORING SYSTEM / EQUIPMENT}

The stormwater monitoring system at each station was comprised of various components. These components included telemetric communication modem, central datalogger / system controller, autosampler, rain gauge, pressure (water level) / temperature transducer, conductivity sensor, salinity sensor, solar panel charger and batteries, and housings and various mountings. All of the sensors and gauges were frequently (typically twice or more a month during their operational periods) calibrated and maintained to assure accurate level data. Diagrams of a general schematic of the monitoring system components are provided in Figure 4. These components are further described below.

Telemetric communication modem: A telemetry communication system was installed at each station and provided remote communication access through the datalogger. Sierra Wireless AirLink Raven XT cellular modems (Campbell Scientific Inc., Logan, Utah), with Code Division Multiple Access (CDMA) digital technology, were utilized as the communication link between the remote user or server and the datalogger. This allowed for either transmission of collected data to an offsite computer and system status checks on a scheduled or ondemand basis or for execution of incoming system commands (e.g. setting or correcting enabling condition thresholds, changing a sample pacing rate, etc.). The use of the Raven XT modem in its project-specific configuration provided highly secure data transmissions, which was of the utmost importance to PSNS\&IMF. Formal security permission was obtained for the modems and dataloggers (see PWP) used in this project. The security permission forms and other pertinent information were also included in each telemetry box.

Datalogger / system controller: Campbell Scientific, Inc. CR1000 (Logan, Utah) custom programmable dataloggers were utilized as the central "brains" of each monitoring system. The CR1000 is capable of storing large quantities of time-series data, as well as, performing a wide range of system control functions. All of the system components, including sensors, autosamplers and peripherals (e.g. batteries and solar charging system) were connected through the datalogger. Calibration of all project sensors, as well as, controlling the enabling conditions for the autosampler was facilitated through the datalogger. Connection to the datalogger could be accomplished either directly or remotely via proprietary software. All field data were automatically stored on the CR1000 datalogger at five-minute intervals.

Dataloggers were programmed to download, via the telemetry system, to a base station computer at the TEC office on a schedule of at least once per day; more frequent downloads occurred during times of need (e.g. storm events, calibrations, etc.).

Autosampler: Stormwater samples were collected using automatic water samplers (autosamplers) installed at each site. Water sampling equipment included Teledyne-Isco® 6700 series samplers (Lincoln, NE), Teflon ${ }^{\mathrm{TM}}{ }^{-l i n e d}$ polyethylene sampler suction line, and 
siliconized Tygon ${ }^{\mathrm{TM}}$ pump and distributor arm tubing. Autosamplers were deployed in an offthe-shelf configuration equipped with $241 \mathrm{~L}$ polypropylene wedge bottles. Each sampler was identically programmed (TEC and PNNL, 2011). The associated dataloggers controlled activation and sample collection pacing. Sampler reports were also remotely downloaded and included in Appendix A.

Rain gauge: Teledyne-Isco® 674 (Lincoln, NE) tipping bucket rain gauges were used to collect rainfall data. These instruments measured rainfall at 0.01 -inch increments. Rainfall data was downloaded via telemetry at least once each day and more frequently during and following targeted storm events. Each rain gauge was connected to its associated datalogger, which recorded rainfall data at 5-minute intervals.

Water level and Temperature: Pressure transducers were used at each monitoring station to record water level and temperature to measure the water level within a selected pipe or vault. Two different types of pressure transducers were used for monitoring and sample collection. These were the Campbell Scientific CS450 and the Instrumentations Northwest Inc. (INW, Kirkland, WA) CT2X. Each of these units measured pressure and temperature to very similar specifications. Water level and temperature were both measured and reported to $1 / 100$ of a foot and degree Celsius, respectively.

Conductivity: Specific conductivity was measured at each station by two different sensor types. The INW CT2X (Kirkland, WA) and YSI (Yellow Springs, OH) 6820 multi-meter sonde were used to collect specific conductivity data. The INW CT2X specific conductivity sensor was incorporated into its associated pressure transducer (each CT2X measured pressure, temperature and specific conductivity). The YSI 6820 is a stand-alone unit that was used in combination with the CS450 transducer. The YSI 6820 also provided redundant temperature data. Both specific conductivity probes recorded values to the nearest 1/100 micromhos $(\mu \mathrm{mho} / \mathrm{cm})$, but were reported to the nearest whole number.

Salinity: Salinity values were generated based on non-temperature compensated conductivity measurements and temperature readings. Stations that utilized the INW CT2X transducer generated salinity data after post-processing through the datalogger using published algorithms. Salinity reported from the YSI 6820 was calculated directly by the multi-meter sonde using the same conversion algorithms. Salinity values from both sensors were recorded to the nearest 1/100 of a part/thousand (ppt) and reported as a whole number.

Solar panel charger and batteries: The telemetry system, datalogger and all associated water quality monitoring components were powered by $12 \mathrm{v}$ deep cycle marine batteries. Typically each station used two batteries; one to power the datalogger, sensors and telemetry system and one to power the autosampler. Campbell Scientific SP20 regulated 20-watt solar panels were used to recharge the battery associated with the datalogger and its connected 
components. Depending on available sunlight exposure at a particular station, it was sometimes necessary to have two batteries connected in parallel powering the datalogger. The stand-alone autosampler battery was removed from the equipment housing after each sampling event, re-charged and replaced prior to the next sampling event.

Housings and mountings: Monitoring stations were designed with modularity and mobility as their main tenets. Each station had the ability of being moved to a new location with minimal setup and demobilization. Sturdy steel, lockable equipment enclosures were used to house the various monitoring system components and to provide a stable platform from which to mount open-air items. Attached 10-foot tall masts supported the solar panels, omnidirectional antennas and rain gauges at each of the housings. Each equipment housing was placed as close to the outfall location as possible. All stations were above-ground setups with conduit lines leading from the housing to the vaults and sampling points. A number of monitoring system components were installed underground at all of the sites. Transmission cables for the pressure transducers and conductivity meters, as well as, the sampler suction lines ran from the equipment housings into the associated vault through heavy-duty plastic conduit. Inside each vault, the sampler suction lines ran along the wall and terminated at the sampler strainers, which were generally installed in the invert of the outlet pipe.

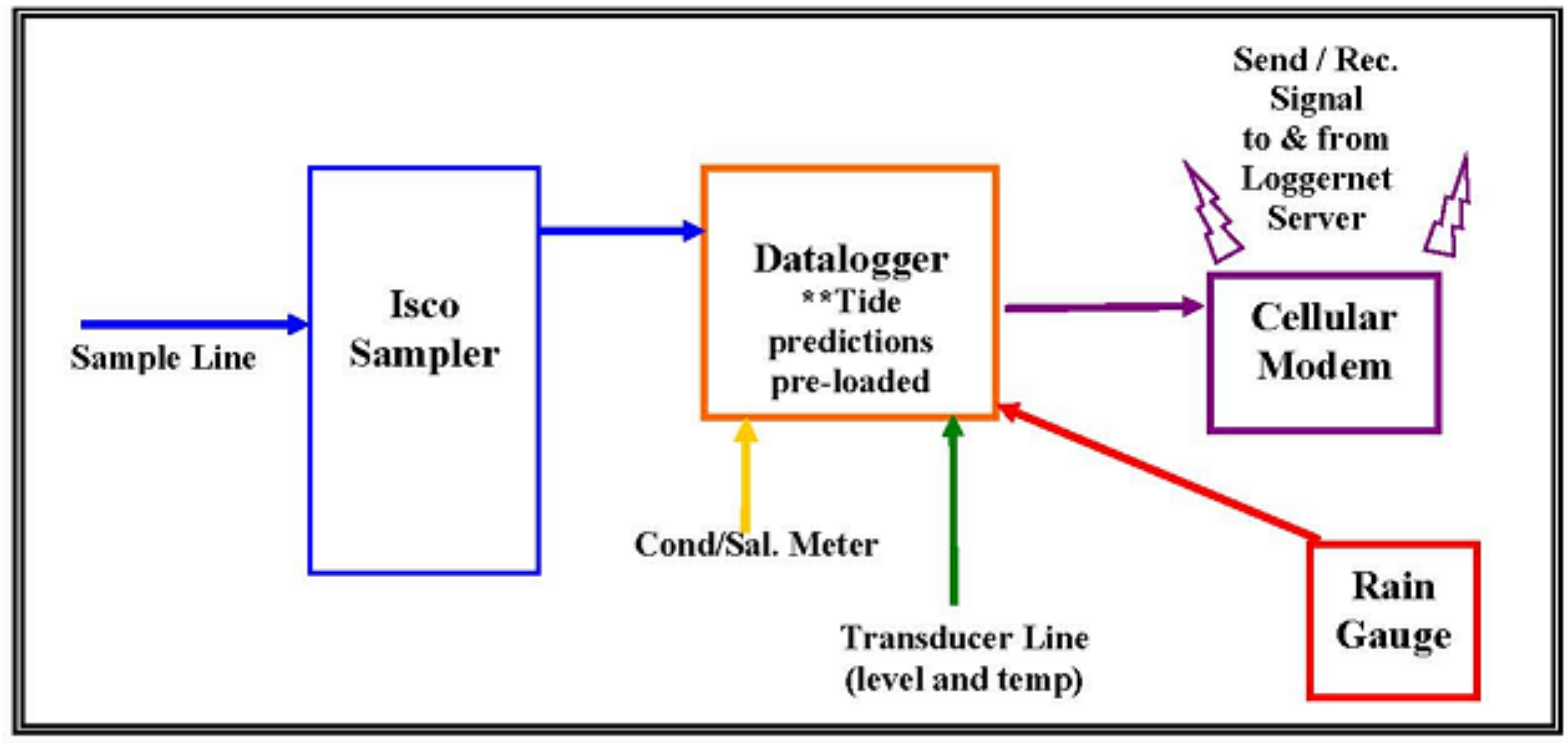

Figure 4. Generalized schematic of monitoring station components.

\subsection{StormWater SAmple Collection}

Seven validated stormwater events were sampled during the 2010-11 field season based on the criteria discussed above. Table 6 presents the date for each storm event, station identification, the number of samples collected during each event, the number of total 
samples collected at each station, and type of sample (e.g. grab or composite). All sample collection and management followed the guidance contained in the PWP (TEC and PNNL 2011). In brief, two types of stormwater samples were collected at each monitoring site: (1) manual grab samples and (2) time-proportionate composite samples. All sample containers and (non-metal) equipment were pre-cleaned as outlined in the PWP Appendix F (TEC and PNNL 2011). The collection containers, pump tubing, and other non-metal sampling equipment were pre-cleaned and packaged to maintain cleanliness (e.g. double bagged and ends of sampling tubing were closed together using silicon tubing). Equipment blanks and field blanks were periodically collected to ensure sampling equipment and collection methods were not a source of contamination.

Routine grab samples were collected into laboratory clean amber glass bottles for total petroleum hydrocarbon - diesel range extended (TPH-Dx) analysis via laboratory cleaned stainless steel cups. Time-paces composites were collected into pre-cleaned polypropylene (PP) containers (wedge bottles) using ISCO pumps equipped with siliconized Tygon ${ }^{\mathrm{TM}}$ pump head tubing, Teflon ${ }^{\mathrm{TM}}$-lined suction line, and Teflon $^{\mathrm{TM}}$ or stainless steel strainers and various connectors/fittings. The event mean composites (EMCs) were composited in a pre-cleaned $10 \mathrm{~L}$ glass bottle with Teflon ${ }^{\mathrm{TM}}$ lined lid.

Four stations were targeted for all events for a total of 60 samples ( 30 grab and 30 composite samples). During Phase I, four field duplicate sets were collected (two each grab and composites). Of the 60 potential samples, 50 were collected (22 grab and 28 composite samples), for a success rate of $73 \%$ for grabs and $93 \%$ for composites. When combined, a total of 50 out of 60 samples were collected, for an overall success rate of $83 \%$.

Deviations from the PWP and corrective actions conducted during individual storms were documented in the storm reports (Appendix A). The anomalies of note included the following: 1) during SW01 a grab sample was collected from PSNS096, but the tidal conditions prevented the collection of the composite sample, 2) during SW05 the tidal conditions again prevented the collection of any samples at PSNS096, and 3) during SW06 a telemetry setting miscue caused the autosampler at PSNS015 to stay disabled, thus preventing the collection of the composite sample. 
Table 6. The outfalls, sample types, and storm event dates sampled during 2010-2011 season.

\begin{tabular}{|c|c|c|c|c|c|c|c|c|c|}
\hline \multirow{4}{*}{ Station } & SW & 01 & 02 & 03 & 04 & 05 & 06 & 07 & \\
\hline & Date & $11 / 17 / 2010$ & $11 / 29 / 2010$ & $12 / 11 / 2010$ & $3 / 1 / 2011$ & $3 / 8 / 2011$ & $3 / 9 / 2011$ & $4 / 13 / 2011$ & \\
\hline & $\begin{array}{c}\text { No. } \\
\text { Grabs }\end{array}$ & 3 & 4 & 5 & 4 & 4 & 2 & 0 & 22 \\
\hline & $\begin{array}{c}\text { No. } \\
\text { Comp. }\end{array}$ & 4 & 4 & 5 & 4 & 4 & 2 & 5 & 28 \\
\hline PSNS126 & & & & Dup-Comp & NT & NT & NT & NT & 7 \\
\hline PSNS096 & & Grab only & & & & & & $\begin{array}{c}\text { Comp } \\
\text { only }\end{array}$ & 10 \\
\hline PSNS082.5 & & & & Dup-Grab & NT & NT & NT & NT & 7 \\
\hline PSNS081.1 & & & & & NT & NT & NT & NT & 6 \\
\hline PSNS032 & & NT & NT & NT & & $\begin{array}{l}\text { Dup- } \\
\text { Grab }\end{array}$ & & $\begin{array}{c}\text { Comp } \\
\text { only }\end{array}$ & 8 \\
\hline PSNS015 & & NT & NT & NT & & & & $\begin{array}{l}\text { Comp } \\
\text { only }\end{array}$ & 5 \\
\hline PSNS008 & & NT & NT & NT & & $\begin{array}{l}\text { Dup } \\
\text { Comp }\end{array}$ & NT & $\begin{array}{l}\text { Comp } \\
\text { only / } \\
\text { Dup }\end{array}$ & 7 \\
\hline
\end{tabular}

= Stations sampled during a particular SW

= Stations with anomalies of note during a storm event that prevented sample collection

NT $=$ Not Targeted 


\subsubsection{Grab Sampling}

Fecal coliform and TPH samples were collected using a manual grab sampler. Grab samples were collected at each station as soon as possible after runoff had commenced and conductivity levels were below 2,000 $\mu \mathrm{mho} / \mathrm{cm}$. Qualifying stormwater conditions (runoff occurrence/hydrograph response and water quality) were verified prior to grab sample collection at each station. A sterilized and pre-cleaned, stainless steel sample vessel was dipped into the flow stream (typically by using an extension pole). The TPH samplers were stored in two separate amber glass containers containing preservative. Fecal coliform samples were collected and managed as described in the Fecal Coliform Monitoring Assessment and Control - Water Year 2011 Quality Assurance Project Plan (Johnston, et al, 2010). Attempts were made to collect both grab and composite samples as an associated pair from the same storm event at each site.

\subsubsection{Automated Time-Proportionate Composite Sampling}

Time-proportionate composite samples were collected using autosamplers at each station during qualifying storm events as described above. Autosamplers were configured to begin sampling when a given combination of rain, and/or water level and/or conductivity conditions met the established criteria. Composite samples were collected for at least the first two hours of non-tidally effected runoff and up to 24-hours. No storm event sampled during the 2010-11 sampling season lasted less than two hours. The PWP details the collection, handling, analytical, and quality control procedures associated with the composite sampling. The following sections briefly described the procedures.

The autosamplers were programmed to collect sequential samples over the course of a sample event. Programming in this manner, while using a 24-bottle configuration, allowed for the greatest amount of sampling resolution. The sequential program allowed for the possibility of selecting a subset of filled bottles (depending on total sample volume needed for the targeted event), which represented the volume and nature of the storm flow and exclusion of sample bottles that were largely filled with tidal flow. Upon completion of a sample event, the contents of each bottle representing the storm flow were composited to produce a single storm event sample or EMC.

The autosamplers were set to initiate their sampling program when a series of enabling conditions were met that indicated storm runoff was occurring and that there was minimal or no tidal influence. These enabling conditions included rainfall, water level, and conductivity. Specifically, the rain gauge must have detected a rain intensity of at least 0.03 inches of precipitation in a one-hour period and the autosampler recorded an increase in the water level as measured by the pressure transducer indicating the storm produced adequate runoff. 
The enabling water level was determined from background water level measurements taken at each station when not affected by storm runoff or tides plus an upward water level change beyond the sensitivity (i.e., noise) of the instrument. This water level change value was typically 0.03 to $0.1 \mathrm{ft}$. The final enabling condition was the conductivity sensor recorded less than $2,000 \mu \mathrm{mho} / \mathrm{cm}$. A variation of the conductivity enable condition was the "repeatable enable". This is where the sampler program was toggled on and off based on the 2,000 $\mu \mathrm{mho} / \mathrm{cm}$ threshold - such that only qualified water would be collected. Various combinations of these enabling conditions were used throughout the individual storm sampling events (see Appendix A).

\subsubsection{Field Sample Validation, Preservation, and Handling}

Prior to creating the storm EMC samples, the individual time-composites (wedge bottles) were validated against criteria presented in Section 2.1. Validation activities for the grab and composite samples are presented below.

\section{Grab Samples}

- Reviewed field forms and the precipitation, water level, and conductivity data to ensure the grab samples were collected during storm runoff;

- Reviewed field notes to determine whether anomalous conditions were encountered that would disqualify the grab samples; and

- Inspected the grab sample containers to ensure they were properly filled and labeled.

\section{Composite Samples}

- Determined if storm runoff occurred during the sample event;

- Reviewed the storm event hyetograph, hydrograph and timing of the sample aliquot collection to ensure that the composite samples were collected within the first two hours of non-tidally influenced runoff;

- Reviewed field notes to determine whether anomalous conditions were encountered that would disqualify the composite sample;

- Tested the conductivity of each $1 \mathrm{~L}$ wedge bottle using a hand-held conductivity meter to ensure levels were below 2,000 $\mu \mathrm{mhos} / \mathrm{cm}$;

- Confirmed the overall composite sample would consist of at least eight $1 \mathrm{~L}$ wedge bottles; and

- Inspected the composite sample containers to ensure they were properly filled and labeled. 
The EMC samples (final composite) were prepared in a $10 \mathrm{~L}$ pre-cleaned glass jar stored at $4 \pm 2^{\circ} \mathrm{C}$ until hand delivered to PNNL. Grab samples collected for TPH were stored at $4 \pm 2^{\circ} \mathrm{C}$ and hand delivered to PNNL. Table 7 lists required sample containers, preservatives, and analytical holding times. Upon receipt at PNNL, the condition of all the samples was verified as acceptable and tracked back to the field chain of custody (COC). In the clean laboratory at PNNL, each glass composite sample was shaken vigorously (prior and between aliquot removal) and aliquots were poured into the following types of containers:

1. $500 \mathrm{~mL}$ Teflon bottle for total metals (TME);

2. $500 \mathrm{~mL} 0.45 \mu \mathrm{m}$ polyvinylidene fluoride (PVDF) filter unit, vacuum filtered in a class 100 clean bench and then poured into a $500 \mathrm{~mL}$ Teflon bottle for dissolved metals;

3. $250 \mathrm{~mL}$ low-density polyethylene (LDPE) bottle precharged with nitric acid preservative for samples to be analyzed for hardness (HRD);

4. $500 \mathrm{~mL}$ LDPE container with sulfuric acid preservative for the analysis of TOC;

5. $60 \mathrm{~mL}$ syringe and ashed glass fiber filter (GFF) in a cleaned filter holder and filtered into a $250 \mathrm{~mL}$ LDPE container with sulfuric acid preservative for the analysis of DOC;

6. $500 \mathrm{~mL}$ or $1 \mathrm{~L}$ LDPE bottle for the analysis of TSS.

The total metal and dissolved metal fractions were acidified inside a Class 100 clean bench to a $\mathrm{pH}$ of $<2.0$ with double distilled nitric acid. The samples were then assigned a central file identification number (3174) and were entered into the Pacific Northwest National Laboratory (PNNL) sample tracking system. The total petroleum hydrocarbon (TPH) grab samples and composites for TOC, DOC, hardness, and TSS were all forwarded to Columbia Analytical Laboratory Services (CAS) for analyses. Appendix B provides the documentation for the sample receipt and handling and the chemistry results for each storm event. 
Table 7. Sample container types, preservatives, recommended handling, and holding times.

\begin{tabular}{|c|c|c|c|}
\hline Parameter & $\begin{array}{c}\text { Container } \\
\text { Type }\end{array}$ & $\begin{array}{l}\text { Handling I } \\
\text { Preservation }\end{array}$ & $\begin{array}{l}\text { Holding } \\
\text { Time }\end{array}$ \\
\hline \multicolumn{4}{|l|}{ Chemicals of Concern } \\
\hline NWTPH-Dx (grab) & $\begin{array}{l}\text { (2) } 1 \mathrm{~L} \text { Amber } \\
\text { Glass }\end{array}$ & $4^{\circ} \mathrm{C} \pm 2^{\circ} \mathrm{C}, \mathrm{H}_{2} \mathrm{SO}_{4}$ & $\begin{array}{l}7 \text { days for extraction, } 40 \text { days } \\
\text { for analysis }\end{array}$ \\
\hline $\begin{array}{c}\text { Total Recoverable Metals } \\
\text { (Al, As, Cu, Cr, Cd, Pb, Zn, } \\
\mathrm{Hg})\end{array}$ & 1L Teflon & $\begin{array}{c}4^{\circ} \mathrm{C} \pm 2^{\circ} \mathrm{C} ; \mathrm{pH}<2.0 \\
\text { with nitric acid }\end{array}$ & $\begin{array}{l}90 \text { days } \mathrm{Hg} \text { and } 6 \text { months } \\
\text { for all others }\end{array}$ \\
\hline $\begin{array}{l}\text { Dissolved Metals (Cu, Cr, } \\
\quad \mathrm{Cd}, \mathrm{Pb}, \mathrm{Zn}, \mathrm{Hg})\end{array}$ & $\begin{array}{l}\text { Filtrate } 500 \mathrm{~mL} \\
\quad \text { Teflon }\end{array}$ & $\begin{array}{c}4^{\circ} \mathrm{C} \pm 2^{\circ} \mathrm{C} ; \mathrm{pH}<2.0 \\
\text { with nitric acid after } \\
\text { filtration }\end{array}$ & $\begin{array}{l}\text { Filter }(0.45 \mu \mathrm{m}) \text { within } 48 \\
\text { hours of composite; once } \\
\text { preserved same as above }\end{array}$ \\
\hline \multicolumn{4}{|l|}{ Conventional Parameters } \\
\hline Turbidity & $\begin{array}{l}\text { From glass } \\
\text { composite }\end{array}$ & $4^{\circ} \mathrm{C} \pm 2^{\circ} \mathrm{C}$ & 48 hours \\
\hline TSS & 1L LDPE & $4^{\circ} \mathrm{C} \pm 2^{\circ} \mathrm{C}$ & 7 days \\
\hline $\begin{array}{l}\text { Hardness, Total (as } \\
\qquad \mathrm{CaCO}_{3} \text { ) }\end{array}$ & 250mL LDPE & $4^{\circ} \mathrm{C} \pm 2^{\circ} \mathrm{C}$ & 14 days \\
\hline TOC & $\begin{array}{l}250 \text { or } 500 \mathrm{~mL} \\
\text { LDPE w/Pres. }\end{array}$ & $4^{\circ} \mathrm{C} \pm 2^{\circ} \mathrm{C}, \mathrm{H}_{2} \mathrm{SO}_{4}$ & 28 days \\
\hline DOC & $\begin{array}{l}250 \text { or } 500 \mathrm{~mL} \\
\text { LDPE w/Pres. }\end{array}$ & $4^{\circ} \mathrm{C} \pm 2^{\circ} \mathrm{C}, \mathrm{H}_{2} \mathrm{SO}_{4}$ & $\begin{array}{l}\text { After field filtration using } \\
\text { GFF filter, } 28 \text { days }\end{array}$ \\
\hline
\end{tabular}

\subsection{ANALYTICAL METHODS}

The chemicals of concern for this project included total recoverable and dissolved $\mathrm{Al}, \mathrm{As}, \mathrm{Cu}$, $\mathrm{Cr}, \mathrm{Cd}, \mathrm{Pb}, \mathrm{Zn}, \mathrm{Hg}$, and TPH (see Table 7). Ancillary parameters included turbidity, TSS, hardness, TOC, and DOC. The sample collection, handling, and analyses methods incorporated aspects of the USEPA Method 1669 (USEPA 1995) for clean hands sample collection and ambient water quality analyses methods [USEPA 1638 for metals (1996a) and USEPA 1631 for $\mathrm{Hg}$ (2002b)] to adequately represent ambient water chemistry. Although stormwater is not considered ambient water, it was critical to incorporate these protocols as industrial areas often have other sources of contamination at the outfall sampling locations. 
Once a sample is collected, it must be isolated from the industrial processes occurring around the manhole as contamination of the sample would no longer represent the chemistry of the stormwater transferred through the piped conveyance. Additionally, these parameters allow the assessment of bioavailability of the metals and the application of the biotic ligand model (BLM). The BLM has been developed to account for the ancillary parameters like DOC that affect Cu bioavailability in freshwater (USEPA 2007) and saltwater (USDOD/EPA 2011; Hydroqual 2011).

The PWP detailed the preparation and analytical methods, method detection limit (MDL), and reporting limit $(R L)$ for each parameter and Table 8 summarizes this information. Appendix $B$ provides the individual chemistry reports for each storm event. These reports include a brief description of the methods, all quality control samples analyzed, and any impacts to the data quality. The methods were either standard methods or modifications of EPA methods. For the metals, one modification was all samples were digested following the total recoverable metal (TRM) method established in USEPA Method 1640 (1996b) prior to analysis by inductively coupled plasma mass spectrometer (ICP-MS). Both the filtered and unfiltered fractions were prepared using this method to destroy any colloidal particles remaining in the dissolved fraction.

Table 8. Preparation and analytical methods for the non-dry dock stormwater samples.

\begin{tabular}{|c|c|c|c|c|}
\hline Parameter & Preparation Method & $\begin{array}{l}\text { Analytical } \\
\text { Method }\end{array}$ & $\begin{array}{l}\text { Method } \\
\text { Detection } \\
\text { Limit } \\
\text { (MDL) }\end{array}$ & $\begin{array}{l}\text { Reporting } \\
\text { Limit (RL) }\end{array}$ \\
\hline TSS & NA & USEPA 160.2 & $5.0 \mathrm{mg} / \mathrm{L}$ & $5.0 \mathrm{mg} / \mathrm{L}$ \\
\hline Turbidity & NA & 180.1 & $0.1 \mathrm{NTU}$ & $0.1 \mathrm{NTU}$ \\
\hline Hardness (as $\mathrm{CaCO}_{3}$ ) & NA & STM2340C & $0.8 \mathrm{mg} / \mathrm{L}$ & $2 \mathrm{mg} / \mathrm{L}$ \\
\hline TOC & SM5310C & SM5310C & $0.07 \mathrm{mg} / \mathrm{L}$ & $0.50 \mathrm{mg} / \mathrm{L}$ \\
\hline DOC & Ashed GFF filtration & SM5310C & $0.07 \mathrm{mg} / \mathrm{L}$ & $0.50 \mathrm{mg} / \mathrm{L}$ \\
\hline TPH (Diesel Range) & EPA 3510C & NWTPH-Dx & $11-13 \mu \mathrm{g} / \mathrm{L}^{1}$ & $250 \mu \mathrm{g} / \mathrm{L}$ \\
\hline TPH (Residual Range) & EPA 3510C & NWTPH-Dx & $19-22 \mu \mathrm{g} / \mathrm{L}^{1}$ & $500 \mu \mathrm{g} / \mathrm{L}$ \\
\hline $\mathrm{Al}$ & TRM EPA 1640m & EPA $1638 \mathrm{~m}$ & $0.3 \mu \mathrm{g} / \mathrm{L}$ & $1.0 \mu \mathrm{g} / \mathrm{L}$ \\
\hline As & TRM EPA 1640m & EPA 1638m & $0.03 \mu \mathrm{g} / \mathrm{L}$ & $0.1 \mu \mathrm{g} / \mathrm{L}$ \\
\hline $\mathrm{Cu}$ & TRM EPA 1640m & EPA 1638m & $0.007 \mu \mathrm{g} / \mathrm{L}$ & $0.02 \mu \mathrm{g} / \mathrm{L}$ \\
\hline $\mathrm{Cr}$ & TRM EPA 1640m & EPA 1638m & $0.08 \mu \mathrm{g} / \mathrm{L}$ & $0.3 \mu \mathrm{g} / \mathrm{L}$ \\
\hline $\mathrm{Cd}$ & TRM EPA 1640m & EPA 1638m & $0.004 \mu \mathrm{g} / \mathrm{L}$ & $0.01 \mu \mathrm{g} / \mathrm{L}$ \\
\hline $\mathrm{Pb}$ & TRM EPA 1640m & EPA 1638m & $0.002 \mu \mathrm{g} / \mathrm{L}$ & $0.006 \mu \mathrm{g} / \mathrm{L}$ \\
\hline $\mathrm{Zn}$ & TRM EPA 1640m & EPA 1638m & $0.05 \mu \mathrm{g} / \mathrm{L}$ & $0.2 \mu \mathrm{g} / \mathrm{L}$ \\
\hline $\mathrm{Hg}$ & EPA 1631 Rev E & EPA 1631 Rev E & $0.1 \mathrm{ng} / \mathrm{L}$ & $0.3 \mathrm{ng} / \mathrm{L}$ \\
\hline
\end{tabular}


The MDL was reported from the annually verified MDL study as determined by seven replicates of deionized water spiked at appropriate concentrations and prepared using the TRM method. The RL $=3.18 \times \mathrm{MDL}$.

${ }^{1}$ MDLs were sample specific based on the volume extracted. See data table for individual MDLs.

\subsection{QUALITY ASSURANCE AND QUALITY CONTROL}

The objective for the usability, quality, type, and output of data collected, as stipulated in the PWP, is to achieve the requirements specified in the draft NPDES permit. The data will also satisfy requirements for non-dry dock stormwater outfalls and provide comparable data into the ENVVEST runoff model. The quality and usability of laboratory data generated in this investigation were evaluated for precision, accuracy (bias), representativeness, comparability, completeness, and sensitivity. The data were found to have acceptable measures of each of these variables with $93 \%$ completeness as discussed above. The overall precision was evaluated using the field duplicates, laboratory duplicates, and duplicate matrix spikes. The accuracy was evaluated using the equipment blank results, matrix spikes (MS), laboratory control standards (LCS), and standard reference material (SRM). The representativeness, comparability, and sensitivity were derived from the laboratory method blanks, MDL, RL, and comparable methodology in collection and analytical procedures.

\subsection{FIELD QUALITY CONTROL}

Field quality control (QC) conducted during this project included documented procedures specific to field activities including calibrating field equipment, documentation, sample collection, QC samples, data review and verification, field team performance and system audits and possible corrective actions for activities. These elements were described in the PWP and are briefly summarized below.

Original field records are maintained in designated binders and databases for all monitoring and field related activities using project-specific forms and established procedures. Field documentation included, but not limited to, stormwater sample event field sheets, maintenance activity logs, instrument calibration logs, work permits for confined space, COC forms, raw data from continuous monitoring instrumentation, and other documentation. These records were included in the storm event reports (Appendix A).

The sampling efforts for this program employed the following field QC procedures to ensure consistency, reduce contamination, and ensure representative samples: 
- Collected composite water samples using automatic samplers.

- Collected samples in certified contaminant-free or properly decontaminated containers.

- Stored sampling containers in clean, sealed boxes or bags prior to use.

- Used "clean hands/dirty hands" sampling techniques (e.g., one team member performs "dirty tasks" such as lifting manhole covers and handling samplers with batteries, while the other member performs "clean tasks" such as handling sample intake lines and sample collection bottles).

- Periodically cleaned or replaced Teflon-lined sampler tubing and sampler strainers.

- Backflushed sampler tubing with deionized water prior to a sampling event.

- Held samples on ice in coolers during retrieval and delivery to laboratory.

- Delivered samples to laboratory with proper $\mathrm{COC}$ forms and within recommended holding times.

Field QC samples were used to assess sample collection procedures, environmental conditions during sample collection, storage, and transport to the laboratory, and the adequacy of equipment and sampling container decontamination. The types of field QC samples collected were field duplicate samples, field blanks, and equipment blanks (including tubing blanks and filtration blanks). Field QC samples were labeled and tracked as samples. The collection frequency was greater than the target of $10 \%$ of the environmental samples collected for chemicals of concern (e.g. metals and TPH).

\subsubsection{Field Duplicates}

The purpose of collecting and analyzing field duplicates was to demonstrate the precision of field sampling and sample processing. All field duplicate samples were collected in an identical manner to the primary "parent" and received an independent sample identification code. The field duplicate samples were used to evaluate if environmental conditions are more variable than the sampling design could accommodate.

Field duplicates consisted of an "internal" duplicate, which included a replicate (composite stormwater) sample collected at the same time using a single autosampler configuration. The autosampler was programmed to collect sequential aliquots of stormwater and deliver them to two separate sets of bottles (see PWP Section 8.2.5). Additionally, field duplicates were collected for those parameters that require grab samples (i.e. TPH, fecal coliform) by filling an additional set of grab sample bottles in rapid succession. 
Twenty-four stormwater composite samples were collected plus six field duplicates for the metals. The relative percent differences (RPD) between the parent and duplicate sample were all less $\leq 32 \%$ RPD. This meets the data quality objective of $\leq 40 \%$ RPD suggesting the methodology accurately captures variability at a particular station within a given storm event. In fact, the average RPD was $\leq 15 \%$ RPD. For TPH, 21 storm grabs were collected plus two field duplicates. The RPD values were also $\leq 40 \%$ RPD with an average of $11 \%$ RPD.

\subsubsection{Field Blanks}

Field collected equipment blanks (EB) exceeded a frequency of 1 out of every 10 samples. They were used to check for possible contamination of laboratory-cleaned grab sample equipment, autosampler equipment and sample containers for the chemicals of concern (TPH and metals). The EBs were also used to detect contamination from the surroundings or cross-contamination during transportation and/or storage. For TPH, two equipment blanks (December and March) were collected by pouring deionized water (DI) into the stainless steel sampling cup and then into an amber glass sample container while at two randomly selected outfall locations. The TPH concentrations in the EBs were not detected above the RL.

For the metals, a total of 18 EBs were collected to evaluate the composite autosampler system. This included blanks from the Teflon $®$ sample line tubing, autosampler pump and distributor arm tubing, wedge bottles and glass composite jars. The EBs included two tubing blanks, eight autosampler system blanks, and eight filtration blanks. The two tubing blanks had metal concentrations less than the MDL and reflected only laboratory cleaning since they were not field deployed. In order to incorporate field conditions, eight field blanks were collected with four in October 2010 prior to the onset of storm event sampling and another four in February after station moves. Deionized water was pumped through the deployed tubing, autosampler, laboratory cleaned sample intake line and strainer and into the precleaned glass composite jar. The EB samples were assigned a unique sample identification code, labeled, and delivered to the laboratory as a sample.

At the laboratory, they were filtered for dissolved metals and analyzed with the other storm event samples. All the EBs were less than the RL for $\mathrm{Hg}$, As, and Ag. Detectable concentrations of $\mathrm{Cd}, \mathrm{Cr}, \mathrm{Cu}, \mathrm{Pb}$, and $\mathrm{Zn}$ triggered the corrective action, which included a review of the analytical method blanks to rule out lab contamination, a review of the clean hands sampling protocol, and all data were evaluated if the storm event concentrations were $<5$ times the EB concentrations. Table 9 summarizes the mean EB concentrations compared to the MDL, RL, and if there were sample concentrations $<5$ times the mean $E B$. The laboratory analyses included a method blank with each analytical batch of samples. The method blank is a sample carried through the preparation and analytical methods to ensure 
there is no significant contamination from the chemical reagents, laboratory handling or analytical equipment. The method blanks results did not suggest a laboratory contamination issue. A review of the sampling equipment identified a stainless steel strainer as the potential problem for $\mathrm{Cr}$ and this was replaced with a plastic strainer after the first set of EB samples were collected. The second set verified the corrective action worked and the overall impact to the data quality was not significant.

Table 9. The summary of equipment blank concentrations for the metals.

\begin{tabular}{|l|l|l|l|l|l|}
\hline & MDL & RL & EB Mean & $\begin{array}{l}\text { Standard } \\
\text { Deviation }\end{array}$ & $\begin{array}{l}\text { No. Samples < 5 times } \\
\text { EB Mean }\end{array}$ \\
\hline $\mathrm{Hg}(\mathrm{ng} / \mathrm{L})$ & 0.1 & 0.3 & $0.115 \mathrm{~J}$ & 0.080 & NA \\
\hline $\mathrm{Ag}(\mu \mathrm{g} / \mathrm{L})$ & 0.002 & 0.006 & $0.002 \mathrm{U}$ & -- & $\mathrm{NA}$ \\
\hline $\mathrm{As}(\mu \mathrm{g} / \mathrm{L})$ & 0.03 & 0.1 & $0.03 \mathrm{U}$ & -- & $\mathrm{NA}$ \\
\hline $\mathrm{Cd}(\mu \mathrm{g} / \mathrm{L})$ & 0.004 & 0.01 & $0.006 \mathrm{~J}$ & 0.007 & $\mathrm{NA}$ \\
\hline $\mathrm{Cr}(\mu \mathrm{g} / \mathrm{L})$ & 0.08 & 0.3 & 0.553 & 1.08 & 29 \\
\hline $\mathrm{Cu}(\mu \mathrm{g} / \mathrm{L})$ & 0.007 & 0.02 & 0.149 & 0.278 & 0 \\
\hline $\mathrm{Pb}(\mu \mathrm{g} / \mathrm{L})$ & 0.002 & 0.006 & 0.0210 & 0.0273 & 0 \\
\hline $\mathrm{Zn}(\mu \mathrm{g} / \mathrm{L})$ & 0.05 & 0.2 & 0.608 & 0.456 & 0 \\
\hline
\end{tabular}

NA - not appropriate because equipment blanks were less than RL.

$U$ Value not detected above the MDL.

$\mathrm{J}$ Estimated concentration below the RL.

\subsubsection{Field Data Review and Verification}

Field data were reviewed and verified following the guidance provided by the USEPA (2002a). The verification included computer entries to field data sheets, calculations, and raw data review for outliers or nonsensical readings. The field data were reviewed on a monthly basis and after each successfully sampled storm event. This included rainfall, water level, temperature, conductivity and salinity data review for gross errors such as spikes or data gaps to determine completeness of the data set. Rainfall, water level, temperature and conductivity measurements were checked as follows: 
- Identified data gaps and determined if they could be filled with alternate data.

- Identified data anomalies or spikes for unrealistic conditions.

- Cross checked data sets against field sheets and calibration records. Determined if data sets needed to be adjusted based on instrument calibration or field staff observations.

- Inspected patterns/yields for a particular basin/area based on previous project or historic data. Comparison of hyetograph to the hydrograph for water level response to rainfall.

The TEC and PNNL reviewed the procedures implemented in the field for consistency with the established protocols. Members of the Navy Project Team also perform field procedural reviews. Sample collection, preservation, labeling, and other procedures were checked for completeness. Where procedures were not in compliance with the established protocols, these deviations were documented and reported in the storm or chemistry reports (Appendices A and B, respectively).

\subsection{LABORATORY QUALITY CONTROL}

The PWP detailed the laboratory procedures necessary to achieve the data quality objectives through appropriate analytical methods, QA/QC, and data validation. The QC samples analyzed with each batch of 20 or fewer field samples included method blanks, LCS, MS, matrix spike duplicates (MSD), laboratory duplicate (DUP), and SRM for the metals. The TPH samples included method blanks, LCS, and lab duplicates. The QC data were provided in the individual storm chemistry reports (Appendix B) and summarized in Table 10 for all the parameters. Overall, data met the required $\mathrm{QC}$ requirements for the project. The laboratory duplicate from PSNS015 during SW05 was highly variable for total Hg (RPD 80\%). Six individual aliquots of this sample were prepared and analyzed. All six maintained a high degree of variability. This was not attributed to the laboratory procedures since all other forms of QA/QC were acceptable during all other storm events. Additional studies are required for this outfall to understand the source and chemical form (e.g. particulate or dissolved) of $\mathrm{Hg}$. 
Table 10. Laboratory quality control sample summary.

\begin{tabular}{|c|c|c|c|c|c|c|c|c|c|c|c|}
\hline QC Type & & $\mathrm{Hg}$ & As & $\mathrm{Ag}$ & Cd & $\mathrm{Cr}$ & $\mathrm{Cu}$ & $\mathrm{Pb}$ & $\mathrm{Zn}$ & $\begin{array}{l}\text { TPH } \\
\text { DRO }\end{array}$ & $\begin{array}{l}\text { TPH } \\
\text { RRO } \\
\end{array}$ \\
\hline MB & $\mathrm{n}=$ & 28 & 8 & 8 & 8 & 8 & 8 & 8 & 8 & 4 & 4 \\
\hline MB & Mean & $<\mathrm{MDL}$ & $<\mathrm{MDL}$ & $<\mathrm{MDL}$ & $<\mathrm{MDL}$ & $<\mathrm{MDL}$ & $<\mathrm{MDL}$ & $<\mathrm{MDL}$ & $<\mathrm{MDL}$ & $<\mathrm{RL}$ & $<\mathrm{RL}$ \\
\hline MB & Stdev & NA & NA & NA & NA & NA & NA & NA & NA & NA & NA \\
\hline \multicolumn{12}{|c|}{ Percent Recovery (\%) } \\
\hline LCS & $\mathrm{n}=$ & 14 & 6 & 6 & 6 & 6 & 6 & 6 & 6 & 6 & 6 \\
\hline LCS & Mean & $100 \%$ & $101 \%$ & $99 \%$ & $100 \%$ & $105 \%$ & $101 \%$ & $102 \%$ & $103 \%$ & $97 \%$ & $92 \%$ \\
\hline MS & $\mathrm{n}=$ & 16 & 13 & 6 & 6 & 6 & 6 & 6 & 6 & NA & NA \\
\hline MS & Mean & $98 \%$ & $103 \%$ & $96 \%$ & $101 \%$ & $101 \%$ & $97 \%$ & $103 \%$ & $103 \%$ & NA & NA \\
\hline SRM & $\mathrm{n}=$ & 6 & 13 & 6 & 6 & 6 & 6 & 6 & 6 & NA & NA \\
\hline SRM & Mean & $95 \%$ & $98 \%$ & $92 \%$ & $99 \%$ & $95 \%$ & $98 \%$ & $98 \%$ & $95 \%$ & NA & NA \\
\hline \multicolumn{12}{|c|}{ Relative Percent Difference (RPD) } \\
\hline Lab Dup & $\mathrm{n}=$ & 10 & 7 & 7 & 7 & 7 & 7 & 7 & 7 & 3 & 3 \\
\hline Lab Dup & Mean & $21 \% a$ & $2 \%$ & $10 \%$ & $4 \%$ & $3 \%$ & $1 \%$ & $2 \%$ & $1 \%$ & $13 \%$ & $12 \%$ \\
\hline Field Dup & $\mathrm{n}=$ & 6 & 6 & 6 & 6 & 6 & 6 & 6 & 6 & 2 & 2 \\
\hline Field Dup & Mean & $15 \%$ & $12 \%$ & $5 \%$ & $4 \%$ & $7 \%$ & $4 \%$ & $13 \%$ & $6 \%$ & $14 \%$ & $7 \%$ \\
\hline \multicolumn{12}{|c|}{ Ancillary Parameters } \\
\hline QC Type & & DOC & TOC & TSS & Hardness & & & & & & \\
\hline MB & $\mathrm{n}=$ & 6 & 10 & 14 & 7 & & & & & & \\
\hline MB & Mean & $<\mathrm{RL}$ & $<\mathrm{MDL}$ & $<\mathrm{MDL}$ & $<\mathrm{MDL}$ & & & & & & \\
\hline MB & Stdev & NA & NA & NA & NA & & & & & & \\
\hline \multicolumn{12}{|c|}{ Percent Recovery (\%) } \\
\hline LCS & $\mathrm{n}=$ & 6 & 10 & 7 & 12 & & & & & & \\
\hline LCS & Mean & $102 \%$ & $102 \%$ & $107 \%$ & $97 \%$ & & & & & & \\
\hline MS & $\mathrm{n}=$ & 5 & 3 & NA & NA & & & & & & \\
\hline MS & Mean & $101 \%$ & $100 \%$ & NA & NA & & & & & & \\
\hline \multicolumn{12}{|c|}{ Relative Percent Difference (RPD) } \\
\hline Lab Dup & $\mathrm{n}=$ & 5 & 4 & 2 & 6 & & & & & & \\
\hline Lab Dup & Mean & $8 \%$ & $13 \%$ & $9 \%$ & $2 \%$ & & & & & & \\
\hline Field Dup & $\mathrm{n}=$ & 2 & 2 & 2 & 2 & & & & & & \\
\hline Field Dup & Mean & $19 \%$ & $14 \%$ & $7 \%$ & $27 \%$ & & & & & & \\
\hline
\end{tabular}

a Righ RPD for PSNS015. Alternate duplicates show this is not attributed to laboratory precision $\mathrm{EB}=$ Equipment Blank; MB = Method Blank; LCS = Laboratory Control Sample; MS = Matrix Spike SRM = Standard Reference Material; Lab Dup = Laboratory Duplicate; Field Dup = Field Duplicate; TPH $=$ Total Petroleum Hydrocarbons; DRO = Diesel Range Organics; RRO = Residual Range Organics 


\subsection{RESULTS AND DISCUSSION}

Seven qualifying storm events were sampled from November 1, 2010 through April 15, 2011 (Table 6). The field collection details for each storm were reported in Appendix A. The chemistry data were reported in Appendix B. Each event report (field and chemistry) contained a summary of storm event specific qualification parameters, sample collection criteria, QC information, and storm and sample validation checklist items (Appendix A and B). The following sections provide a synopsis of this information.

\subsection{RAINFALL DATA}

Rainfall data was collected from each station and from the PSNS gauge atop Building 427 inside of the CIA. Table 11 presents a summary of the rainfall data collected during the 201011 season for both storm events and stations. The table also provides rainfall averages, minimum / maximum depths and the Project ENVVEST storm size classification. Table 12 presents more detailed rainfall and water quality data measured from within the vaults at each site and storm including maximum one-hour rainfall intensity and event average onehour rainfall intensity (both in inches/hour). Sample event rainfall was also assessed in 5minute intervals. The 5-minute intervals provide a greater resolution when comparing storms of similar size.

There are some nuances to this type of data including: vault levels that may be negative due to transducer placement; negative conductivity values due to calibration issues typically associated with stations where the conductivity values are in the tens of thousands for a majority of the storm; salinity values constrained to values between 2 and $42 \mathrm{ppt}$ for the stations utilizing the CT2X transducer due to the conductivity to salinity conversion algorithm used for post-calculation (although the conductivity values were not constrained by this algorithm); and salinity data collected via the YSI 6820 multi-parameter sonde was capable of calculating values outside of the 2 to 42 ppt range mentioned above. See Appendix A for more detailed discussions of data nuances for each storm.

Historic rainfall records have been maintained for the Bremerton, WA area since 1899. These data sets are available through the Western Regional Climate Center (http://www.wrcc.dri.edu/). Table 13 presents monthly statistical rainfall summary data for Bremerton, WA (station 450872). The "wet season" in western Washington is from October through April, with a monthly range of 2.7 inches in April to 7.7 inches in December. The yearly average is 47.9 inches. The project sampling season was conducted for nearly the entire duration of the 2010-11 wet season; November 1, 2010 through April 15, 2011. During that five and a half month period 106 days of at least 0.01 " in a 24-hour period of rain were 
recorded by the PSNS gauge at B427. The project site experienced a slightly wetter than average period (6.3\% above average) for the $2010-11$ sampling duration with 36.98 " compared to the historic data, which was 34.78 " for the same period. The months of December and March had notably higher amounts of rainfall than average, while the other months were below average. Table 14 details the total rainfall at the PSNS site for the Phase I sampling period along with the descriptive statistics. 
Table 11. Total rainfall for each storm event and the ENVVEST storm size classification.

\begin{tabular}{|l|c|c|c|c|c|c|c|c|}
\hline \multirow{2}{*}{ Station } & $\mathbf{S W}$ & $\mathbf{0 1}$ & $\mathbf{0 2}$ & $\mathbf{0 3}$ & $\mathbf{0 4}$ & $\mathbf{0 5}$ & $\mathbf{0 6}$ & $\mathbf{0 7}$ \\
\cline { 2 - 8 } & Date & $\mathbf{1 1 / 1 7 / 2 0 1 0}$ & $\mathbf{1 1 / 2 9 / 2 0 1 0}$ & $\mathbf{1 2 / 1 1 / 2 0 1 0}$ & $\mathbf{3 / 1 / 2 0 1 1}$ & $\mathbf{3 / 8 / 2 0 1 1}$ & $\mathbf{3 / 9 / 2 0 1 1}$ & $\mathbf{4 / 1 3 / 2 0 1 1}$ \\
\hline B427 - Navy Gauge & 0.57 & 1.32 & 4.79 & 0.60 & 0.19 & 2.60 & 0.78 \\
\hline PSNS126 & 0.51 & 1.23 & 3.71 & $\mathrm{Na}$ & $\mathrm{na}$ & $\mathrm{Na}$ & $\mathrm{Na}$ \\
\hline PSNS096 & 0.61 & 1.18 & 4.47 & 0.59 & 0.16 & 2.39 & 0.75 \\
\hline PSNS082.5 & 0.59 & 1.25 & 4.44 & $\mathrm{Na}$ & $\mathrm{na}$ & $\mathrm{Na}$ & $\mathrm{Na}$ \\
\hline PSNS081.1 & 0.46 & 1.05 & 3.57 & $\mathrm{Na}$ & $\mathrm{na}$ & $\mathrm{Na}$ & $\mathrm{Na}$ \\
\hline PSNS032 & $\mathrm{na}$ & $\mathrm{Na}$ & $\mathrm{na}$ & 0.53 & 0.17 & 2.05 & 0.73 \\
\hline PSNS015 & $\mathrm{na}$ & $\mathrm{Na}$ & $\mathrm{na}$ & 0.54 & 0.17 & 2.21 & 0.75 \\
\hline PSNS008 & $\mathrm{na}$ & $\mathrm{Na}$ & $\mathrm{na}$ & 0.66 & 0.19 & $\mathrm{Na}$ & 0.86 \\
\hline Storm Average (in.) & 0.55 & 1.21 & 4.20 & 0.58 & 0.18 & 2.31 & 0.77 \\
\hline
\end{tabular}

\begin{tabular}{|l|c|c|c|c|c|c|c|}
\hline Min (in.) & 0.46 & 1.05 & 3.57 & 0.53 & 0.16 & 2.05 & 0.73 \\
\hline Max (in.) & 0.61 & 1.32 & 4.79 & 0.66 & 0.19 & 2.60 & 0.86 \\
\hline $\begin{array}{l}{ }^{2} \text { ENVVEST Storm } \\
\begin{array}{l}\text { Size Classification } \\
\text { (Brandenberger et al. } \\
2007 a)\end{array}\end{array}$ & Medium & Med-Large & Large & Medium & Small & Large & Medium \\
\hline
\end{tabular}

${ }^{1}$ Rainfall units are in inches

${ }^{2}$ Storm Size Classification: Small = <0.5", Medium = $0.5-1.0 "$, Med-Large = $1.0-2.0 "$ " Large $=\geq 2.0 "$

$\mathrm{Na}=$ Not sampled during that storm event. 
Table 12. Storm event rainfall descriptive summary for each 2010-11 storm and station.

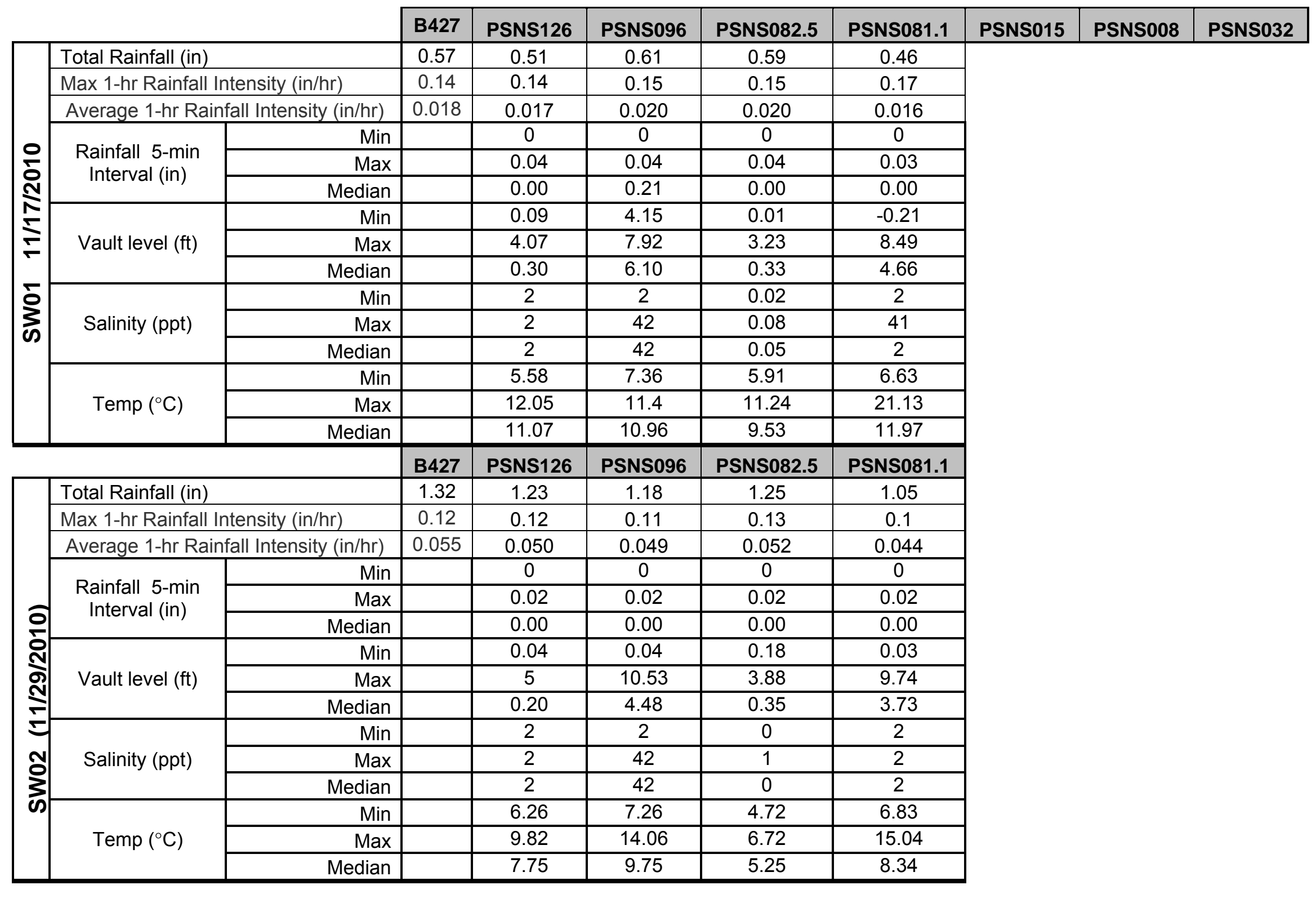


Table 12. Continued.

\begin{tabular}{|c|c|c|c|c|c|c|c|c|c|c|}
\hline & B427 & PSNS126 & PSNS096 & PSNS082.5 & PSNS081.1 & PSNS015 & PSNS008 & PSNS032 \\
\hline & \multicolumn{2}{|c|}{ Total Rainfall (in) } & 4.79 & 3.71 & 4.47 & 4.44 & 3.57 & & & \\
\hline & \multicolumn{2}{|c|}{ Max 1-hr Rainfall Intensity (in/hr) } & 0.41 & 0.33 & 0.43 & 0.42 & 0.34 & & & \\
\hline & \multicolumn{2}{|c|}{ Average 1-hr Rainfall Intensity (in/hr) } & 0.184 & 0.152 & 0.171 & 0.174 & 0.136 & & & \\
\hline \multirow{6}{*}{$\begin{array}{l}\text { 어 } \\
\text { - } \\
\text { N్} \\
\text { ㄱ. } \\
\text { ㄱ. }\end{array}$} & \multirow{3}{*}{$\begin{array}{l}\text { Rainfall 5-min } \\
\text { Interval (in) }\end{array}$} & \begin{tabular}{r|r} 
& Min
\end{tabular} & & 0 & 0 & 0 & 0 & & & \\
\hline & & Max & & 0.04 & 0.05 & 0.05 & 0.04 & & & \\
\hline & & Median & & 0.01 & 0.010 & 0.010 & 0.01 & & & \\
\hline & \multirow{3}{*}{ Vault level (ft) } & Min & & 0.1 & 0.6 & 0.21 & 0.17 & & & \\
\hline & & Max & & 5.3 & 10.82 & 5.2 & 10.54 & & & \\
\hline & & Median & & 0.39 & 4.49 & 0.39 & 4.06 & & & \\
\hline \multirow{6}{*}{ 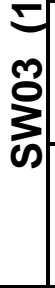 } & \multirow{3}{*}{ Salinity (ppt) } & Min & & 2 & 2 & 0 & 2 & & & \\
\hline & & Max & & 2 & 42 & 1 & 2 & & & \\
\hline & & Median & & 2 & 2 & 0 & 2 & & & \\
\hline & \multirow{3}{*}{ Temp $\left({ }^{\circ} \mathrm{C}\right)$} & Min & & 6.7 & 7.34 & 5.7 & 7.01 & & & \\
\hline & & Max & & 12.6 & 12.83 & 11.16 & 13.09 & & & \\
\hline & & Median & & 10.22 & 10.18 & 7.46 & 10.45 & & & \\
\hline & & & B427 & & PSNS096 & & & PSNS015 & PSNS008 & PSNS032 \\
\hline & \multicolumn{2}{|l|}{ Total Rainfall (in) } & 0.6 & & 0.59 & & & 0.54 & 0.66 & 0.53 \\
\hline & \multicolumn{2}{|c|}{ Max 1-hr Rainfall Intensity (in/hr) } & 0.06 & & 0.07 & & & 0.06 & 0.08 & 0.06 \\
\hline & \multicolumn{2}{|c|}{ Average 1-hr Rainfall Intensity (in/hr) } & 0.019 & & 0.018 & & & 0.018 & 0.021 & 0.018 \\
\hline \multirow{12}{*}{ 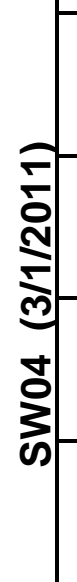 } & \multirow{3}{*}{$\begin{array}{l}\text { Rainfall 5-min } \\
\text { Interval (in) }\end{array}$} & Min & & & 0 & & & 0 & 0 & 0 \\
\hline & & Max & & & 0.01 & & & 0.01 & 0.02 & 0.01 \\
\hline & & Median & & & 0 & & & 0 & 0 & 0 \\
\hline & \multirow{3}{*}{ Vault level (ft) } & Min & & & 0 & & & 0.18 & 0 & 0 \\
\hline & & Max & & & 9.8 & & & 8.48 & 2.74 & 3.32 \\
\hline & & Median & & & 4.49 & & & 4.17 & 0.22 & 0.29 \\
\hline & \multirow{3}{*}{ Salinity (ppt) } & Min & & & 0 & & & 2 & 2 & 2 \\
\hline & & Max & & & 41 & & & 42 & 42 & 42 \\
\hline & & Median & & & 40 & & & 2 & 2 & 2 \\
\hline & \multirow{3}{*}{ Temp $\left({ }^{\circ} \mathrm{C}\right)$} & Min & & & 6.79 & & & 4.78 & 4.29 & 4.68 \\
\hline & & Max & & & 12.29 & & & 9.68 & 9.11 & 8.44 \\
\hline & & Median & & & 7.13 & & & 7.18 & 6.58 & 7.24 \\
\hline
\end{tabular}


Table 12. Continued.

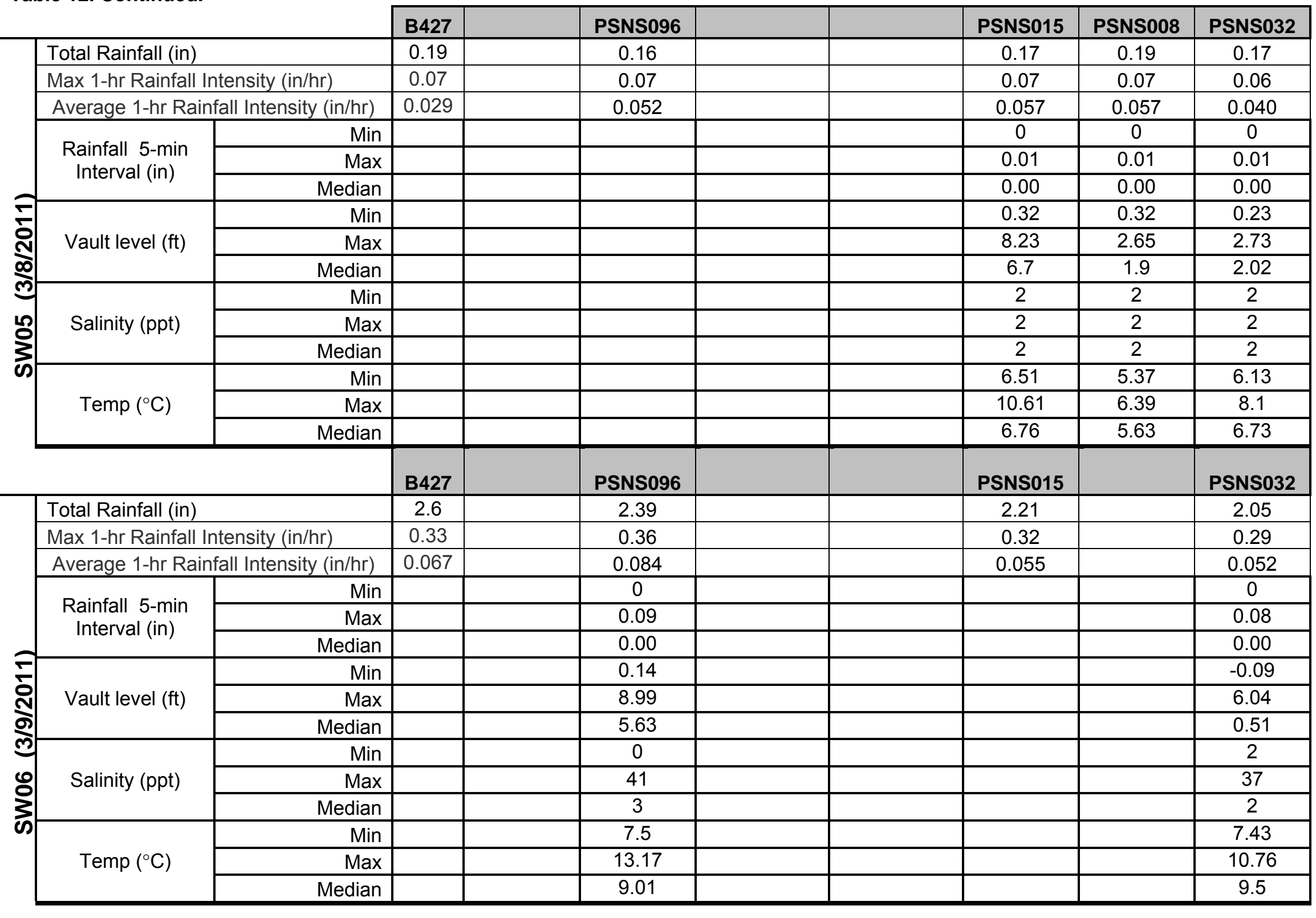


Table 12. Continued.

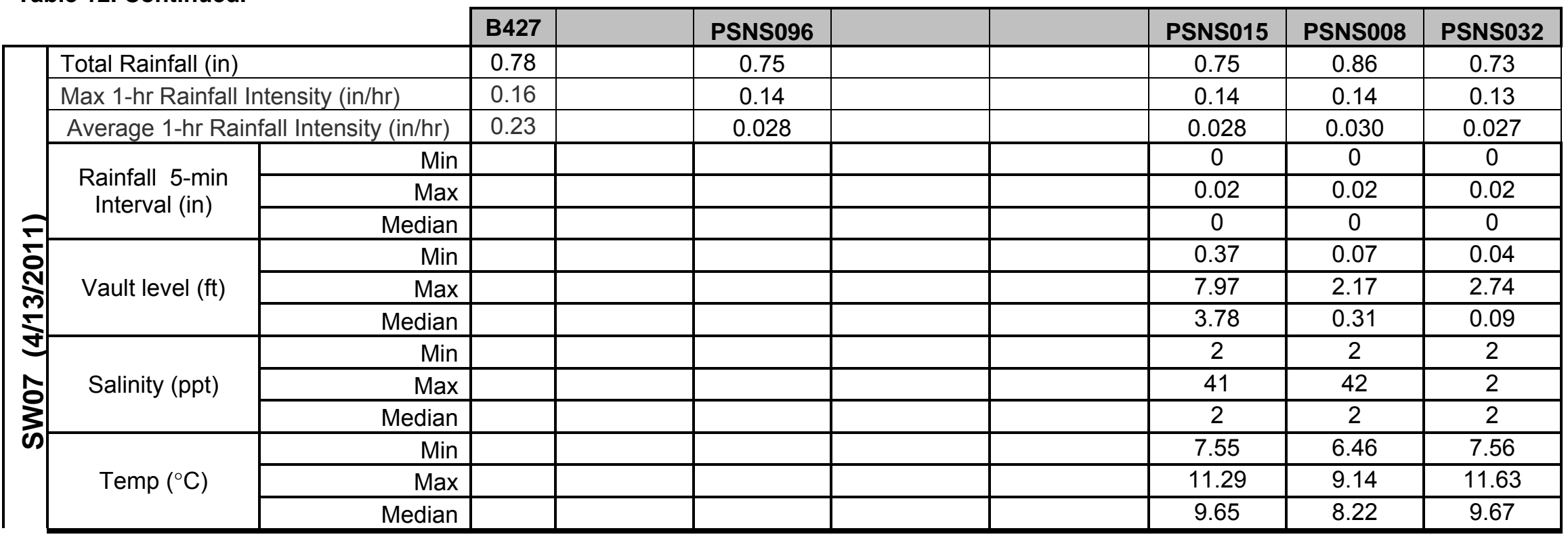

Table 13. Historical monthly rainfall summary (inches) for Bremerton, WA (450872) from 1899 to 2010 (http://www.wrcc.dri.edu/).

\begin{tabular}{|c|c|c|c|c|c|c|c|c|c|c|c|c|c|}
\hline & JAN & FEB & MAR & APR & MAY & JUN & JUL & AUG & SEP & OCT & NOV & DEC & ANNUAL \\
\hline AVE & 7.26 & 5.33 & 4.54 & 2.7 & 1.81 & 1.44 & 0.72 & 0.87 & 1.65 & 3.99 & 7.25 & 7.7 & 45.25 \\
\hline MAX & 20.08 & 18.03 & 12.19 & 7.67 & 5.46 & 4.52 & 3.11 & 3.97 & 7.09 & 14.12 & 21.64 & 16.22 & 75.81 \\
\hline MIN & 0.61 & 0.27 & 0.27 & 0.26 & 0.13 & 0.04 & 0 & 0 & 0 & 0.16 & 0.83 & 0.44 & 22.73 \\
\hline $\begin{array}{l}\text { No. } \\
\text { YRS }\end{array}$ & 95 & 99 & 98 & 104 & 105 & 106 & 103 & 104 & 106 & 101 & 94 & 96 & 63 \\
\hline
\end{tabular}

Period of Record: 5/1/1899 to 12/31/2010. Percent of possible observations for period of record; Precipitation $=96.2 \%$. 
Table 14. PSNS Building 427 monthly rain gauge summary for 2010-11 sampling period.

\begin{tabular}{|l|c|c|c|c|c|c|}
\hline $\begin{array}{l}\text { B427 Rain Gauge } \\
\text { Statistics }\end{array}$ & Nov & Dec & Jan & Feb & Mar & Apr \\
\hline Days of rain (\#) & 18 & 21 & 13 & 14 & 26 & 14 \\
\hline Total Rainfall (in) & 5.81 & 12.27 & 4.04 & 4.16 & 9.35 & 1.35 \\
\hline Daily average (in) & 0.32 & 0.58 & 0.31 & 0.30 & 0.36 & 0.10 \\
\hline Daily Min (in) & 0.01 & 0.01 & 0.01 & 0.01 & 0.01 & 0.01 \\
\hline Daily Max (in) & 1.52 & 3.01 & 1.53 & 1.25 & 1.93 & 0.62 \\
\hline Median (in) & 0.18 & 0.34 & 0.13 & 0.1 & 0.17 & 0.05 \\
\hline
\end{tabular}

${ }^{1}$ only 16 days used for calculation of monthly totals 


\subsection{SAMPLE EVENT RunOfF}

A continuous rainfall record allowed for the establishment of a rainfall/runoff relationship at each station. These relationships were used to estimate the total volume of discharge sampled using the RCM calculations discussed previously in Section 2.2.1. This method uses the total storm rainfall, pervious and impervious drainage area size, and a runoff coefficient to calculate the total runoff volume in cubic feet. Runoff coefficients for the selected stations where chosen from published values and were provided in Table 5 along with total basin area, type of surface, percentage of drainage basin surface type, area of surface type, runoff coefficient range, area of basin surface type with maximum coefficient value applied and total discharge volume formula for each Phase I station.

The coefficient range gives latitude for consideration of particular basin characteristics. Typically the maximum coefficient range values are applied to the more impervious portions and the lower end of the coefficient range values are applied to the more pervious portions of a certain surface type when calculating runoff volumes. In all cases, when calculating runoff volumes for Phase I, the maximum coefficient values were applied due to the high proportion of impervious surface in each drainage basin. Table 15 lists the storm runoff volumes for each station and sampled storm event. Tidal effects at PSNS096 caused very brief sampling opportunities. 
Table 15. Station runoff (RO) summary for each storm event.

\begin{tabular}{|c|c|c|c|c|c|c|c|c|c|}
\hline \multirow{2}{*}{ Station } & sw & 01 & 02 & 03 & 04 & 05 & 06 & 07 & \multirow{2}{*}{ TOTAL } \\
\hline & Date & $11 / 17 / 2010$ & $11 / 29 / 2010$ & $12 / 11 / 2010$ & $3 / 1 / 2011$ & $3 / 8 / 2011$ & $3 / 9 / 2011$ & $4 / 13 / 2011$ & \\
\hline PSNS126 & $\begin{array}{l}\text { Storm } \\
\mathrm{RO}\left(\mathrm{ft.}^{3}\right)\end{array}$ & 25,155 & 60,668 & 182,989 & - & - & - & - & 268,811 \\
\hline PSNS096 & $\begin{array}{l}\text { Storm } \\
\mathrm{RO}\left(\mathrm{ft}^{3}{ }^{3}\right)\end{array}$ & 32,295 & 62,473 & 236,655 & 31,236 & 8,471 & 126,533 & 39,707 & 537,370 \\
\hline PSNS082.5 & $\begin{array}{l}\text { Storm } \\
\mathrm{RO}\left(\mathrm{ft}^{3}{ }^{3}\right)\end{array}$ & 4,069 & 8,621 & 30,623 & - & - & - & - & 43,313 \\
\hline PSNS081.1 & $\begin{array}{l}\text { Storm } \\
\mathrm{RO}\left(\mathrm{ft}^{3}{ }^{3}\right)\end{array}$ & 32,548 & 74,294 & 252,598 & - & - & - & - & 359,440 \\
\hline PSNS032 & $\begin{array}{l}\text { Storm } \\
\left.\text { RO }\left(\mathrm{ft}^{3}\right)^{2}\right)\end{array}$ & - & - & - & 8,156 & 2,616 & 31,546 & 11,233 & 53,551 \\
\hline PSNS015 & $\begin{array}{l}\text { Storm } \\
\text { RO }\left(\mathrm{ft}^{3}{ }^{3}\right)\end{array}$ & - & - & - & 108,509 & 34,160 & 444,083 & 150,707 & 737,459 \\
\hline PSNS008 & $\begin{array}{l}\text { Storm } \\
\left.\mathrm{RO}\left(\mathrm{ft}^{3}\right)^{2}\right)\end{array}$ & - & - & - & 23,630 & 6,803 & - & 30,791 & 61,223 \\
\hline TOTAL & $\begin{array}{l}\text { Storm } \\
\mathrm{RO}\left(\mathrm{ft}^{3}\right)\end{array}$ & 94,067 & 206,055 & 702,865 & 171,531 & 52,050 & 602,162 & 232,438 & $2,061,167$ \\
\hline
\end{tabular}




\subsection{STORMWATER CHEMISTRY}

The descriptive statistics for the metals chemistry are summarized in Tables 16 for the metals listed in the draft permit and Table 17 for additional metals that support the Navy mass balance calculations for Sinclair and Dyes Inlets (Brandenberger et al. 2008). The statistics were calculated on the pooled data from all stations and storms and then individual stations. The total recoverable (TR) draft permit limits were provided in Table 16 and statistics exceeding the draft permit concentrations were highlighted. The stormwater EMCs for TR Cu and Zn exceeded the draft permit guidance at select stations. The distribution of the data from all stations and storms shows a high probability for the TR Cu to exceed the draft permit even $25 \%$ of the time for outfalls with basin characteristics similar to those in this Phase I study. The TR Zn data for all stations and storms shows the EMCs might exceed the draft permit value $50 \%$ of the time. The distribution of the data for all metals was highly variable (Figure 5 ) and not normally distributed. Therefore, the median should be used for evaluating overall trends and metal loads.

Evaluating the data on a station level supports identification of critical areas for further investigation and process improvement. Figures 6 and 7 illustrate the inter-storm and station variability for $\mathrm{Cu}$ and $\mathrm{Zn}$. The existing and draft permit concentrations are provided for reference. For $\mathrm{Cu}$, all stations and storms would exceed the draft permit concentration. Two of the 24 stormwater sampled collected would exceed the NPDES permit of $33 \mu \mathrm{g} / \mathrm{L} \mathrm{TR} \mathrm{Cu}$. The stations that either exceeded or were within $10 \%$ of the NPDES permit concentration were PSNS081.1, 081.5, and 096. Although the permit is based on TR Cu (top of the bars), the figures also show the partitioning of the chemistry between particulate and dissolved phases.

The fraction of the TR Cu occurring as dissolved Cu ranged from 10-68\%. The fraction of dissolved can be used to identify the types of Cu entering the systems, predict the best management practices for a particular stormwater system, and evaluate the fate of the $\mathrm{Cu}$ once it enters the marine receiving waters of Sinclair Inlet. The TR Cu concentrations in Sinclair Inlet ambient waters are $60-90 \%$ d Cu (Brandenberger et al. 2008). Therefore stations with less than $50 \%$ d Cu might be targeted for particulate Cu sources, especially those such as metal particles that do not really dissolved in seawater. Since all but two storm events and stations had $>50 \%$ d Cu, the stations with less than $30 \%$ d Cu were PSNS082.5, 081.1, 032, and 096. The percentage of TR Zn occurring as dissolved ranged from $29-79 \%$. In seawater, $\mathrm{Zn}$ occurs as $90-100 \%$ dissolved and would be expected to readily dissolve after entering seawater. Stations with $<50 \%$ d Zn were PSNS082.5, 032, and 096. All of these stations except PSNS032 are in the CIA and support vessel maintenance. 
The Phase I data can be compared to other regional data, which will be discussed in detail later. Outfall PSNS126 was sampled during the ENVVEST 2003-2005 stormwater quality project (Brandenberger et al. 2007 a, b) using the same time-paced, autosampler collection methods. The TR Cu concentrations for ENVVEST ranged $27-55 \mu \mathrm{g} / \mathrm{L}$ (ppb or parts - perbillion) at this station compared to the 7.64-15.0 $\mu \mathrm{g} / \mathrm{L}$ reported for the 2010-11 sampling. The TR Zn concentrations from ENVVEST ranged 88-96 $\mu \mathrm{g} / \mathrm{L}(\mathrm{ppb})$ for PSNS126 compared to the 2010-11 range of $49-62 \mu \mathrm{g} / \mathrm{L}$. The variability is too high to assess a significant decrease in concentrations. However, the $\mathrm{Cu}$ data suggests a measure of process improvement in the subbasin and additional information on changes in practices may be useful to qualitatively evaluate BMPs.

Figures 8 illustrate the inter-storm and station variability for dissolved, particulate, and TR Hg. The concentrations are well below the draft permit concentration of $2100 \mathrm{ng} / \mathrm{L} \mathrm{TR} \mathrm{Hg}$; however, they are significantly elevated in the NBK region of the shipyard and particularly PSNS015 and 032. The fraction of the TR Hg in the ambient waters of Sinclair/Dyes Inlet that occur as $\mathrm{d} \mathrm{Hg}$ averages approximately $50 \%$ with a range from $30-80 \%$. The Phase I stormwater EMCs averaged 24\% d Hg with stations PSNS081.1, 096, 015 and 032 showing the highest fraction of particulate $\mathrm{Hg}$ with $\mathrm{d} \mathrm{Hg}<10 \%$. The Phase I sampling also identified PSNS015 and PSNS032 as critical outfall sub-basins for further $\mathrm{Hg}$ studies. Additional studies by U.S. Geological Survey (USGS) and PNNL are underway to understand the sources of $\mathrm{Hg}$ in the region of NBK. In addition, sediment samples from the storm drains were collected during Phase II to further support the understanding of links between the sediment, regional mussel watch data, ambient water column data, and non-dry dock stormwater data. 


\begin{tabular}{|c|c|c|c|c|c|c|c|c|c|c|c|}
\hline Station & & $\mathrm{Hg}$ & $\mathrm{Hg}$ & As & As & $\mathrm{Cu}$ & $\mathrm{Cu}$ & $\mathrm{Pb}$ & $\mathrm{Pb}$ & $\mathrm{Zn}$ & $\mathrm{Zn}$ \\
\hline Fraction & & Dissolved & Total & Dissolved & Total & Dissolved & Total & Dissolved & Total & Dissolved & Total \\
\hline \multicolumn{12}{|c|}{ Units: $\mu \mathrm{g} / \mathrm{L}$} \\
\hline \multicolumn{3}{|c|}{ Draft Permit } & 2.1 & & 69 & & 5.8 & & 221 & & 95 \\
\hline All & Mean & 0.00272 & 0.0237 & 1.26 & 1.59 & 6.88 & 19.6 & 0.472 & 7.93 & 57.0 & 102 \\
\hline All & Stdev. & 0.00144 & 0.0384 & 1.12 & 1.14 & 4.57 & 11.6 & 0.499 & 3.72 & 22.4 & 34.3 \\
\hline All & 25th & 0.00183 & 0.00797 & 0.690 & 0.977 & 4.67 & 11.5 & 0.179 & 4.49 & 45.0 & 75.9 \\
\hline All & Median & 0.00221 & 0.0107 & 0.870 & 1.35 & 5.26 & 15.7 & 0.301 & 7.66 & 50.1 & 103 \\
\hline All & 75th & 0.00314 & 0.0135 & 1.43 & 1.81 & 7.10 & 25.8 & 0.479 & 11.4 & 62.5 & 120 \\
\hline All & $\mathrm{n}$ & 24 & 24 & 24 & 24 & 24 & 24 & 24 & 24 & 24 & 24 \\
\hline PSNS008 & Mean & 0.00197 & 0.0109 & 2.18 & 2.47 & 5.45 & 14.3 & 0.228 & 5.11 & 99.6 & 141 \\
\hline PSNS008 & Stdev. & 0.000252 & 0.00201 & 3.05 & 3.17 & 0.744 & 2.28 & 0.110 & 1.05 & 14.5 & 12.9 \\
\hline PSNSO08 & Min & 0.00181 & 0.0087 & 0.380 & 0.586 & 4.92 & 12.9 & 0.139 & 3.95 & 82.8 & 132 \\
\hline PSNS008 & Max & 0.00226 & 0.0126 & 5.70 & 6.13 & 6.30 & 16.9 & 0.351 & 6.00 & 108 & 156 \\
\hline PSNS008 & $\mathrm{n}$ & 3 & 3 & 3 & 3 & 3 & 3 & 3 & 3 & 3 & 3 \\
\hline PSNS015 & Mean & 0.00487 & 0.0961 & 0.874 & 1.07 & 5.17 & 10.2 & 1.68 & 10.8 & 48.7 & 72.6 \\
\hline PSNS015 & Stdev. & 0.00135 & 0.0730 & 0.152 & 0.208 & 0.167 & 1.83 & 0.264 & 2.33 & 1.56 & 6.58 \\
\hline PSNS015 & Min & 0.00332 & 0.0182 & 0.781 & 0.918 & 4.98 & 8.23 & 1.38 & 8.12 & 47.3 & 65.0 \\
\hline PSNS015 & Max & 0.00584 & 0.163 & 1.05 & 1.31 & 5.30 & 11.8 & 1.86 & 12.5 & 50.4 & 76.4 \\
\hline PSNS015 & $\mathrm{n}$ & 3 & 3 & 3 & 3 & 3 & 3 & 3 & 3 & 3 & 3 \\
\hline PSNS032 & Mean & 0.00391 & 0.0284 & 0.753 & 1.24 & 3.12 & 10.1 & 0.322 & 8.62 & 33.6 & 95.3 \\
\hline PSNS032 & Stdev. & 0.00196 & 0.0349 & 0.221 & 0.289 & 0.845 & 2.58 & 0.207 & 3.61 & 2.71 & 24.0 \\
\hline PSNS032 & Min & 0.00246 & 0.00669 & 0.480 & 0.936 & 1.92 & 6.97 & 0.179 & 4.17 & 30.4 & 71.8 \\
\hline PSNS032 & Max & 0.00681 & 0.0806 & 1.00 & 1.63 & 3.90 & 12.4 & 0.623 & 11.8 & 37.0 & 118 \\
\hline PSNS032 & $\mathrm{n}$ & 4 & 4 & 4 & 4 & 4 & 4 & 4 & 4 & 4 & 4 \\
\hline & & & & & & & & & & & \\
\hline
\end{tabular}


Table 16. Descriptive statistics for Phase I Event Mean Composite (EMC) stormwater samples. The draft permit concentrations are included for reference and all concentrations greater than the draft permit concentration are highlighted orange.

\begin{tabular}{|c|c|c|c|c|c|c|c|c|c|c|c|}
\hline Station & & $\mathrm{Hg}$ & $\mathrm{Hg}$ & As & As & $\mathrm{Cu}$ & $\mathrm{Cu}$ & $\mathrm{Pb}$ & $\mathrm{Pb}$ & $\mathrm{Zn}$ & $\mathrm{Zn}$ \\
\hline Fraction & & Dissolved & Total & Dissolved & Total & Dissolved & Total & Dissolved & Total & Dissolved & Total \\
\hline PSNS081.1 & Mean & 0.00259 & 0.0167 & 1.15 & 1.48 & 13.9 & 34.8 & 0.367 & 10.8 & 82.2 & 138 \\
\hline PSNS081.1 & Stdev. & 0.000446 & 0.00872 & 0.411 & 0.434 & 6.24 & 6.87 & 0.179 & 4.54 & 10.3 & 31.4 \\
\hline PSNS081.1 & Min & 0.00216 & 0.00981 & 0.679 & 1 & 7.23 & 30.6 & 0.198 & 6.05 & 71.6 & 116 \\
\hline PSNS081.1 & Max & 0.00305 & 0.0265 & 1.40 & 1.85 & 19.6 & 42.7 & 0.555 & 15.1 & 92.1 & 174 \\
\hline PSNS081.1 & $\mathrm{n}$ & 3 & 3 & 3 & 3 & 3 & 3 & 3 & 3 & 3 & 3 \\
\hline PSNS082.5 & Mean & 0.00189 & 0.00724 & 0.572 & 0.791 & 10.7 & 30.4 & 0.343 & 6.01 & 51.3 & 119 \\
\hline PSNS082.5 & Stdev. & 0.000216 & 0.00401 & 0.268 & 0.394 & 6.79 & 18.0 & 0.318 & 4.16 & 1.65 & 38.9 \\
\hline PSNS082.5 & Min & 0.00164 & 0.0037 & 0.292 & 0.383 & 6.44 & 16.4 & 0.149 & 2.74 & 49.7 & 80.2 \\
\hline PSNS082.5 & Max & 0.00204 & 0.0116 & 0.827 & 1.17 & 18.5 & 50.7 & 0.710 & 10.7 & 53.0 & 158 \\
\hline PSNS082.5 & $\mathrm{n}$ & 3 & 3 & 3 & 3 & 3 & 3 & 3 & 3 & 3 & 3 \\
\hline PSNS096 & Mean & 0.00168 & 0.00917 & 1.25 & 1.73 & 5.37 & 25.5 & 0.279 & 9.47 & 53.2 & 98.5 \\
\hline PSNS096 & Stdev. & 0.000476 & 0.00306 & 0.429 & 0.345 & 1.68 & 5.72 & 0.121 & 2.77 & 5.05 & 15.3 \\
\hline PSNS096 & Min & 0.00100 & 0.00472 & 0.730 & 1.38 & 3.05 & 17.8 & 0.149 & 5.35 & 47.5 & 74.5 \\
\hline PSNS096 & Max & 0.00227 & 0.0133 & 1.77 & 2.23 & 7.65 & 32.5 & 0.453 & 12.2 & 59.5 & 116 \\
\hline PSNS096 & $\mathrm{n}$ & 5 & 5 & 5 & 5 & 5 & 5 & 5 & 5 & 5 & 5 \\
\hline PSNS126 & Mean & 0.00244 & 0.00570 & 2.25 & 2.38 & 6.74 & 10.8 & 0.256 & 3.46 & 40.8 & 54.9 \\
\hline PSNS126 & Stdev. & 0.000951 & 0.00234 & 0.532 & 0.509 & 3.43 & 3.78 & 0.0985 & 0.745 & 5.74 & 6.85 \\
\hline PSNS126 & Min & 0.00166 & 0.00435 & 1.64 & 1.8 & 3.35 & 7.64 & 0.159 & 2.60 & 34.7 & 48.8 \\
\hline PSNS126 & Max & 0.00350 & 0.0084 & 2.62 & 2.75 & 10.2 & 15.0 & 0.356 & 3.90 & 46.1 & 62.3 \\
\hline PSNS126 & $\mathrm{n}$ & 3 & 3 & 3 & 3 & 3 & 3 & 3 & 3 & 3 & 3 \\
\hline
\end{tabular}


Table 17. Descriptive statistics for composite stormwater samples collected during the Phase I 2010-11 storm season. The metals are not included in the draft permit, but provided for project ENVVEST mass balance calculations.

\begin{tabular}{|c|c|c|c|c|c|c|c|}
\hline Station & & $\mathrm{Ag}$ & $\mathrm{Ag}$ & $\mathrm{Cd}$ & $\mathrm{Cd}$ & $\mathrm{Cr}$ & $\mathrm{Cr}$ \\
\hline Fraction & & Dissolved & Total & Dissolved & Total & Dissolved & Total \\
\hline \multicolumn{8}{|c|}{ Units: $\mu \mathrm{g} / \mathrm{L}$} \\
\hline All & Mean & 0.00517 & 0.0312 & 0.156 & 0.340 & 1.82 & 6.61 \\
\hline All & Stdev. & 0.00434 & 0.0189 & 0.109 & 0.274 & 1.10 & 12.6 \\
\hline All & 25 th & 0.00200 & 0.0239 & 0.101 & 0.195 & 1.18 & 2.62 \\
\hline All & Median & 0.00315 & 0.0271 & 0.111 & 0.272 & 1.45 & 3.35 \\
\hline All & 75th & 0.00546 & 0.0349 & 0.187 & 0.367 & 2.08 & 5.00 \\
\hline All & $\mathrm{n}$ & 24 & 24 & 24 & 24 & 24 & 24 \\
\hline PSNS008 & Mean & 0.00288 & 0.0162 & 0.187 & 0.327 & 1.62 & 3.86 \\
\hline PSNS008 & Stdev. & 0.000901 & 0.0125 & 0.0443 & 0.0344 & 0.771 & 0.675 \\
\hline PSNSO08 & Min & 0.00200 & 0.002 & 0.148 & 0.300 & 0.946 & 3.2 \\
\hline PSNS008 & Max & 0.00380 & 0.0251 & 0.235 & 0.366 & 2.46 & 4.55 \\
\hline PSNS008 & $\mathrm{n}$ & 3 & 3 & 3 & 3 & 3 & 3 \\
\hline PSNS015 & Mean & 0.00346 & 0.0457 & 0.0353 & 0.0658 & 1.94 & 3.01 \\
\hline PSNS015 & Stdev. & 0.00118 & 0.0418 & 0.00386 & 0.0134 & 0.867 & 1.26 \\
\hline PSNS015 & Min & 0.00272 & 0.014 & 0.0325 & 0.0556 & 1.36 & 2.22 \\
\hline PSNS015 & Max & 0.00482 & 0.0931 & 0.0397 & 0.0810 & 2.94 & 4.46 \\
\hline PSNS015 & $\mathrm{n}$ & 3 & 3 & 3 & 3 & 3 & 3 \\
\hline PSNS032 & Mean & 0.00325 & 0.0260 & 0.102 & 0.239 & 0.986 & 2.80 \\
\hline PSNSO32 & Stdev. & 0.00155 & 0.00602 & 0.00564 & 0.0608 & 0.486 & 0.769 \\
\hline PSNS032 & Min & 0.00200 & 0.0199 & 0.0931 & 0.184 & 0.412 & 1.74 \\
\hline PSNS032 & Max & 0.00520 & 0.0343 & 0.105 & 0.317 & 1.58 & 3.50 \\
\hline PSNS032 & $\mathrm{n}$ & 4 & 4 & 4 & 4 & 4 & 4 \\
\hline
\end{tabular}


Table 17. Descriptive statistics for composite stormwater samples collected during the Phase I 2010-11 storm season. The metals are not included in the draft permit, but provided for project ENVVEST mass balance calculations.

\begin{tabular}{|c|c|c|c|c|c|c|c|}
\hline Station & & $\mathrm{Ag}$ & $\mathrm{Ag}$ & $\mathrm{Cd}$ & $\mathrm{Cd}$ & $\mathrm{Cr}$ & $\mathrm{Cr}$ \\
\hline Fraction & & Dissolved & Total & Dissolved & Total & Dissolved & Total \\
\hline PSNS081.1 & Mean & 0.0104 & 0.0467 & 0.157 & 0.345 & 2.55 & 7.36 \\
\hline PSNS081.1 & Stdev. & 0.00376 & 0.0221 & 0.0558 & 0.0703 & 1.54 & 1.39 \\
\hline PSNS081.1 & Min & 0.00624 & 0.0288 & 0.109 & 0.266 & 1.44 & 5.99 \\
\hline PSNS081.1 & Max & 0.01350 & 0.0714 & 0.218 & 0.4 & 4.31 & 8.76 \\
\hline PSNS081.1 & $\mathrm{n}$ & 3 & 3 & 3 & 3 & 3 & 3 \\
\hline PSNS082.5 & Mean & 0.00291 & 0.0298 & 0.317 & 0.892 & 1.59 & 3.97 \\
\hline PSNS082.5 & Stdev. & 0.00158 & 0.0184 & 0.0617 & 0.331 & 0.351 & 1.59 \\
\hline PSNS082.5 & Min & 0.00200 & 0.012 & 0.277 & 0.596 & 1.35 & 2.31 \\
\hline PSNS082.5 & Max & 0.00474 & 0.0488 & 0.388 & 1.25 & 1.99 & 5.49 \\
\hline PSNS082.5 & $\mathrm{n}$ & 3 & 3 & 3 & 3 & 3 & 3 \\
\hline PSNS096 & Mean & 0.00246 & 0.0258 & 0.183 & 0.363 & 2.44 & 17.4 \\
\hline PSNS096 & Stdev. & 0.000656 & 0.00908 & 0.165 & 0.230 & 1.68 & 26.7 \\
\hline PSNS096 & Min & 0.00200 & 0.0138 & 0.0845 & 0.208 & 1.10 & 2.71 \\
\hline PSNS096 & Max & 0.00341 & 0.0394 & 0.476 & 0.77 & 5.19 & 64.7 \\
\hline PSNS096 & $\mathrm{n}$ & 5 & 5 & 5 & 5 & 5 & 5 \\
\hline PSNS126 & Mean & 0.0132 & 0.0337 & 0.109 & 0.169 & 1.48 & 2.03 \\
\hline PSNS126 & Stdev. & 0.00301 & 0.00320 & 0.0356 & 0.0391 & 0.818 & 0.828 \\
\hline PSNS126 & Min & 0.00979 & 0.0304 & 0.0712 & 0.139 & 0.744 & 1.32 \\
\hline PSNS126 & Max & 0.0155 & 0.0368 & 0.142 & 0.213 & 2.36 & 2.94 \\
\hline PSNS126 & $\mathrm{n}$ & 3 & 3 & 3 & 3 & 3 & 3 \\
\hline
\end{tabular}



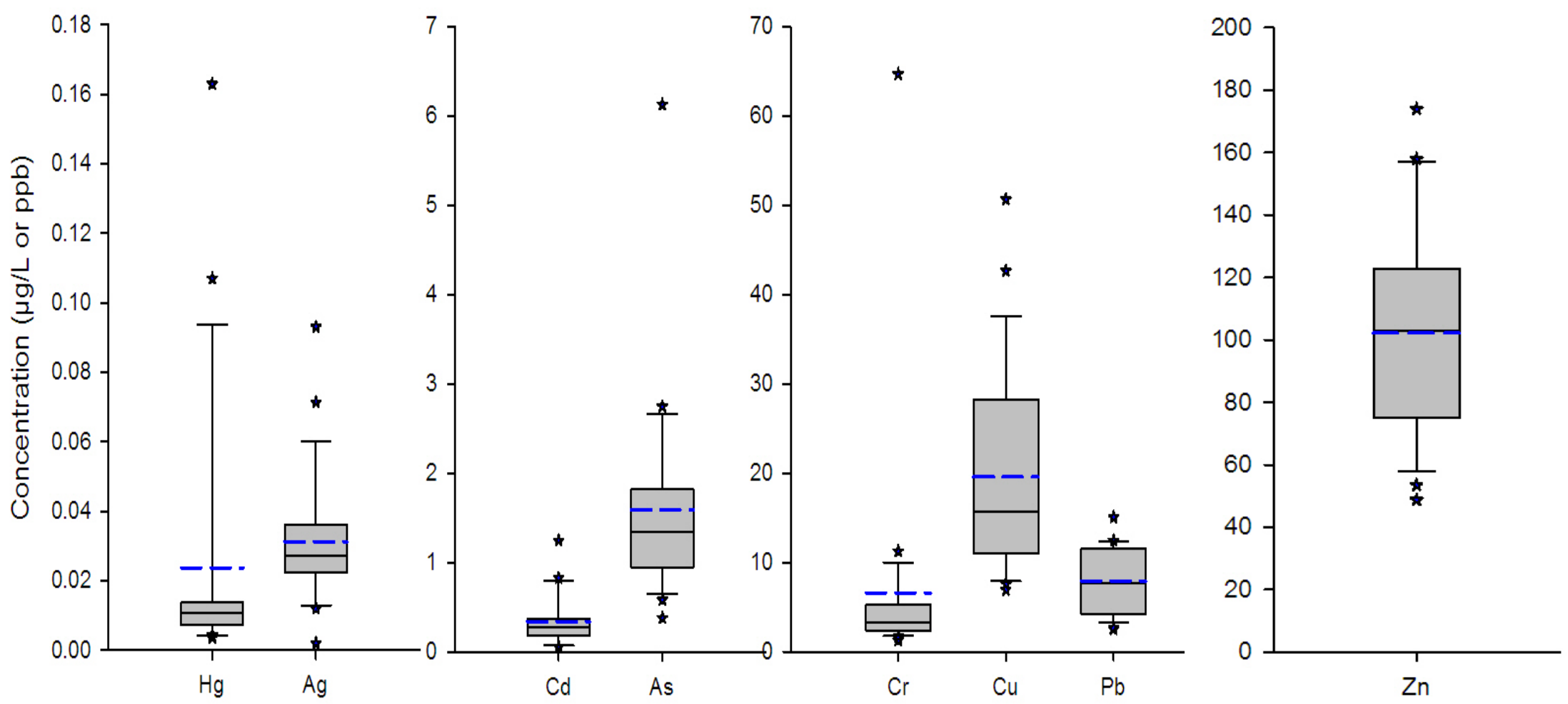

Figure 5. Total metal event mean concentrations (EMCs) in stormwater collected from the seven Phase I outfalls during seven storm events. The top, middle black line, and bottom of the box represent the 75th percentile, 50th, and 25th percentile, respectively. The whiskers are the 5th and 95th percentile and the asterisks are outliers in this sampling set $(n=24)$. The blue dashed line is the average. 


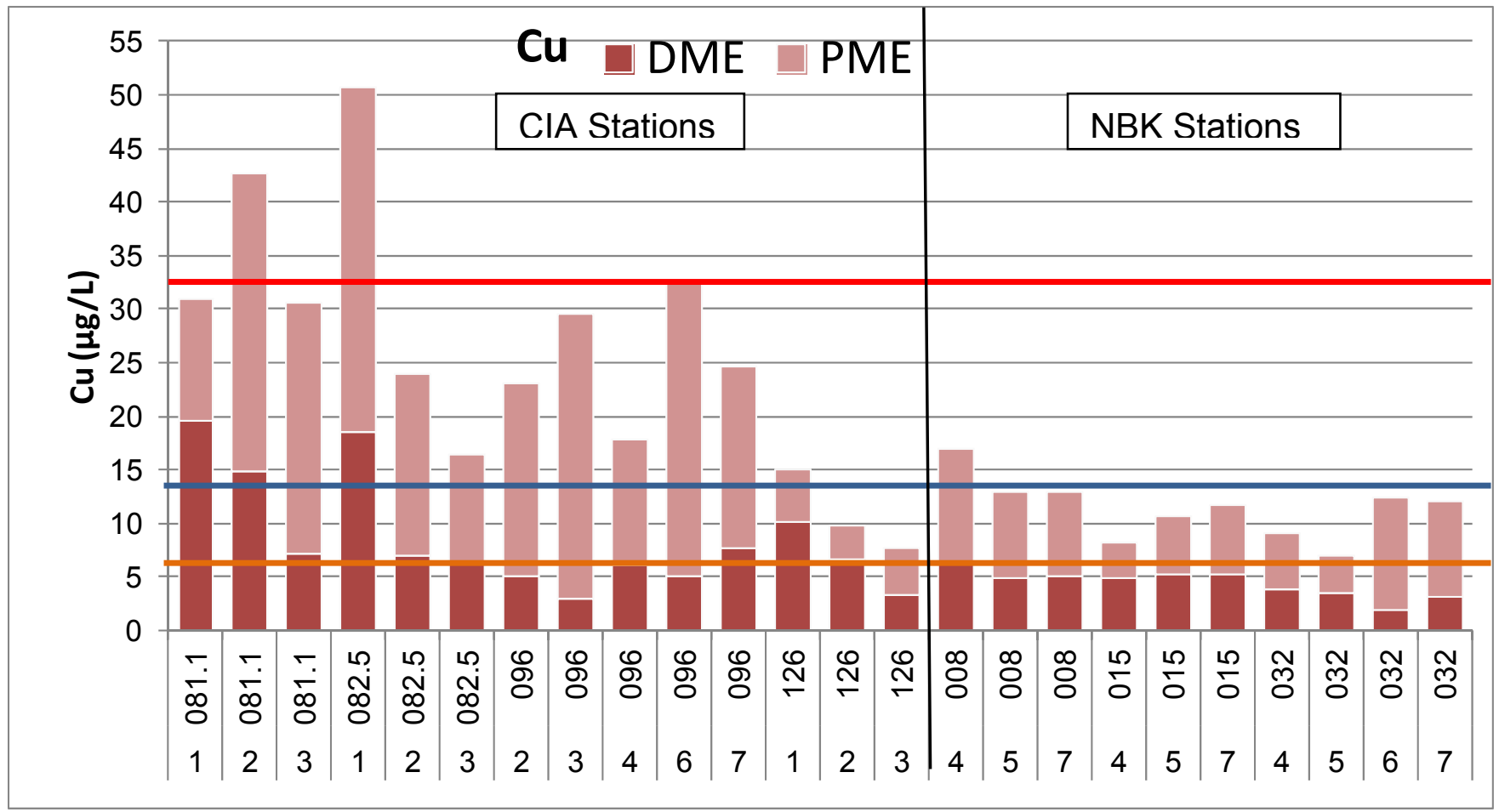

Figure 6. The concentrations of dissolved (DME) and particulate (PME) Cu measured in event mean concentration samples from CIA and NBK outfalls. The storm event number (SW01, etc.) is on the x-axis below the station name. The tops of each column represent the total recoverable (TR) Cu. The reference lines are the NPDES outfall permit concentration (red = $33 \mu \mathrm{g} / \mathrm{L}$ ), Navy General Permit (blue $=14 \mu \mathrm{g} / \mathrm{L}$ ) and draft permit for (orange $=5.8 \mu \mathrm{g} / \mathrm{L}$ ) for TR Cu. 


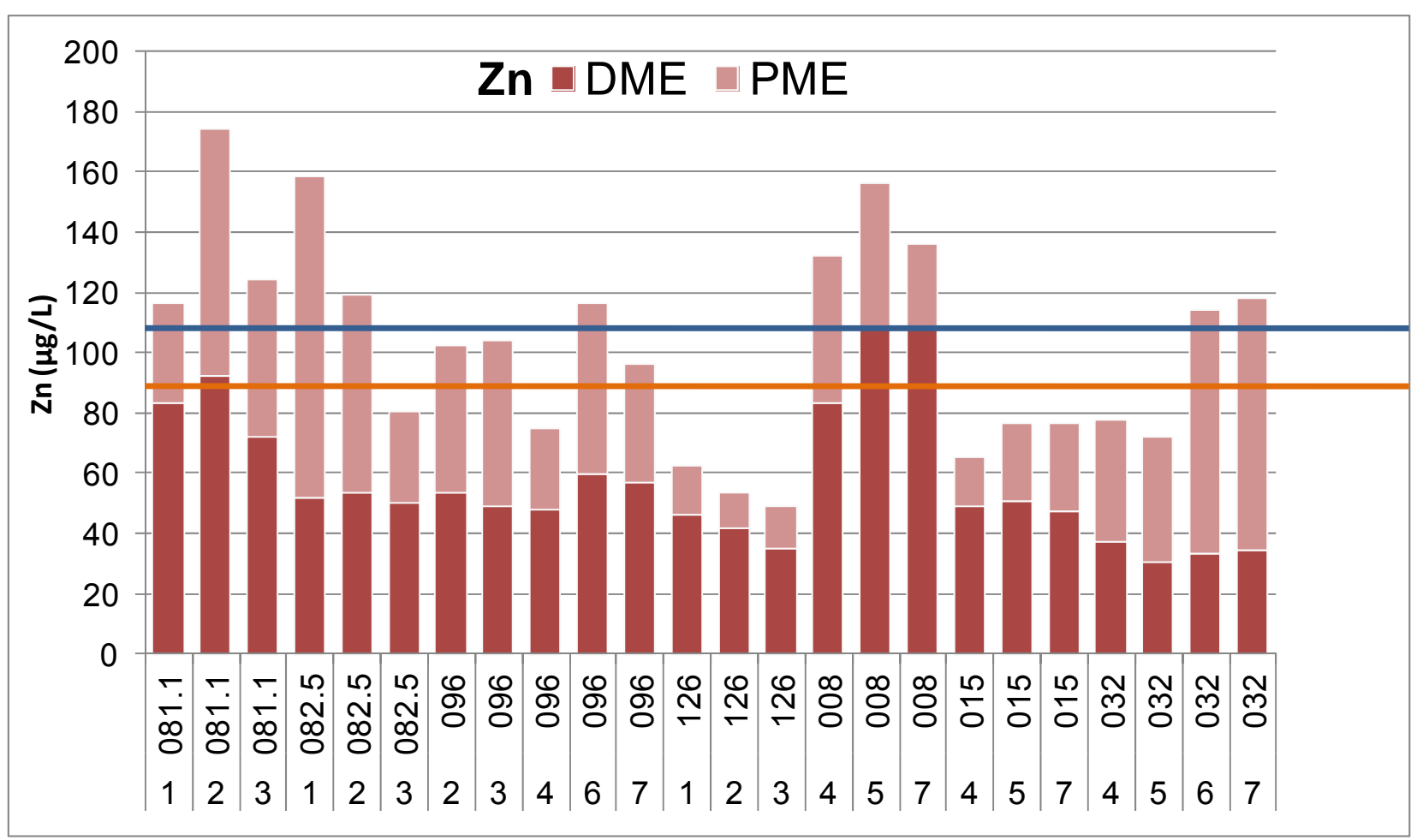

Figure 7. The concentrations of dissolved (DME) and particulate (PME) Zn measured in event mean concentration samples from CIA and NBK outfalls. The storm event number (SW01, etc.) is on the x-axis below the station name. The tops of each column represent the total recoverable (TR) $\mathrm{Zn}$. The reference lines are the Navy General Permit (blue $=117.0 \mu \mathrm{g} / \mathrm{L}$ ) and draft permit for (orange $=95.0 \mu \mathrm{g} / \mathrm{L}$ ) for TR $\mathrm{Zn}$.

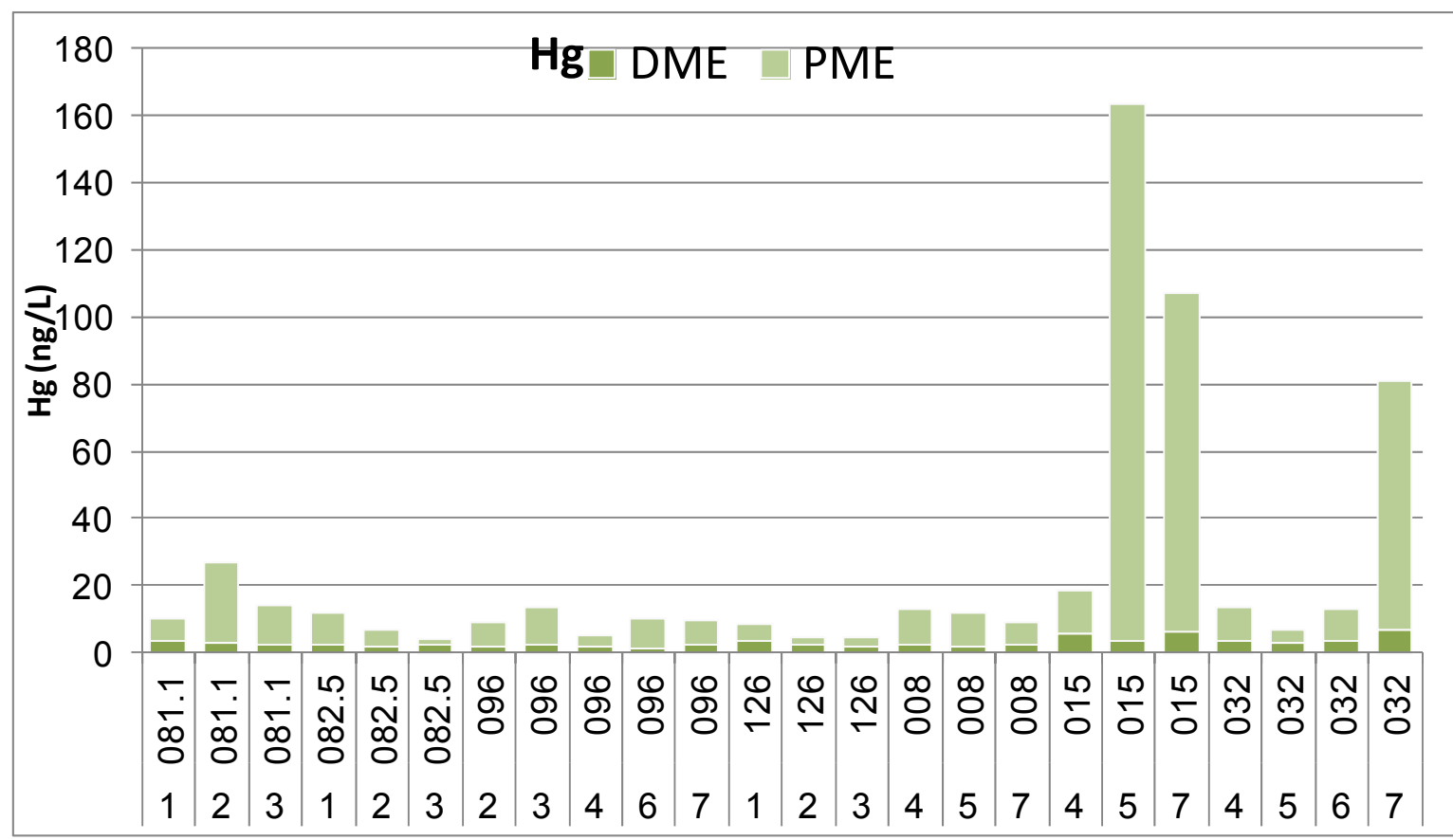

Figure 8. The concentrations of dissolved (DME) and particulate (PME) $\mathrm{Hg}$ measured in event mean concentration samples from CIA and NBK outfalls. The storm event number (SW01, etc.) is on the X-axis below the station name. The tops of each column represent the total recoverable (TR) $\mathrm{Hg}$. 
The ancillary parameters are necessary to establish potential fate and transport pathways, transformation upon entering the seawater, and also bioavailability to evaluate potential impacts to beneficial uses. These analyses will be conducted in the final report with the full set of data and are not discussed in detail in this interim report. Table 24 provides the descriptive statistics for the TPH (diesel and residual range) and ancillary parameters for all stations and storms. The TPH data are all qualified as either less than the RL or there is an interference that could bias the results due to a false positive.

Table 18. Descriptive statistics for total petroleum (TPH) diesel range (DRO) and residual range (RRO) along with the ancillary parameters for all stations.

\begin{tabular}{|l|l|l|l|l|l|l|l|}
\hline Station & & $\begin{array}{l}\text { TPH } \\
(\mathrm{DRO})\end{array}$ & $\begin{array}{l}\text { TPH } \\
(\mathrm{RRO})\end{array}$ & $\begin{array}{l}\text { Hardness } \\
(\mathrm{as} \\
\left.\mathrm{CaCO}_{3}\right)\end{array}$ & $\mathrm{TOC}$ & $\mathrm{DOC}$ & $\mathrm{TSS}$ \\
\hline & Units: & $\mu \mathrm{g} / \mathrm{L}$ & $\mu \mathrm{g} / \mathrm{L}$ & $\mathrm{mg} / \mathrm{L}$ & $\mathrm{mg} / \mathrm{L}$ & $\mathrm{mg} / \mathrm{L}$ & $\mathrm{mg} / \mathrm{L}$ \\
\hline All & Mean & 159 & 391 & 71 & 2.68 & 3.12 & 22 \\
\hline All & Stdev. & 215 & 341 & 161 & 1.78 & 1.83 & 11 \\
\hline All & 25 th & 75.5 & 188 & 14 & 1.51 & 2.00 & 14 \\
\hline All & 50 th & 100 & 280 & 23 & 2.17 & 2.71 & 19 \\
\hline All & 75 th & 170 & 448 & 40 & 2.86 & 3.18 & 27 \\
\hline
\end{tabular}

\subsection{CONCLUSION AND RECOMMENDATIONS}

The study design focused the data quality objectives to answer the following questions:

1. Are discharges from shipyard industrial outfalls and storm drains protective of beneficial uses of Sinclair Inlet?

2. How does the water quality of storm water runoff compare between various drainage basins in the Shipyard that support different types of activities (e.g. CIA versus NBK)?

3. What is the status and trend of stormwater quality relative to previous Shipyard stormwater sampling in 2003-2005 and/or other Puget Sound industrial areas?

Since this is an interim report only for Phase I, the data will not be completely synthesized to address these questions. However, the 2010-11 dataset can be used to inform the Phase II sampling, other stormwater sampling programs, and also identify areas of concern for future studies. Table 19 summarizes the data from the Phase I 2010-11 PSNS outfall sampling compared to the draft stromwater permit, the Navy general permit and other regional commercial/industrial stormwater outfall sampling. Multiple lines of evidence may be used to assess recommended actions for the Phase I outfalls and inform other outfall sampling. Table 
20 summarizes the major activities within each outfall sub-basin and recommendations for each outfall. The lines of evidence include: 1) exceedence of draft permit, 2) exceedence of Navy General Permit, 3) loading of metals relative to other outfalls, 4) potential for particulate versus dissolved sources, and 5) comments relative to historical or regional data. Seven of the seven sampled outfalls exceeded the draft permit concentration for TR Cu during the storms sampled. For Zn, five out of seven outfalls had at least one EMC greater than the draft permit. Using the Navy General Permit as guidance (Table 19), five of the seven outfalls contained at least one EMC greater than the permit for $\mathrm{Cu}$ and four out of seven for $\mathrm{Zn}$ (Table 20).

The next line of evidence was the loading from specific outfalls relative to all other outfalls sampled. Appendix $\mathrm{C}$ summarizes the loads calculated for each storm event sampled from each outfall. The relative contribution from a specific outfall compared to the others sampled was calculated and used to identify basins that contributed more than $25 \%$ of the load for each metal. The fraction of this load contributed to the particulate phase versus the dissolved phase was also used as a line of evidence. Figure 9 illustrates the outfalls with a high fraction of particulate metal versus dissolved, which would provide a means to select a BMP appropriate for the dominant metal phase.

There are three points of reference that can be used to bound these data with respect to regional and comparable LULC stormwater data. The first the 2003-2005 PSNS outfall stormwater sampling conducted by ENVVEST (Brandenberger et al. 2007 a, b). These data were collected using similar methodologies for both collection and analyses. The range of concentrations reported in the Phase I 2010-11 PSNS outfalls sampling were overall lower than the 2003-2005 ENVVEST study. No definitive conclusions can be drawn, but additional information will be synthesized in the final report on efforts for process improvement.

The second study was the recent Ecology report on stormwater concentrations measured in two basins of Puget Sound (Puyallup and Snohomish) with specific LULC distributions with sub-basins (Herrera Environmental Consultants, Inc. 2011). The median for the commercial/industrial LULC provides a measure of regional comparison. Overall the concentrations from the PSNS outfalls were higher, but the data should be compared with caution. Herrera Environmental Consultants Inc. (2011) reports stormwater concentration based on grab samples that were composited to reflect a storm event concentration, therefore, the data are not directly comparable.

The third study was the ENVVEST 2003-2005 Urban stormwater collected from stormwater outfalls within the Sinclair/Dyes Inlet study area. In many cases the data sets overlap, 
suggesting the sources may not be specific to Shipyard activities and may be driven more by activities occurring in both urban and industrial settings (e.g. vehicle, roof runoff, etc.).

Table 19. Comparison of 2010-11 stormwater concentrations with regional urban stormwater outfall and commercial/industrial (C\&l) land use/cover stormwater concentrations.

\begin{tabular}{|l|l|l|l|l|l|}
\hline TR Conc. & $\mathbf{C u}(\boldsymbol{\mu g} / \mathbf{L})$ & $\mathbf{Z n}(\boldsymbol{\mu g} / \mathbf{L})$ & $\mathbf{P b}(\boldsymbol{\mu g} / \mathbf{L})$ & As $(\boldsymbol{\mu g} / \mathbf{L})$ & $\mathbf{H g}(\mathbf{n g} / \mathbf{L})$ \\
\hline $\begin{array}{l}\text { PSNS Draft } \\
\text { Permit }\end{array}$ & 5.8 & 95 & 221 & 69 & 2100 \\
\hline $\begin{array}{l}\text { Navy General } \\
\text { Permit }\end{array}$ & 14.0 & 117 & & & \\
\hline $\begin{array}{l}2010-11 \text { PSNS } \\
\text { Median } \\
\text { (range) }\end{array}$ & $\begin{array}{l}15.7 \\
(7.0-51)\end{array}$ & $\begin{array}{l}103 \\
(49-174)\end{array}$ & $\begin{array}{l}7.7 \\
(2.6-15)\end{array}$ & $\begin{array}{l}1.4 \\
(0.38-6.1)\end{array}$ & $\begin{array}{l}10.7 \\
(3.7-163)\end{array}$ \\
\hline $\begin{array}{l}\text { ENVVEST } \\
\text { 2003-05 } \\
\text { PSNS Outfalls }\end{array}$ & $12-123$ & $35-257$ & $4-32$ & $1-12$ & $12-123$ \\
\hline $\begin{array}{l}\text { ENVVEST } \\
\text { Urban Outfalls }\end{array}$ & $5-27$ & $18-140$ & $3-25$ & $0.5-14$ & $6-56$ \\
\hline $\begin{array}{l}\text { Herrera 2011 } \\
\text { Median C\& }{ }^{2}\end{array}$ & 3.84 & 37.2 & 1.68 & 0.92 & 7 \\
\hline
\end{tabular}

${ }^{1}$ Brandenberger et al. (2007 a, b) and Cullinan et al. (2007)

${ }^{2}$ Herrera Environmental Consultants, Inc. (2011) 
Table 20. The lines of evidence used to prioritize the Phase I stations including: 1) total number of event mean concentrations (EMC) greater than the draft NPDES permit; 2) Navy General Permit; 3) high relative load for permitted metals; and 4) high fraction of particulate versus dissolved metals.

\begin{tabular}{|c|c|c|c|c|c|}
\hline Outfall & Area & $\begin{array}{l}\text { No. > Draft } \\
\text { NPDES }^{1}\end{array}$ & $\begin{array}{l}\text { No. > Navy } \\
\text { General } \\
\text { Permit }\end{array}$ & $\begin{array}{l}\text { Metal Load } \\
\text { Relative to } \\
\text { Other Outfalls }{ }^{2}\end{array}$ & $\begin{array}{l}\text { Particulate } \\
\text { Versus } \\
\text { Dissolved }^{3}\end{array}$ \\
\hline 126 & CIA & $3 / 3 \mathrm{Cu}$ & $1 / 3 \mathrm{Cu}$ & $\begin{array}{l}<25 \% \text { for all } \\
\text { metals }\end{array}$ & $>43 \%$ dissolved \\
\hline 096 & CIA & $\begin{array}{l}5 / 5 \mathrm{Cu} \\
4 / 5 \mathrm{Zn}\end{array}$ & $5 / 5 \mathrm{Cu}$ & $\begin{array}{l}81 \% \mathrm{Cr} \\
42-42 \% \mathrm{Cu}, \mathrm{Cd} \\
32-37 \% \mathrm{As}, \mathrm{Pb}, \\
\mathrm{Zn}\end{array}$ & $\begin{array}{l}\text { Particle driven for } \\
\mathrm{Cu}, \mathrm{Hg}<25 \% \\
\text { dissolved }\end{array}$ \\
\hline 082.5 & CIA & $\begin{array}{l}3 / 3 \mathrm{Cu} \\
2 / 3 \mathrm{Zn}\end{array}$ & $\begin{array}{l}3 / 3 \mathrm{Cu} \\
2 / 3 \mathrm{Zn}\end{array}$ & $\begin{array}{l}<8 \% \text { for all } \\
\text { metals }\end{array}$ & $\begin{array}{l}\text { Particle driven } \\
\text { average } 38 \% \\
\text { dissolved }\end{array}$ \\
\hline 081.1 & CIA & 3/3 Cu, Zn & 3/3 Cu, Zn & $\begin{array}{l}31-35 \% \mathrm{Cu}, \mathrm{Zn} \\
26-29 \% \mathrm{Ag}, \mathrm{Cd} \text {, } \\
\mathrm{Pb}\end{array}$ & $\begin{array}{l}\text { Particle driven for } \\
\mathrm{Hg}<19 \% \\
\text { dissolved }\end{array}$ \\
\hline 032 & NBK & $\begin{array}{l}4 / 4 \mathrm{Cu} \\
2 / 4 \mathrm{Zn}\end{array}$ & $1 / 4 \mathrm{Zn}$ & $\begin{array}{l}<4 \% \text { for all } \\
\text { metals }\end{array}$ & $\begin{array}{l}\text { Particle driven } \\
\text { average } 31 \% \\
\text { dissolved }\end{array}$ \\
\hline 015 & NBK & $3 / 3 \mathrm{Cu}$ & & $\begin{array}{l}62 \% \mathrm{Hg} \\
29 \% \mathrm{Ag}\end{array}$ & $\begin{array}{l}\text { Particle driven for } \\
\mathrm{Hg}<12 \% \\
\text { dissolved }\end{array}$ \\
\hline 008 & NBK & 3/3 Cu, Zn & $\begin{array}{l}1 / 3 \mathrm{Cu} \\
3 / 3 \mathrm{Zn}\end{array}$ & $\begin{array}{l}<9 \% \text { for all } \\
\text { metals }\end{array}$ & $\begin{array}{l}\text { Particle driven for } \\
\mathrm{Cu}, \mathrm{Hg}<28 \% \\
\text { dissolved }\end{array}$ \\
\hline
\end{tabular}

${ }^{1}$ No. exceedences out of total number EMCs sampled at each outfall.

${ }^{3}$ Metals not listed have percent loads $<25 \%$.

${ }^{2}$ Based on average statistics for $\mathrm{Cu}, \mathrm{Zn}$, and $\mathrm{Hg}$. 


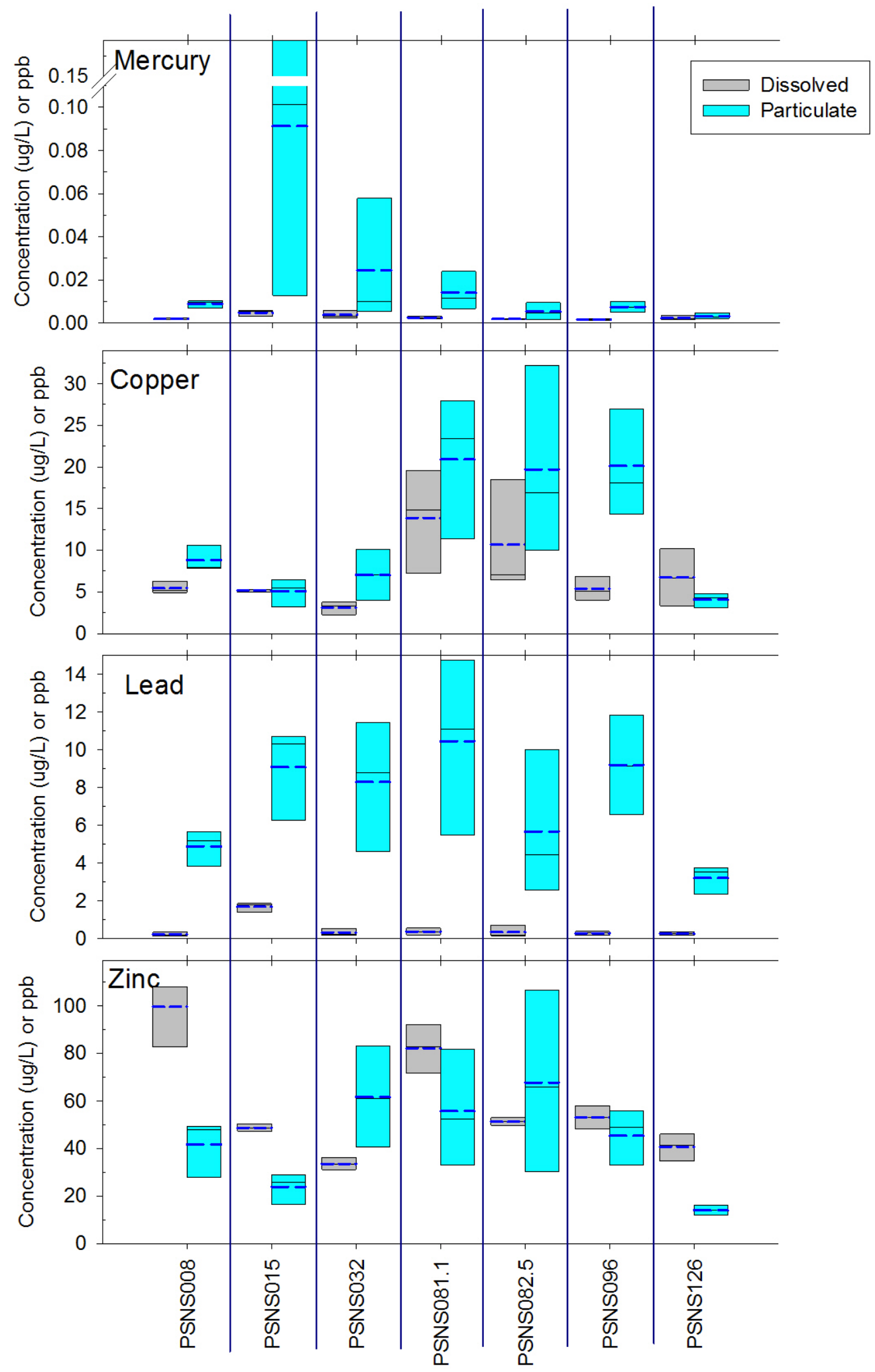

Figure 9. The particulate versus dissolved concentration ranges for each outfall during Phase I. 
The Phase I results suggest additional studies are required to provide scientific credibility in support of or to refute the draft permit limits for $\mathrm{Cu}$ and $\mathrm{Zn}$ as a function of actual bioavailability instead of TR (e.g. implementing the BLM for site specific criteria) and if there are truly impairments to beneficial uses within Sinclair/Dyes Inlet. Specific areas of the Shipyard identified for further study included the CIA for sources of $\mathrm{Cu}$ and $\mathrm{Zn}$ and NBK for sources of $\mathrm{Hg}$ at PSNS015 and PSNS032. The final report will provide specific recommendation when all the stormwater data have been collected and synthesized with information on Shipyard practices within each sub-basin.

Due to the expense of collecting composite stormwater samples, this study was designed to allow direct comparable across collection and analytical methods for ENVVEST Relational Runoff Model (Brandenberger et al. 2007 a, b; Cullinan et al. 2007). This allows a vast in-kind contribution both to the evaluation of stormwater outfalls within the Shipyard, but also the watershed-scale loading studies for Sinclair/Dyes Inlet. All stormwater collection studies including the Remedial Investigation monitoring for OUB should follow similar protocol to increase the sample size and statistical power of the ENVVEST dataset and models that relate stormwater quality with event size and LULC within the sub-basin to allow some measure of predictive simulations for outfalls. Examples of the relational model are provided in Figures 10 and 11. The relationship between storm size and TR and $\mathrm{d} \mathrm{Cu}$ along with the level of development within a sub-basin are used to develop relationship and build predictions for outfalls and storm events of similar characteristics. Figure 11 shows the prediction for the 2010-11 outfall samples relative to measured concentration. The model contains many gaps and therefore incorporating additional data will help to build a more robust model that would provide a predictive concentration for all outfalls, as all outfalls cannot be sampled for each storm.

The final recommendation derived from the Phase I study was that careful field collection in industrial areas where post collection contamination is easier must be a factor incorporate into the planning and collection of the Shipyard outfall stormwater. The water in the piped conveyance could easily be contaminated after collection due to industrial activities surrounding the manhole. All sample containers should be left closed while removing from the autosamler and carried back to the stormwater lab for compositing. The concentrations of the draft permit are approaching levels measured in streams during storm conditions; therefore additional precautions should be taken to ensure that the samples represent the chemistry of the water in the conveyance and not of particles that may contaminant a small volume of sample after collection. 


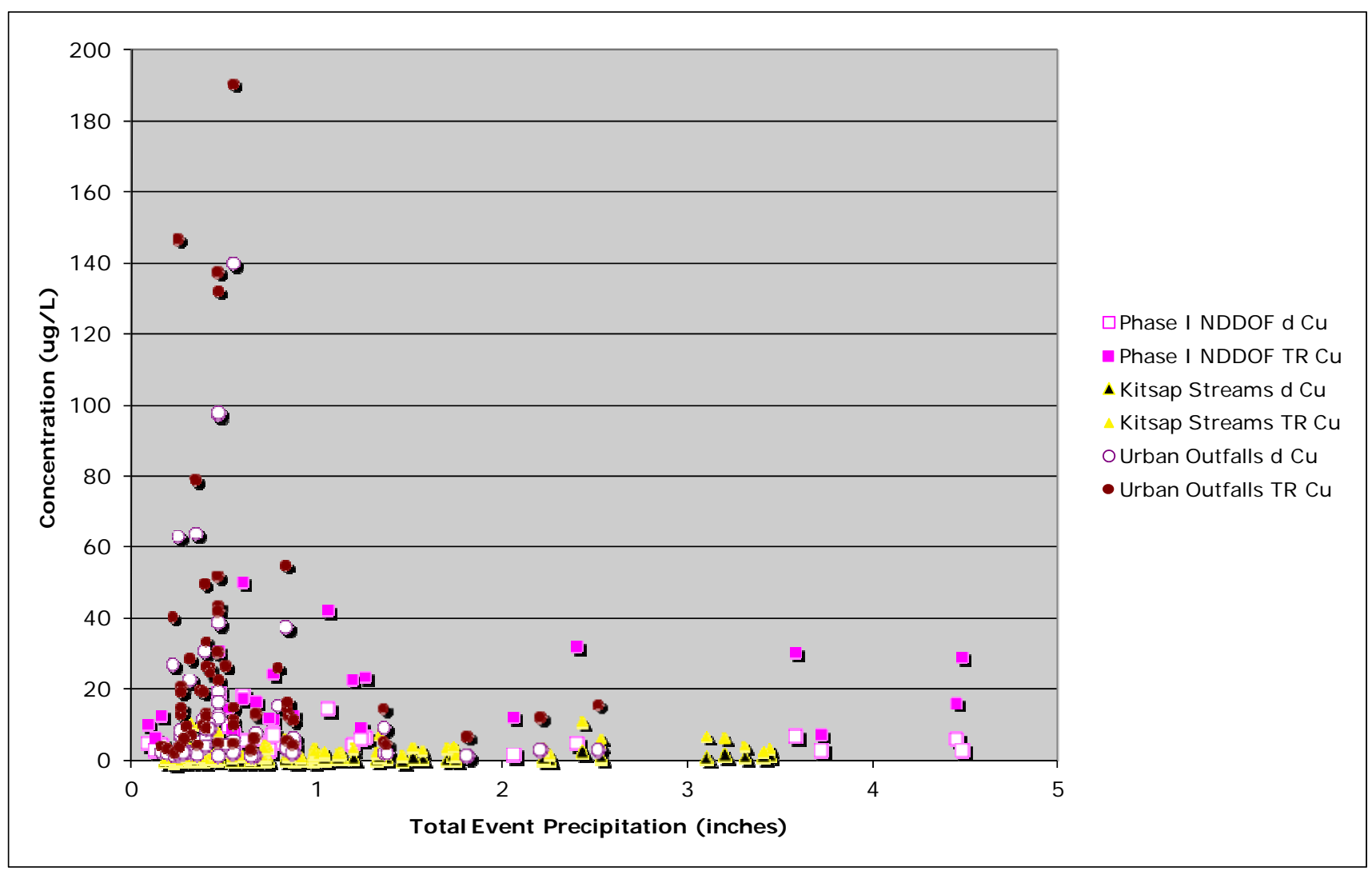

Figure 10. The total recoverable (TR) and dissolved (d) Cu from the Phase I 2010-11, Kitsap County streams, and Urban outfalls from Kitsap County as a function of storm size.

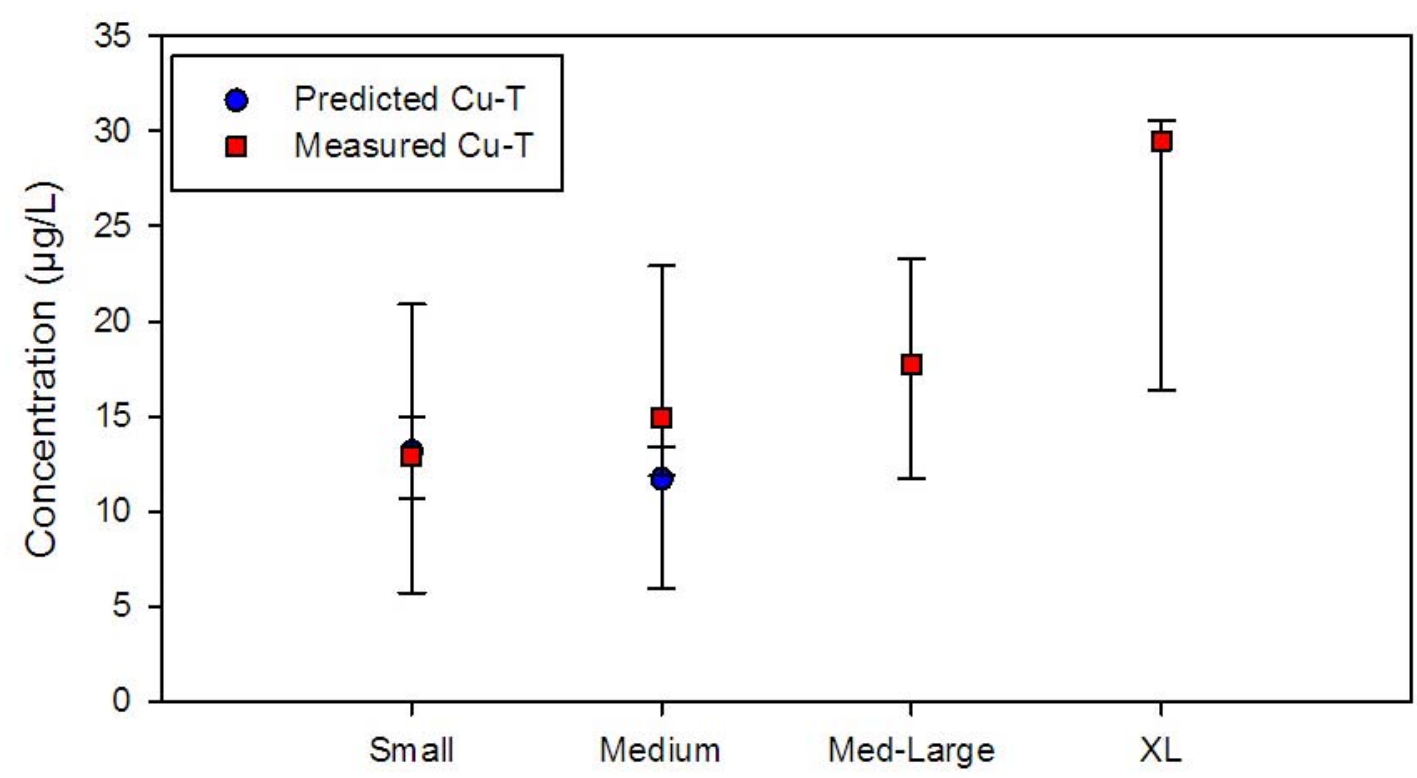

Figure 11. The ENVVEST relational model (Cullinan et al. 2007) predicted concentrations and Phase I 2010-11 measured total recoverable $\mathrm{Cu}$ concentrations in industrial outfalls. The existing relational model does not have sufficient data to predict concentrations for larger storm sizes. 


\subsection{REFERENCES}

Brandenberger J. M., E.A. Crecelius, and R. K. Johnston. (2008). Contaminant Mass Balance for Sinclair and Dyes Inlets, Puget Sound, Washington. Prepared for the Puget Sound Naval Shipyard and Intermediate Maintenance Facility Project ENVVEST Bremerton, Washington under Contract DE-AC06-76RLO 1830, Pacific Northwest National Laboratory, Richland, Washington.

Brandenberger, J. M., C.W. May, V.I Cullinan, R. K. Johnston. (2007a). Surface and Stormwater Quality Assessment for Sinclair and Dyes Inlet, Washington. June 2007, Prepared for the Puget Sound Naval Shipyard and Intermediate Maintenance Facility Project ENVVEST Bremerton, Washington, under Contract DE-AC06-76RLO 1830 Pacific Northwest National Laboratory Richland, Washington.

Brandenberger, Jill M., Chris May, and Valerie Cullinan Robert K. Johnston, Dwight E. Leisle, Bruce Beckwith, and Gerald Sherrell, David Metallo, and Ryan Pingree. (2007b). 20032005 Contaminant Concentrations in Storm Water from Sinclair/Dyes Inlet Watershed a Subasin of Puget Sound, WA, USA. Proceedings of the 2007 Georgia Basin Puget Sound Research Conference, Puget Sound Action Team and Environment Canada. http://www.engr.washington.edu/epp/psgb/2007psgb/2007proceedings/papers/9f brand .pdf

Cullinan,Valerie I., Christopher W. May, Jill M. Brandenberger, and Chaeli Judd, and Robert K. Johnston. (2007). Development Of An Empirical Water Quality Model For Stormwater Based on Watershed Land-Use in Puget Sound. Proceedings of the 2007 Georgia Basin Puget Sound Research Conference, Puget Sound Action Team and Environment Canada.

http://www.engr.washington.edu/epp/psgb/2007psgb/2007proceedings/papers/5e culli. $\underline{\mathrm{pdf}}$

ENVVEST. (2006). Puget Sound Naval Shipyard \& Intermediate Maintenance Facility Project ENVVEST Community Update June 2006. Brochure and CD.

ENVVEST. (2002a). PSNS Project ENVVEST Technical Work Masterplan, of May 2002, prepared by PSNS Project ENVVEST Technical Steering Committee. https://www.mesodat.org/ENVVEST/tech master plan 06 f2 web2b.pdf

ENVVEST. (2002b). 303d Scoping Summary for Sinclair and Dyes Inlets and Watershed. Puget Sound Naval Shipyard Project ENVVEST, Bremerton, Washington. September 20, 2002. https://www.mesodat.org/ENVVEST/Envest 303d scope9-20-02.pdf

Herrera Environmental Consultants, Inc. (2011). Control of Toxic Chemicals in Puget Sound Phase 3 Data and Load Estimates. Washington Department of Ecology. Publication No. 11-03-010. www.ecy.wa.gov/biblio/1103010.htm.

Hydroqual. (2011). DRAFT UPDATE OF AQUATIC LIFE AMBIENT SALTWATER QUALITY CRITERIA FOR COPPER, in review.

Jabloner et al. (2009). All Known, Available, and Reasonable Methods of Treatment (AKART) Study for Puget Sound Naval Shipyard \& IMF. Prepared by Naval Facilities Engineering 
Command Northwest. Draft Report, July 2009.

http://www.mesodat.org/ENVVEST/NPDES/Index.htm\# Toc247683321

Johnston, R. K., J. Young, E. Mollerstuen, J. Wright, B. Beckwith, E. Beckley. (2010). Fecal

Coliform (FC) Monitoring Assessment and Control -Water Year 2011 Quality Assurance

Project Plan.

http://www.mesodat.org/ENVVEST/AMB Monitoring/FC QAPP Oct2010.pdf

Johnston, R. K., G.H. Rosen, J.M. Brandenberger, V.S. Whitney, J.M. Wright. (2009).

Sampling and Analysis Plan for Ambient Monitoring and Toxicity Testing for Sinclair and

Dyes Inlets, Puget Sound, Washington. U.S. Navy Project ENVVEST.

Skahill, B.E., and C. LaHatte (2007). Hydrological Simulation Program- Fortran Modeling of the Sinclair-Dyes Inlet Watershed for the Puget Sound Naval Shipyard \& Intermediate Maintenance Facility Environmental Investment Project - FY 2007 REPORT. US Army

Engineer Research and Development Center, Waterways Experiment Station, Vicksburg, MS. Report to the US Navy Puget Sound Naval Shipyard and Intermediate Maintenance Facility Environmental Division.

Taylor Associates Inc. (2009). Quality Assurance Plan for Non-Dry Dock Stormwater Monitoring Conducted Under the National Pollutant Discharge Elimination System by Puget Sound Naval Shipyard \& Intermediate Maintenance Facility. Contract W912DW06-D-1007, USACE Delivery Order 023, December 2009. Report and Supporting Information

http://www.mesodat.org/ENVVEST/Reports/TaylorAssoc 2009 Report/TaylorAssoc 20 09 Report.html

TEC and PNNL. (2011). Project Work Plan for Non-Dry Dock Stormwater Monitoring Conducted at Puget Sound Naval Shipyard Bremerton, WA. Prepared for the U. S. Navy under Contract No.: N4523A10MP00034 Amendment 1.

TEC (2003a). Sampling and Analysis Plan for Sampling and Analysis of In-Stream and Storm Water Chemical and Flow Characteristics PSNS Project ENVVEST Study Area Bremerton, Washington. TEC Inc. Bellevue, WA. Contract No.: N44255-98-D-4416 Contract Task Order: 0068. 19 SEPT 2003.

http://www.ecy.wa.gov/programs/wq/tmdl/sinclair\%2Ddyes\%5Finlets/sinclair\%5Fcd/Wat ershed/StreamStormSampling2002-2003/Instream Storm Sampling.htm

TEC (2003b). Annual Report 2002-2003 - In-Stream Storm Flow Sampling Puget Sound Naval Shipyard (PSNS) Project Environmental Investment (ENVVEST), September 2003. http://www.ecy.wa.gov/programs/wq/tmdl/sinclair\%2Ddyes\%5Finlets/sinclair\%5Fcd/Wat ershed/StreamStormSampling2002-2003/Instream_Storm_Sampling.htm

TEC (2003c). Site Evaluation Report for Sampling and Analysis of In-Stream and Storm Water Chemical and Flow Characteristics PSNS Project ENVVEST Study Area Bremerton, Washington. TEC Inc. Bellevue, WA. Contract No.: N44255-98-D-4416 Contract Task Order: 0068. 19 SEPT 2003.

http://www.ecy.wa.gov/programs/wq/tmdl/sinclair\%2Ddyes\%5Finlets/sinclair\%5Fcd/Wat ershed/StreamStormSampling2002-2003/Instream Storm Sampling.htm

USDOD/EPA (U.S. Department of Defense/Environmental Protection Agency). (2011).

Webinar: New Data and Tools for Updating Aquatic Life Ambient Saltwater Criteria for 
Copper, Thursday, August 4, 2011 9:00 AM -11:00 AM Pacific Standard Time. https://connect.dco.dod.mil/mblm http://water.epa.gov/scitech/swguidance/standards/criteria/aqlife/pollutants/copper/additi onal.cfm

USEPA (Environmental Protection Agency). (2008a). Draft Working NPDES Permit for the Puget Sound Naval Shipyard, US EPA Region X, 6 May 2008.

USEPA (2008b). Draft Working NPDES Fact Sheet for Puget Sound Naval Shipyard, US EPA Region X, 6 May 2008.

USEPA Office of Water. (2007). Aquatic Life Ambient Freshwater Quality Criteria - Copper 2007 Revision. EPA-822-R-07-001.

USEPA (2002a). Guidance on Environmental Data Verification and Data Validation, EPA QA/G-8.

USEPA (2002b). EPA Method 1631, Revision E. Mercury in Water by Oxidation, Purge and Trap, and Cold Vapor Atomic Fluorescence Spectrometry.

USEPA (1996a). Method 1638: Determination of Trace Elements in Ambient Waters by Inductively Coupled Plasma-mass Spectrometry. Report No. 821R96005, 53pp.

USEPA (1996b). Method 1640: Determination of Trace Elements in Ambient Waters by OnLine Chelation Preconcentration and Inductively Coupled Plasma-Mass Spectrometry Report No. 821R96007, 51pp.

USEPA (1995). Method 1669, Sampling Ambient Water for Determination of Trace Metals in Environmental Samples. EPA/600-R-94-111.

US Navy (1996). NAVSHIPYD PUGET NPDES Permit Sampling and Analysis Plan. April 30, 1996. 